THERMAL PERFORMANCE IMPACTS OF VENTING EIFS ASSEMBLIES

Khaled H. Khaled,

BSc. Civil Engineering, Queen's University, 2012

\author{
A Major Research Project \\ presented to \\ Ryerson University \\ in partial fulfillment of the \\ requirements for the degree of \\ Master of Building Science \\ in the Program of \\ Building Science \\ Toronto, Ontario, Canada \\ (C) Khaled H. Khaled, 2019
}




\section{Author's Declaration}

I hereby declare that I am the sole author of this MRP. This is a true copy of the MRP, including any required final revisions.

I authorize Ryerson University to lend this MRP to other institutions or individuals for the purpose of scholarly research.

I further authorize Ryerson University to reproduce this MRP by photocopying or by other means, in total or in part, at the request of other institutions or individuals for the purpose of scholarly research.

I understand that my MRP may be made electronically available to the public. 


\title{
Thermal Performance Impacts of Venting EIFS Assemblies
}

Khaled H. Khaled

Master of Building Science - Winter 2019

Program of Building Science

Ryerson University

\begin{abstract}
One of the key improvements in EIFS is the addition of a geometrically defined drainage gap in the continuous insulation layer to allow water that has penetrated the outer EIFS lamina to drain out by gravity to the exterior. The integration of this cavity has raised questions regarding its impact on the thermal performance of wall assemblies constructed with these vented EIFS. The objective of this research is to evaluate the thermal performance impacts, as a percentage reduction in the effective RSI-Value, of a vented EIFS assembly against a face-sealed EIFS and expand the results with respect to increased building height and wind velocities. It can be concluded from the results that a vented EIFS assembly with 2-inches of EPS foam insulation and 4-inches of fiberglass cavity insulation experiences a maximum reduction of $4 \%$ in the whole assembly's effective RSI-value against a face-sealed EIFS assembly. Furthermore, increased wind speeds, caused by installing EIFS at higher elevations from the grade had negligible effects on the thermal resistances of the face-sealed and vented EIFS.
\end{abstract}




\section{Acknowledgements}

I thank God for the wisdom and perseverance that he has bestowed upon me throughout my life. I would like to gratefully acknowledge the contributions and support made by my family. Without your support and endless encouragement, I would not be whom I am today.

I would like to express sincere appreciation for Dr. Russell Richman, my supervisor and mentor, for all his efforts and guidance towards completing the master's degree. More importantly, I would like to thank him for his confidence in me which has allowed me to explore my interests.

I wish to thank all representatives of the Master of Building Science program at Ryerson University including Dr. Umberto Berardi, Professor Hitesh Doshi, Dr. Mark Gorgolewski and Dr. Ramani Ramakrishnan for all their academic and professional support towards completing this degree. 


\section{Table of Contents}

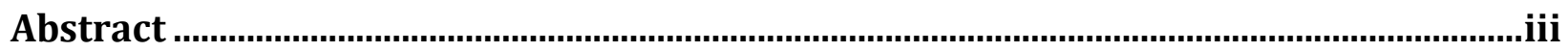

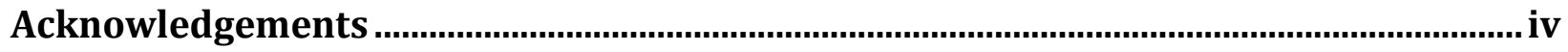

Abbreviations ..................................................................................................................vii

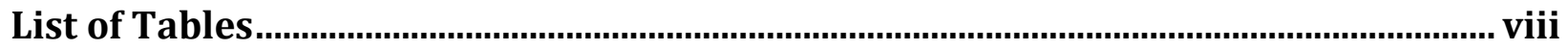

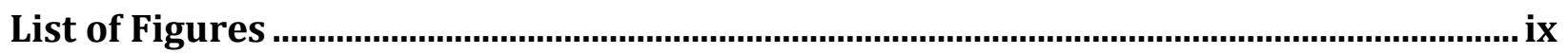

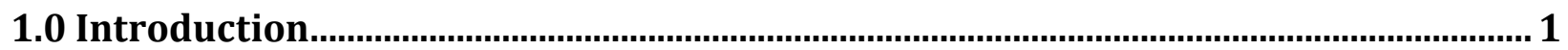

1.1 Research Objectives .......................................................................................

2.0 Literature Review

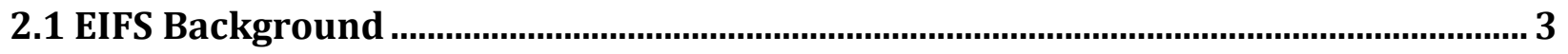

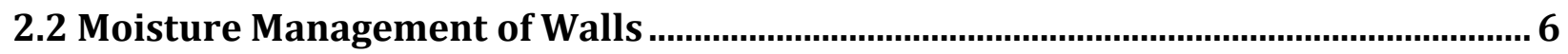

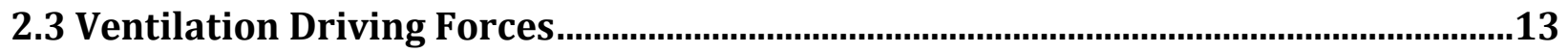

2.3.1 Stack Effect (Thermal Buoyancy) ….................................................................15

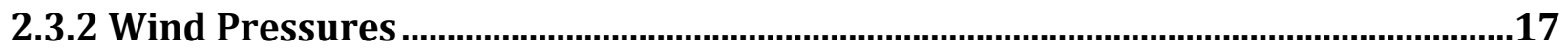

2.4 Ventilation Flow Mechanics ...............................................................................21

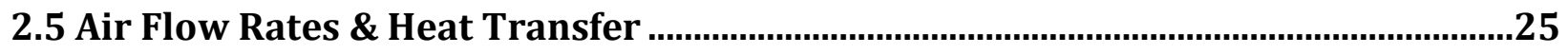

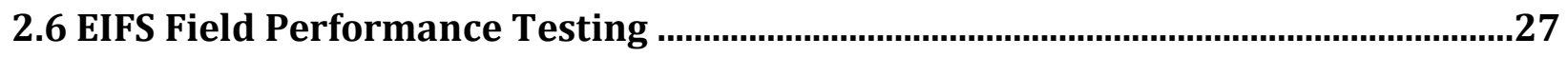

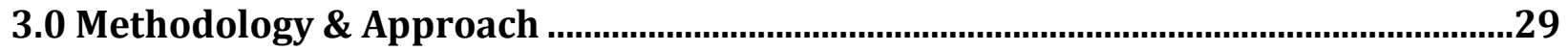

3.1 Model Geometry \& Material Properties.........................................................................30

3.2 Boundary \& Initial Conditions ……....................................................................

3.3 Theory of COMSOL's Heat Transfer Module …..............................................................36

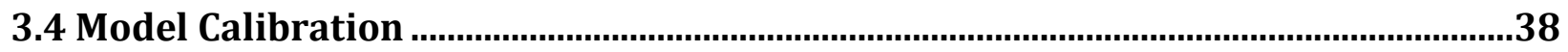




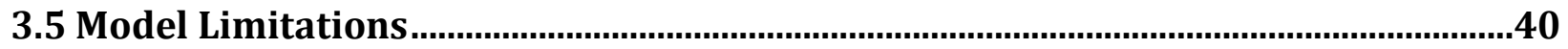

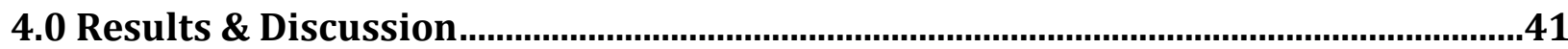

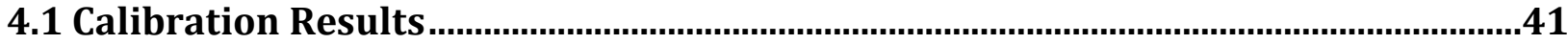

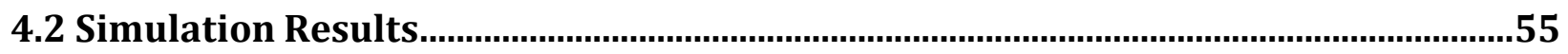

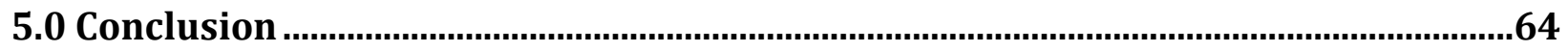

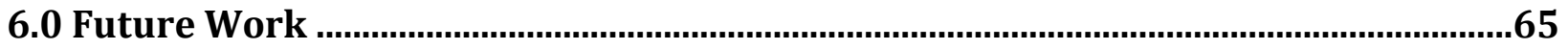

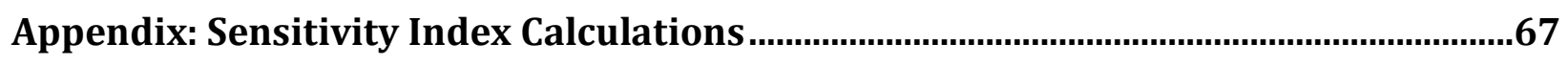

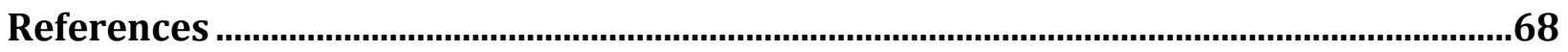




\author{
Abbreviations \\ Cv (RMSE) - Coefficient of variation of the Root Mean Square Error. \\ $\mathrm{ACH}$ - Air Exchange Rate Between Cavity and Exteriors. \\ EIFS - Exterior Insulation Finishing Systems. \\ EFC - External Forced Convection. \\ ENC - External Natural Convection. \\ EPS - Expanded Polystyrene. \\ ETICS - External Thermal Insulation Composite Systems. \\ MBE - Mean Bias Error. \\ RDH - RDH Building Science Inc. \\ WRB - Water Resistive Barrier.
}




\section{List of Tables}

Table 1. Initial Material Properties and Color Legend ................................... 32

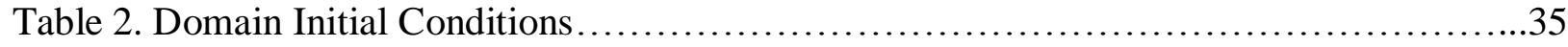

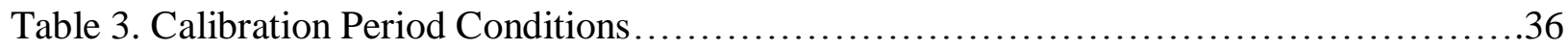

Table 4. Statistical Indices Thresholds Criteria......................................40

Table 5. Calibration Procedure Based on Sensitivity Analyses.............................44 


\section{List of Figures}

Figure 1. Typical EIFS Construction in North America................................... 4

Figure 2. Different Composite Wall Types with Different Moisture Management Strategies......7

Figure 3. Vented Vs. Ventilated EIFS (Smegal, 2017).........................................10

Figure 4. Ventilation Stack Effect..................................................... 15

Figure 5. Ventilation Induced by Wind Pressures...................................... 18

Figure 6. Cavity Ventilation Mechanics for Upward Flow (Left) and Downward Flow (Right)..22 Figure 7. Tested EIFS assemblies and sensor locations (Smegal, 2007) .....................28

Figure 8. Problem Solving Steps............................................................ 30

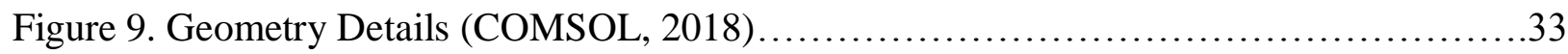

Figure 10. Schematic Representations of ENC, EFC correlations (COMSOL, 2018) ..............35

Figure 11. Average Temperature of Exterior Surface of Interior Gypsum Board .................46

Figure 12. Monitored Interior Temperature Throughout Calibration Period.....................46

Figure 13. Average Temperature of Exterior Surface of Interior Gypsum Board (Vented) ........47

Figure 14. Average Temperature of EIFS Top Coat (Face-Sealed)..........................48

Figure 15. Average Temperature of EIFS Top Coat (Vented) ...............................49

Figure 16. Monitored Exterior Ambient Temperature Throughout Calibration Period...........50

Figure 17. Solar Radiation Received by The Experimental Wall Models.......................50

Figure 18. Average Mid-Sheathing Temperature (Face-Sealed) .............................51

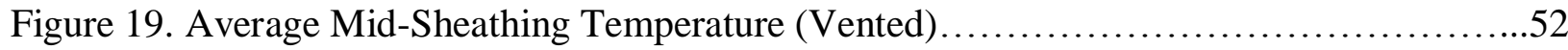

Figure 20. Heat Flux through Mid-Sheathing (Face-Sealed)..............................5

Figure 21. Heat Flux through Mid-Sheathing (Vented)..................................5

Figure 22. EIFS Installed at Different Building Heights and Types. (EIMA, 2019)..............56

Figure 23. Wind Velocity Variation with Height and Terrain................................57

Figure 24. Wind Speeds Corresponding to Different Building Elevations......................57

Figure 25. Thermal Performance of (FS VS. Vented EIFS) on Low-Rise Buildings..............60

Figure 26. Thermal Performance of (FS VS. Vented EIFS) on Mid-Rise Buildings..............61

Figure 27. Thermal Performance of (FS VS. Vented EIFS) on High-Rise Buildings..............61

Figure 28. Thermal performance of the Face-Sealed EIFS Against Building Height..............62 
Figure 29. Thermal performance of the Vented EIFS Against Building Height..............63 


\subsection{Introduction}

Since the 1973 oil crisis, there has been a world-wide trend towards energy efficiency in all sectors. In developed nations with a defined heating season, buildings account for $40 \%$ of all consumed energy, while space heating accounts for $40 \%$ of this energy (IEA, 2012). These percentages increase for climates with longer heating seasons and higher heating degree days, such as Canada. In Canada, Buildings significantly contribute to climate change and account for $14 \%$ of the country's greenhouse gas emissions (Environment Canada, 2016). To reduce building energy demands, enhance material durability and provide the desired aesthetics in a costeffective manner, Exterior Insulated Finishing Systems (EIFS) have been successfully used for decades as non-load bearing cladding systems. The main advantage of using EIFS is enhancing the thermal performance of the building envelope, which plays a fundamental role in energy consumption since a significant amount of energy is required to balance the heat transfers

through the envelope. This enhancement comes in the form of eliminating thermal bridging by providing continuous insulation over the building structure.

EIFS (Exterior Insulation Finishing Systems) or ETICS (External Thermal Insulated Composite Systems) as called in Europe, were developed in Austria in the 1950s due to cement shortages after World War II. EIFS were then introduced in North America in the 1960s by Dryvit Systems Inc. and were mainly applied on commercial buildings. However, due to the increased attention and demand for energy efficiency in the early 1970s, EIFS were adopted for residential use. In Europe, EIFS were typically applied over substrates with high moisture capacity such as concrete, or for retrofitting existing buildings by over-cladding brick with EIFS. North American walls are typically constructed as composite wall systems, made of multiple layers of different materials with significantly lower moisture capacities than concrete. Hence, the use of moisture sensitive gypsum board and OSB sheathings in North America caused moisture performance problems in walls utilizing EIFS.

Currently EIFS account for $17 \%$ and $3 \%$ of the American commercial and residential building sectors respectively, and approximately 200 million square feet are being specified annually with 
sales expected to continue to grow a rate of $10 \%$ annually (Markets and markets, 2018). Although EIFS owns a significant market share in North America, the 1980's Canadian Leaky Condo crisis left EIFS with a reputation associated with water intrusion failures and high moisture damage repair and control costs. Similar failures were also found in housing stocks in North Carolina and New Zealand. Since then, EIFS have been undergoing through extensive research and development and have seen significant improvements. One of the key improvements is the addition of a geometrically defined drainage gap in the continuous insulation layer to allow water that penetrated the outer EIFS lamina to drain out by gravity to the exterior. The gap also provides an opportunity for enhancing the convective drying ability of the wall assembly by introducing air flow (referred to as drained/vented or drained/ventilated EIFS assemblies). The integration of this cavity has raised questions regarding its impact on the thermal performance of wall assemblies constructed with these EIFS.

\subsection{Research Objectives}

The objective of this research is to evaluate the thermal performance impacts, as a percentage reduction in the effective RSI-Value of a vented EIFS assembly against a face-sealed EIFS by conducting thermal numerical simulations and expand the results with respect to increased building heights and wind velocities. The purpose of this research is to provide building professionals with information about the thermal performance for these EIFS assemblies to support design decisions on current and future projects as emphasis is being placed on developing building designs with greatly reduced energy use. It is recognized that venting can reduce the thermal performance of wall assemblies and thus can affect the overall thermal performance and the total energy use by buildings. Such effects also produce other undesirable risks such as the thermal discomfort and condensation in walls. Specific research questions are:

1. What impacts does venting have on the thermal performance of EIFS wall assemblies applied on a single-story building?

2. What impacts does the application of EIFS (Face-sealed and vented) on mid-rise and high-rise buildings have on the thermal performance of wall assemblies? 


\subsection{Literature Review}

The starting point of this review provides an overview of EIFS thermal and moisture performances, durability, and issues facing the EIFS industry in Canada. The review continues with introducing three different types of EIFS including: face-sealed, vented, and ventilated. The building physics of cavity ventilation, including ventilation driving forces and ventilation flow mechanics is also reviewed and the impact of air flow on heat transfer and its application on vented and ventilated EIFS assemblies is discussed. Finally, a previous initiative (Smegal, 2017) for full scale EIFS field testing is analyzed and its parameters and results are used to calibrate a simulation model for predicting the thermal performance impacts of using vented EIFS assemblies at different building heights, as discussed later in the Methodology and Approach section.

\subsection{EIFS Background}

In North America, EIFS are constructed of a specific thickness (typically 2 - 6 inches) of rigid foam insulation (typically EPS Type 1) attached to a structurally supported substrate using trowel-applied adhesive and/or by mechanical means. A liquid-applied membrane also covers the substrate to act as the main water/air control layer in the assembly, while being vapor permeable allowing the assembly to dry out to the exteriors, and the interiors when interior vapor barriers are not specified. Towards the exterior, the insulation board is covered with a durable and waterresistant base coat embedded with mesh reinforcement to provide its strength and durability to prevent cracking. The base coat is covered by a finish coat (typically acrylic polymer) to give the final appearance of the building's facade. The base coat, mesh reinforcement and the finish coat are referred to as "lamina". Figure 1 demonstrates typical EIFS construction used nowadays in North America. The EPS insulation may or may not include a geometrically defined cavity spaces (grooves) to facilitate water drainage and allow for cavity ventilation to enhance convective drying. 


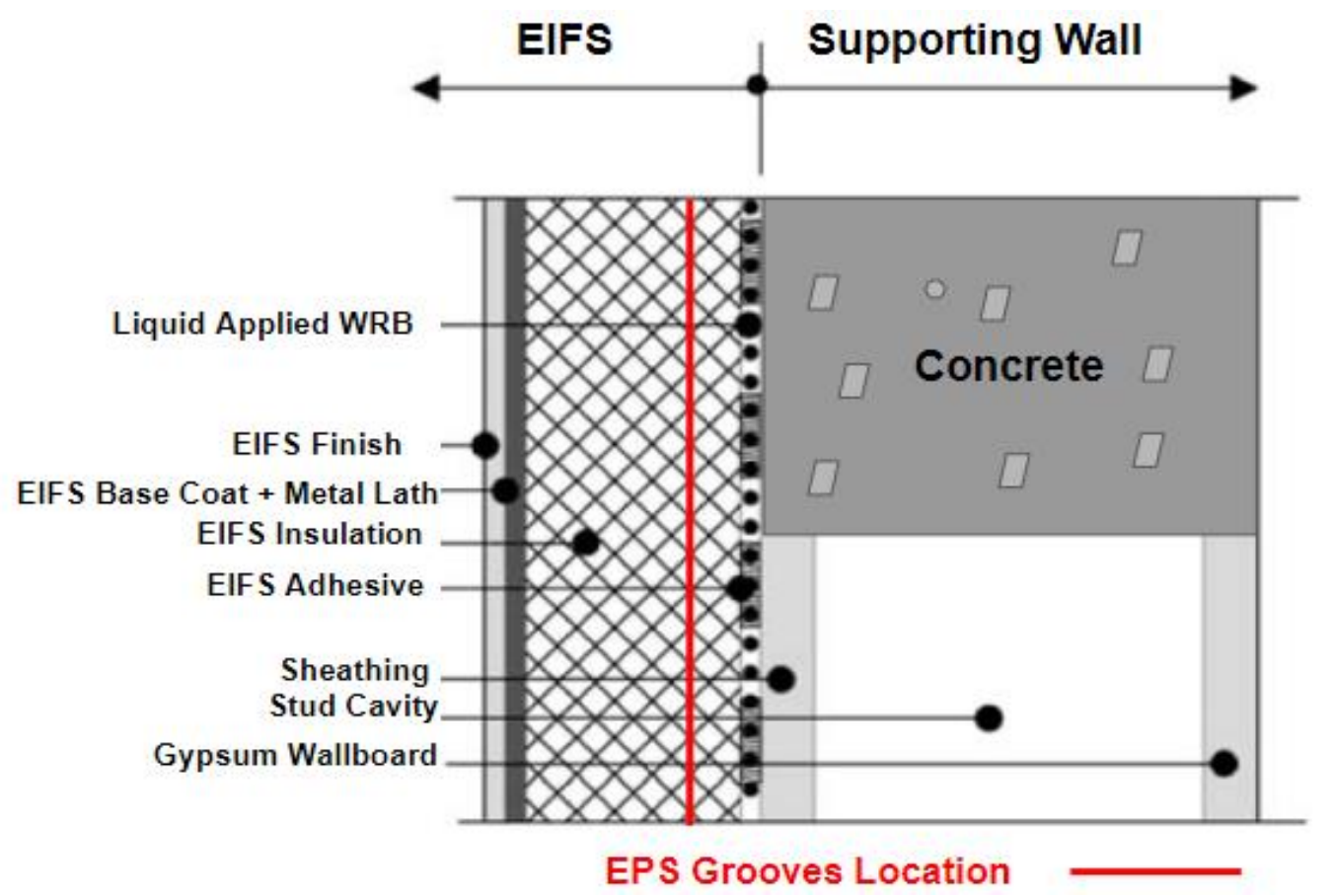

Figure 1. Typical EIFS Construction in North America. (Kesik, 2014)

As mentioned earlier, the greatest advantage of using EIFS is the elimination of thermal bridging by providing continuous insulation over the building structure. In common building assemblies not utilizing EIFS or other continuous insulation systems, thermal bridging can significantly reduce the effective thermal resistance of a wall by more than 50\% (Morrison Hershfield, 2011). ASHRAE 90.1 defines continuous insulation as insulation that is continuous across all structural members without thermal bridges other than fasteners and service openings (ASHRAE, 2010). Eliminating thermal bridges positively affects the durability of the envelope by keeping control layers and substrate warm, and the interior surfaces at a temperature above the dew point of interior air, thus preventing condensation and moisture damage. Other advantages of using EIFS is there lower initial costs as they are less material and labor intensive in addition to their lower life cycle costs due to their improved thermal performance during the building's operation stage. EIFS low embodied energy ranks them among the lowest carbon footprint cladding systems, as EPS has a modest global warming potential when compared to other insulation types such as Rockwool (Kesik, 2014). In general, EIFS can serve for 25 - 30 years based on their use, maintenance and the performance of other materials making up the wall assembly such as 
sheathings. Asset management programs that regularly inspect, clean and maintain EIFS do exist in North America.

Although EIFS provide many advantages, they also have limitations. Firstly, their low impact resistance makes it impractical to apply EIFS on areas prone to abuse and abrasion. EIFS assemblies can also suffer from moisture damage, as observed in Vancouver's marine climate, where face-sealed EIFS were applied on gypsum sheathing with interior vapor barriers that inhibited the drying ability of the assembly to the interiors. The finish coat also acted as a vapor retarder by restricting drying of water to the exterior causing moisture damage. Typical moisture damage patterns in EIFS include formation of mold and fungi within the cavity insulation and sheathings, wood decay of sheathings and wood studs, loss of adhesive strength, corrosion of steel studs, dimensional instability, and discoloration of interior and exterior finishes. (Lstiburek, 2007)

EIFS are typically manufactured as proprietary systems, where the insulation, adhesives and/or fasteners and lamina are provided by a single EIFS manufacturer responsible for compatibility between components and performance testing integrity of EIFS. Kesik (2005) provided an indepth discussion on the Canadian EIFS industry, where he conducted an extensive literature review on EIFS, their performance, economy, sustainability and durability. Kesik conducted an integrative industry review and surveyed various stakeholders including EIFS manufacturers, suppliers, contractors and building professionals to provide different perspectives on EIFS and identify their main strengths and issues in Canada. Kesik concluded that although information about the performance, economy, durability and sustainability of EIFS cladding is technically supported, the construction industry continues to specify EIFS for applications that are not suited for its intended use. In addition, he stated that "The main issue in the Canadian EIFS industry is that inaccurate, outdated and unsupported misinformation about EIFS is being broadcasted in the absence of a strong consumer and industry voice advocating the EIFS industry in Canada. The absence of proactive advocacy exposes the EIFS industry to the risk of litigation.” (Kesik, 2005) 


\subsection{Moisture Management of Walls}

There are three main strategies to prevent rainwater from penetrating through the building envelope. The oldest strategy is to provide a substrate with high moisture capacity that acts as a hygric buffer, thus storing and re-distributing moisture for sufficient time until the relative humidity across the enclosure drops, enabling the substrate to dry by evaporation and vapor diffusion. Modern walls however are composite, constructed of multiple layers each with its own function. Typically, these layers do not have sufficient moisture capacity and thus are not able to store moisture without causing damage or deterioration. These walls must be constructed with moisture management strategies in mind and designed such that their rate of drying exceeds their rate of wetting. Both, the rate of wetting and drying of a building assembly are functions of climate, design, construction and operation (Lstiburek, 2007).

According to Straube (2005), there are four major sources of moisture in building envelope assemblies 1) Bulk water from precipitation; 2) Water vapor present in indoor/outdoor air; 3) Built--in moisture in building materials, 4) Liquid water from soil. After any wetting event, moisture can be transported within or dried out of a wall assembly by a combination of the following four mechanisms 1) Drainage by gravity; 2) Vapor transport by diffusion and/or air leakage; 3) Ventilation drying; 4) Evaporation of water from the surface of the wet material. For a building envelope to experience moisture damage, the following five elements must all be present 1) A moisture source; 2) A path through the building envelope; 3) A driving force; 4) A material susceptible to moisture damage; 5) The safe storage capacity of the material must be exceeded for sufficient time to cause damage.

It is impossible to eliminate all moisture sources, and it is commonly acceptable in the construction industry for a building envelope to have imperfections either in the short term or sometime throughout the lifespan of the building, thus a path is almost always present. In addition, a driving force is always present due to the different environmental conditions

experienced by each side of the enclosure. Hence, the only strategies left is to either use materials not susceptible to moisture damage, which is not cost-effective nowadays and would 
take us back to the old moisture storage strategy or design the wall assembly such that the rate of drying is higher than the rate of wetting taking the materials' safe storage capacities into consideration. Thus, a wall must be designed and constructed such that it avoids wetting and/or encourages drying. Moisture management can be achieved by 1) Deflecting rain from the exterior wall by using overhangs; 2) Drain out by gravity the rain that could not be deflected; 3) Control air flows that drive rain penetration; 4) Control vapor flow. Figure 2 demonstrates three moisture management strategies, where the last two strategies are incorporated in modern composite wall designs.

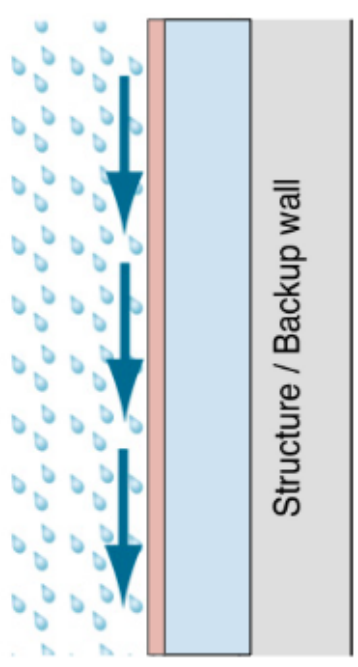

Face-Sealed Wall

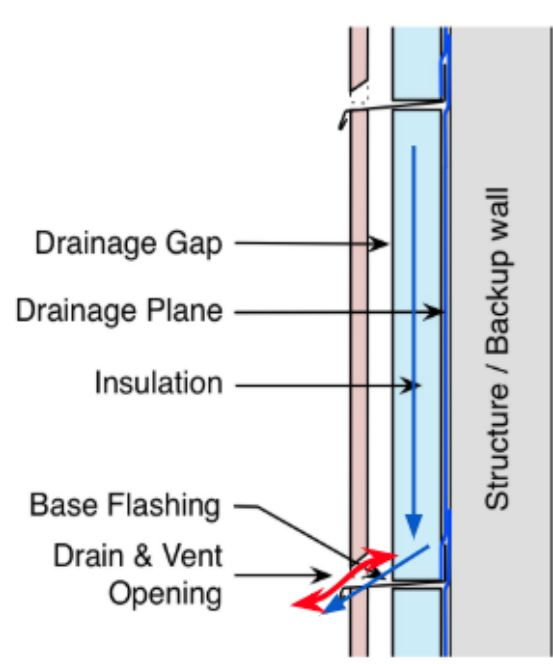

Drained-Vented Wall

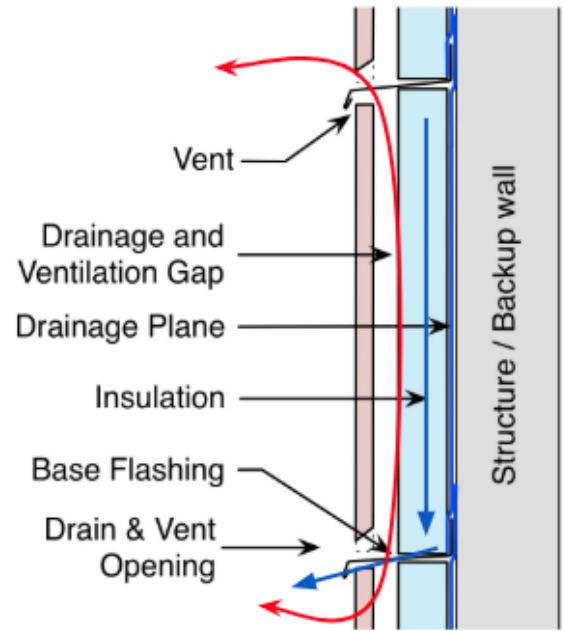

Drained-Ventilated Wall

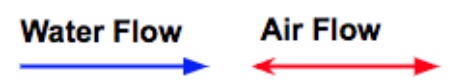

Figure 2. Different Composite Wall Types with Different Moisture Management Strategies.

A face-sealed wall is designed to act as a perfect barrier, thus allowing no water to penetrate through it. A face-sealed strategy does not provide redundancy for draining any water that penetrated the one and only exterior line of defense. It is commonly accepted that no enclosure can be perfect for its lifespan, thus a small amount of water is always expected to penetrate the exterior cladding. Even if a wall panel is designed, fabricated and succeeded to act as a perfect barrier, the joints and sealants between different panels usually fail to provide sufficient tightness against air and moisture. This occurs due to seasonal thermal expansion/contraction, differential 
settlement of the building, material degradation, incompatibility between materials, impractical designs and poor workmanship. The use of face-sealed assemblies was proven to cause performance problems and is deemed to be inherently defective for all climates except dry ones with less than 20-inches of annual precipitation, and where the monthly average outdoor temperatures stay above $7^{\circ} \mathrm{C}$ throughout the year (Lstiburek, 2007).

A drained wall was later invented to fix the design defects found in face-sealed assemblies by providing provisions for drainage of water that penetrated the outer surface. A drained wall assembly can be either vented or ventilated. However, both configurations are comprised of five main components as suggested by Straube (2005):

1) Exterior cladding (Rainscreen) acts as a first line of defense against environmental loads.

2) Drainage gap.

3) Drainage plane acting as a capillary break and a second line of defense against water.

4) Flashing system to direct drained water out.

5) Weep holes or vents to allow drained water to pass the cladding to the exterior.

The drainage gap (air cavity) provides the following functions:

1) Acts as a capillary break for penetrating water.

2) Provides an effective drainage space for water to prevent the buildup of hydrostatic pressure across the water control layer.

3) Provides a ventilation chamber to enhance drying.

4) Can contribute to pressure moderation between the cavity and the exteriors.

Ventilating the air space offers two additional benefits:

1) Replacement of moist cavity air by dryer outside air (typically in winter), thus drying materials making up the cavity walls. 
2) Allow for water vapor diffusing to the exterior (typically in winter) to bypass the vapor resistance of the exterior cladding.

A drained-vented wall is constructed with a hole (vent) at its base to allow for a limited amount of air to enter the drainage cavity. Vented walls allow only for a limited degree of water vapor diffusion and air mixing between the cavity and the exterior, allowing water that was not drained out by gravity and adhered to the surface of the materials exposed to the cavity to dry out. Thus, air flow rate and air velocity in vented cavities are relatively small, and thermal buoyancy and air infiltration play significant roles in driving the air flow followed by wind pressures (Straube, 2012).

A drained-ventilated wall is constructed with two holes, located at the base and the top to allow for a large volume of air to enter and exit the cavity. The air volume might have lower or higher moisture content than the air in the cavity. However, ventilated walls are usually designed to allow for air to dry out moisture from the interior surface of the cladding and the exterior surface of the substrate. Air flow rate in ventilated walls are significantly higher than rates experienced by vented walls and are influenced mainly by wind pressure gradients followed by thermal buoyancy. Air infiltration can be neglected in the case of a ventilated assembly due to its insignificance relative to the main driving forces (Straube, 2012).

EIFS assemblies are classified as modern composite wall assemblies and are manufactured in different configurations as face-sealed, drained-vented or drained-ventilated, as demonstrated in Figure 3. Rain is the main wetting mechanism for EIFS, and its severity and frequency determine the approach necessary to control it. Face-sealed EIFS assemblies lack an intentional drainage mechanism and the EPS is attached directly to the sheathing with adhesive and/or fasteners to the studs. The drainage cavities in vented and ventilated systems are provided as geometrically defined grooves in the continuous insulation layer. For vented EIFS, the top of the cavity is air-sealed by the means of a 12-inches EPS closure blocks to prevent air flow out of the gap, however, the grooves are left open for air flow and water drainage at the base of the wall. Common vented EIFS vent hole cross-sectional area is $0.01 \%$ of the wall with a cavity depth of 
$12 \mathrm{~mm}$. For ventilated assemblies, both the top and bottom and sides are left open, where $12 \mathrm{~mm}$ deep horizontal and vertical grooves for every square meter with total vent holes cross-sectional area that makes up $1 \%$ of the wall area are specified to encourage airflow.

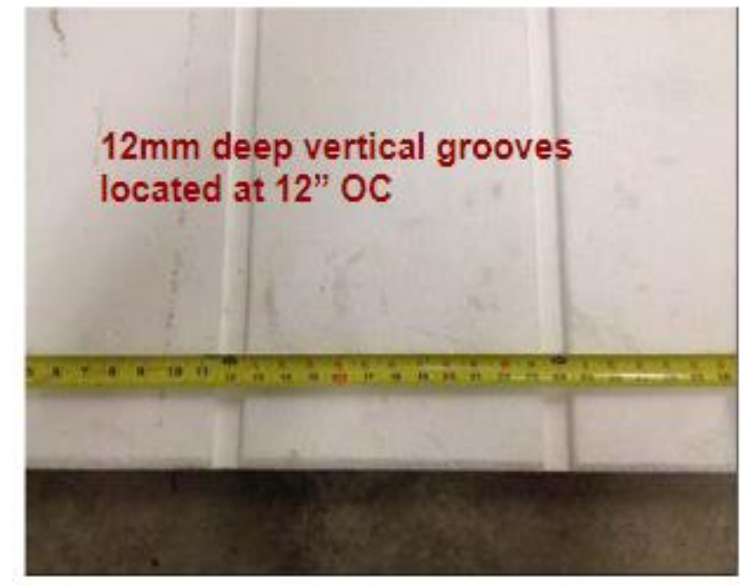

Drained/Vented EIFS

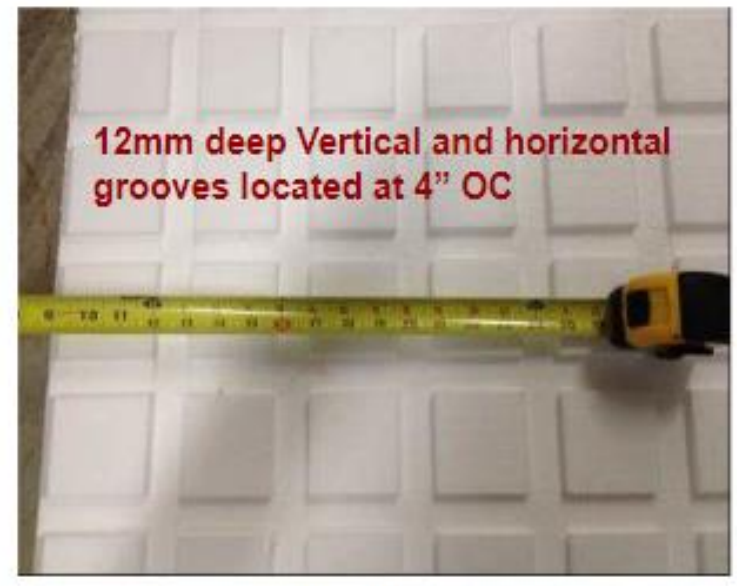

Drained/Ventilated EIFS

Figure 3. Vented Vs. Ventilated EIFS. (Smegal, 2017)

Many field and laboratory studies were conducted to better understand the highly complex functionality of air cavities for a limited number of parameters in attempts to optimize the cavity design and enhance the moisture performance of walls. Smegal (2007) argued that the 10mm gap behind drained claddings required in the National Building Code of Canada is not intended to ensure effective drainage but to assist in ventilation drying and to accommodate construction tolerances. Smegal added that some products such as grooved EPS insulation are designed to ensure that a minimum drainage gap is provided, and hence, should not require a 10mm gap and demonstrated that a $1 \mathrm{~mm}$ gap will drain water at a rate significantly greater than it is expected behind claddings in extreme conditions in Canada based on laboratory testing. The same study concluded that EIFS with a drainage gap (Grooves) of $3 \mathrm{~mm}$ depths sufficiently drain out all water and effectively relieve the hydrostatic pressure in the cavity.

Salonvaara et. al. (1998) conducted laboratory experiments and numerical simulations with the aid of hygrothermal modelling on various types of walls including EIFS to assess the 
contribution of ventilated and vented cavities to ventilation drying and the wall's hygrothermal performance. The study founded that air exchange rates between the cavities and exteriors of less than $15 \mathrm{ACH}$ had significant positive effects on the moisture performance of the walls. It was also concluded that ventilated assemblies dried faster than vented assemblies, which in turn dried faster than face-sealed, and that a direct relation exist between the cavity depth and the air exchange rate, which contributed to the moisture performance of the walls.

In a larger study, Forintek (2001) studied more parameters contributing to ventilation drying in simulated settings for stucco and vinyl sidings and was completed in two phases. The first phase simulated wind effects on the cavity ventilation by introducing pressure differences up to $5 \mathrm{~Pa}$ between the top and bottom vents of ventilated and vented wall assemblies, in addition to solar effects by simulating solar radiation up to $120 \mathrm{~W} / \mathrm{m}^{2}$ (Equivalence of diffuse radiation experienced by North walls in Vancouver). The second phase acted as a baseline without simulating wind or solar effects. Both walls were pre-soaked with water and their drying rates were monitored. The conclusions were close to Salonvaara's and included cavity depths of $19 \mathrm{~mm}$ and $10 \mathrm{~mm}$ concluding that drying is significantly affected by the cavity air flow rate which in turn is significantly influenced by cavity depths. Forintek (2001) also realized that assemblies with plywood sheathings dried faster than others constructed with OSB due to the latter's high vapor resistance. Finally, it was pointed that solar radiation effects on drying the wet assemblies were significant but smaller than wind pressures and cavity depths.

Contradictory and controversial results were reported earlier by Fraunhofer-Institute for Building Physics (Kunzel, 1983) which concluded that air spaces had no effects on the moisture performance of brick wall assemblies. Similarly, Morrison Hershfield (1999) completed full scale laboratory studies to assess the impact of venting/ventilating on the moisture performance of wood-frame walls with stucco cladding in Vancouver, BC. The study was initiated as a reaction to the Leaky Condo Crisis and the walls were wetted from the interior, and simulated exterior temperatures were maintained at $10^{\circ} \mathrm{C}$ without accounting for wind or solar effects. The study concluded that the air spaces did not enhance the ability of the assemblies to dry and all 
walls experienced long drying periods. Although wind and solar effects were not simulated, the study concluded that they have no significant effects on drying the wall assemblies.

Hundreds of other studies were conducted to assess ventilation drying, moisture performance, cavity airflow nature and air exchange rates behind different vented/ventilated cladding types with different geometry and arrangements, and few are summarized in this paper under related sections. From the few cases mentioned above, different studies reached to contradictory conclusions regarding the effectivity of ventilation drying in different climates. It is also clear that cavity ventilation is a complex subject since it is affected by several factors including size and arrangement of vents, cavity shape including height and depth, as well as properties of materials making up the cavity walls such as emissivity and roughness. To make it more complicated, the review also revealed that the air flow is also driven by wind, thermal and moisture buoyancies, infiltration and other driving forces, while the nature of the flow is dependent on both the vectors of driving forces and all the above. Although many studies dealt with most of these aspects in the context of enhancing the moisture performance of the wall, it was realized by the author that minimal efforts have been put towards evaluating the thermal performance of the vented/ventilated EIFS assemblies, which are also affected by the same parameters above. Also, studies conducted were mainly for non-EIFS ventilated assemblies, with fewer studies addressing EIFS in general and vented EIFS in particular.

The upcoming sections focus on the fundamental physics of the cavity airflow and attempts to build-up knowledge with the aim of evaluating the thermal performance impacts of vented/ventilated EIFS assemblies. It is important to note that ventilated EIFS assemblies are rarely used in North America due to evident thermal impacts. Thus, this research focuses on vented EIFS assemblies. However, both vented and ventilated assemblies share the same fundamental physics and could be evaluated with the proposed approach. The following two sections provide the theory behind cavity ventilation and are heavily based on Straube (1995, 1998, 2004, 2012). In 1995, Straube developed equations linking ventilation rates with wind pressures, buoyancy and cavity geometry. 


\subsection{Ventilation Driving Forces}

In this section, forces that drive the ventilation flow by creating air pressure difference between the cavity and the exteriors are reviewed, and the significance of each driving force on the ventilation air flow is discussed. Cavity airflow is mainly driven by:

1) Stack Effect (Thermal Buoyancy).

2) Wind Pressures.

Other less significant forces include moisture buoyancy, air infiltration, thermal pumping and wind pumping. Since the density of air decreases as its moisture content and temperature increase, Pi.on (2014) was able to demonstrate that moisture buoyancy is a significant driving force only when the moisture content of the cavity air is significantly higher than the exterior, which only happens for short periods of time. Since the aim of this research is to determine if there is a difference in the thermal resistances of vented and face-sealed assemblies as a result of different construction, moisture buoyancy was not considered. Air infiltration was also neglected since the liquid applied WRBs used in vented/ventilated EIFS assemblies are effective in controlling air leakage through the building enclosure, hence infiltration effects are expected to be relatively insignificant. The general equation that will be utilized in this paper is:

$$
\Delta P \text { Total }=\Delta P \text { Stack }+\Delta P \text { Wind }
$$

Where:

- $\triangle P$ Total is the total pressure difference driving ventilation in $(\mathrm{Pa})$.

- $\triangle P$ Stack is pressure difference generated due to thermal buoyancy in $(\mathrm{Pa})$.

- $\triangle P$ Wind is the pressure difference generated due to wind pressures in $(\mathrm{Pa})$.

The direction of airflow inside the cavity could be from the top to the bottom vent or reversed depending on the combination of the driving forces and the ventilation rate depends on cladding and venting configuration (size and arrangements) and is strongly influenced by weather events 
including solar radiation and wind. Since air flows is constantly being exchanged between the cavity and the exteriors attempting to equalize air pressures, it will be shown in the next two sections that at equilibrium Equation (1) is equivalent to:

$$
\Delta P \text { Total }=2 *\left(\frac{Q}{0.62 * A \text { vent }}\right)^{2}+\left(\frac{Q * h}{4611 * \gamma * d^{3} * b}\right)
$$

Where:

- $Q$ is the ventilation flow rate in $\left(\mathrm{m}^{3} / \mathrm{s}\right)$.

- A vent is the cross-sectional area of the vent in $\left(\mathrm{m}^{2}\right)$.

- $h$ is the vertical distance between the top and the bottom vents in (m).

- $\gamma$ is the cavity blockage factor ( $\gamma=1$ for EPS grooves with no blockage assumed).

- $d$ is the cavity depth in (m).

- $b$ is the cavity width in (m).

While:

$$
\begin{aligned}
& Q=A C H * V \text { cavity } \\
& Q=U \text { cavity } * A \text { cavity }
\end{aligned}
$$

Where:

- $A C H$ is the air exchange rate between the cavity and the exterior in (1/hr.).

- $\quad V$ cavity is the cavity volume in $\left(\mathrm{m}^{3}\right)$.

- $U$ cavity is air velocity inside the cavity in $(\mathrm{m} / \mathrm{s})$.

- A cavity is the cavity cross-sectional area in $\left(\mathrm{m}^{2}\right)$. 


\subsubsection{Stack Effect (Thermal Buoyancy)}

Stack effect takes place due to differences in densities between cavity and exterior air and is driven by solar radiation and gravity. Solar radiation can increase the cladding temperature to $40^{\circ} \mathrm{C}$ above ambient air temperature during the day, this heat is transferred to the air cavity reducing its density and resulting in its rise creating positive air pressure at the top of the cavity and negative air pressure at the bottom. Warm air escaping to the outside creates an air current that draws colder air at the bottom to replace it. In the case of ventilated assemblies, the open top will provide an opportunity for the less dense warmer cavity air to escape to the exterior, while denser and colder exterior air is sucked into the cavity through the bottom. Figure 4 demonstrates the process of thermal buoyancy taking place across ventilated cladding for most time of the year in cold climates.

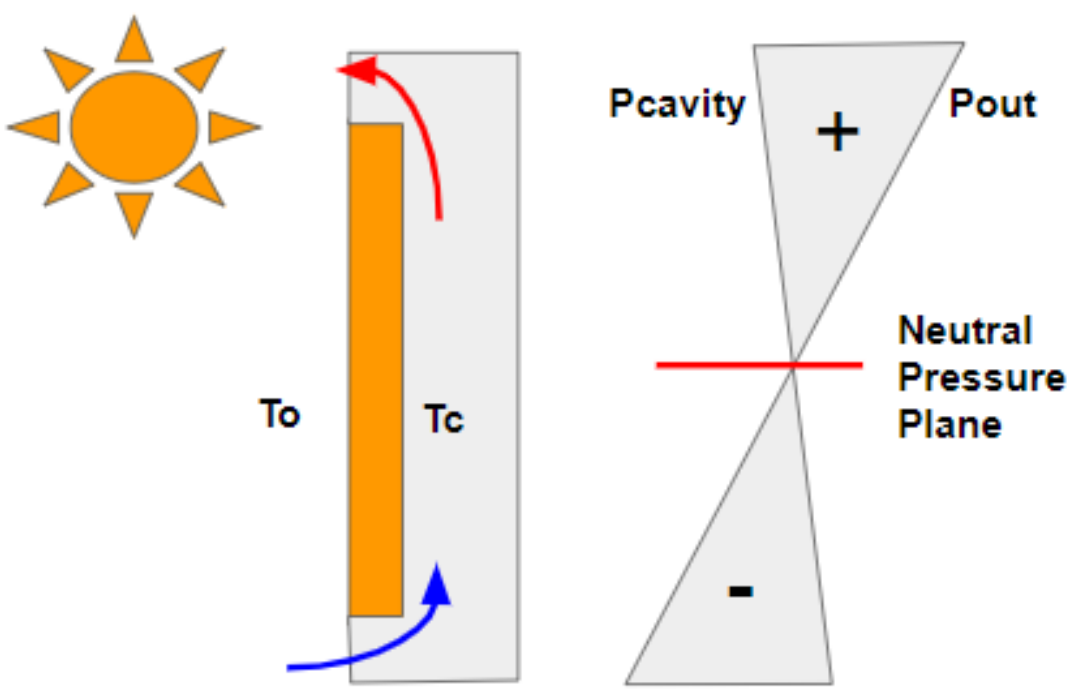

Figure 4. Ventilation Stack Effect.

For vented assemblies, cavity air is not allowed to escape from the top while it is still warming up due to solar radiation forcing it to leak through cracks in the EPS insulation and lamina to the exteriors, or to the inside of the building through joints and imperfections in the air barrier system. It is also believed that the use of closure blocks in EIFS vented assemblies breaks the 
integrity of the EPS insulation system allowing air to leak out through micro spaces between the insulation board and the closure block. Hence, it is safe to deal with vented assemblies in a similar approach to ventilated assemblies with very small openings at the top. Bassett and Mcneil (2005) measured ventilation rates in vented wall assemblies in a test facility at in New Zealand. Their methodology for calculating theoretical ventilation rates in vented walls was to treat them as ventilated walls with top vent size of $18 \%\left(100 \mathrm{~mm}^{2}\right)$ of the bottom vent size. The same study stated that only vertical pressure gradients in the cavity are generated due to thermal buoyancy, while wind pressures generate horizontal, vertical and diagonal gradients in the cavity space. Furthermore, it was demonstrated that higher the pressure differences between exterior and cavity air is caused by increasing the cavity height due to greater distances between the vents and the Neutral Pressure Plane (NPP).

Straube (2004) argued that in cold climates, temperature differences of $3-10^{\circ} \mathrm{C}$ between the cavity and the exterior air occurs for most of the time, while $30^{\circ} \mathrm{C}$ happens occasionally. Ventilation pressures due to thermal buoyancy at $10^{\circ} \mathrm{C}$ temperature difference could reach to $1 \mathrm{~Pa}$ and $3 \mathrm{~Pa}$ for a $2.4 \mathrm{~m}$ and a $6 \mathrm{~m}$ cavity height respectively. For $30^{\circ} \mathrm{C}$, pressure differences of $3 \mathrm{~Pa}$ and $8 \mathrm{~Pa}$ for a $2.4 \mathrm{~m}$ and a $6 \mathrm{~m}$ cavity height respectively. Tabulated values of pressure difference driving ventilation due to stack effect can be found in Straube (2004) up to $6 \mathrm{~m}$ height and $30^{\circ} \mathrm{C}$ temperature difference. Similar data that could be used for high-rise building analysis can be found in Hucheon (1983). The latter provides stack pressures data up to $300 \mathrm{~m}$ from NPP and $70^{\circ} \mathrm{C}$ temperature difference. However, it is important to note that such temperature differences are meant to be representative for indoor-outdoor temperatures while solar radiation is increasing the temperature of the cladding. In lieu of using the published values, the pressure difference due to stack effect for cavity applications can be calculated as:

$$
\Delta \text { Pstack }=3465 * h *(1 / \text { To }-1 / T c)
$$

Where:

- $\triangle P$ Stack is pressure difference generated due to thermal buoyancy in $(\mathrm{Pa})$.

- $h$ is the vertical distance between the top ven and the bottom vent in (m). 
- To is the outdoor air temperature in (Kelvin).

- $T c$ is the cavity air temperature in (Kelvin).

Instances when the outdoor air temperature becomes higher than the cavity, the upward cycle of cavity air is reversed. Due to daily cycles of heating and cooling the cavity air, one daily cycle of contraction and expansion of air cavity volume takes place, referred to as thermal pumping. This change in cavity volume can be calculated as a function of the temperature difference between cavity and exterior air. Straube (2004) showed that for a one-story height wall $(2.5 \mathrm{~m})$ with a continuous cavity of $25 \mathrm{~mm}$ depth and at a temperature difference of $30^{\circ} \mathrm{C}$, only $0.000077 \mathrm{~L} / \mathrm{s}$ of air is exchanged due to thermal pumping. Thus, it is assumed for the purpose of this research that thermal pumping is negligible due to its insignificance particularly when used with the horizontally compartmentalized $12 \mathrm{~mm}$ deep grooves in vented EIFS assemblies. Finally, it is important to note that solar radiation is the main driver for generating stack pressure, hence north-facing walls experience lower temperature differences and lower pressure differences are generated due to stack effect.

\subsubsection{Wind Pressures}

Wind pressures acting on building assemblies are more difficult to deal with than stack pressures due to the transient nature of wind pressures acting on different parts of the building. Furthermore, buildings experience gradients of pressures across the surfaces due to the increased wind velocity at higher elevations from the grade, and the horizontal and vertical gradients which form as wind flows around a structure. In ventilated assemblies, wind pressures cause the air in the cavity to either move up or down, mostly depending on the direction of the wind. In cases where continuous non-compartmentalized cavities are used such as in brick veneer walls, wind pressures cause airflow between vents in horizontal, vertical and diagonal directions. Mayer and Kunzel (1983) measured ventilation and drying rates behind large cladding panels on a threestory building. It was concluded that wind direction influenced the ventilation air velocity more than wind-speed. In addition, cavity air velocities were measured between $0.05 \mathrm{~m} / \mathrm{s}$ to $0.15 \mathrm{~m} / \mathrm{s}$ with wind speeds of $1 \mathrm{~m} / \mathrm{s}$ and $3 \mathrm{~m} / \mathrm{s}$ respectively. Silberstein (2006) argued that the air velocity in 
the cavity is hardly influenced by the wind speed for a low-rise building and determined that the average air velocity inside the cavity is $0.06 \mathrm{~m} / \mathrm{s}$.

Practically, in ventilated assemblies the flow of air is mainly downwards due to higher wind pressures acting on the top of the wall as demonstrated in Figure 5. The absence of a top vent in vented assemblies is expected to greatly reduce the effect of the pressure difference generated due to wind pressures on the cavity ventilation, especially in the case of a vented EIFS assembly where the cavity is horizontally compartmentalized and wind pressures are expected to cause air to enter and exit the cavity through the same vent (bottom). Straube (1998) argued that for wind pressures to drive cavity ventilation, a pressure difference must exist between two connected vent openings.

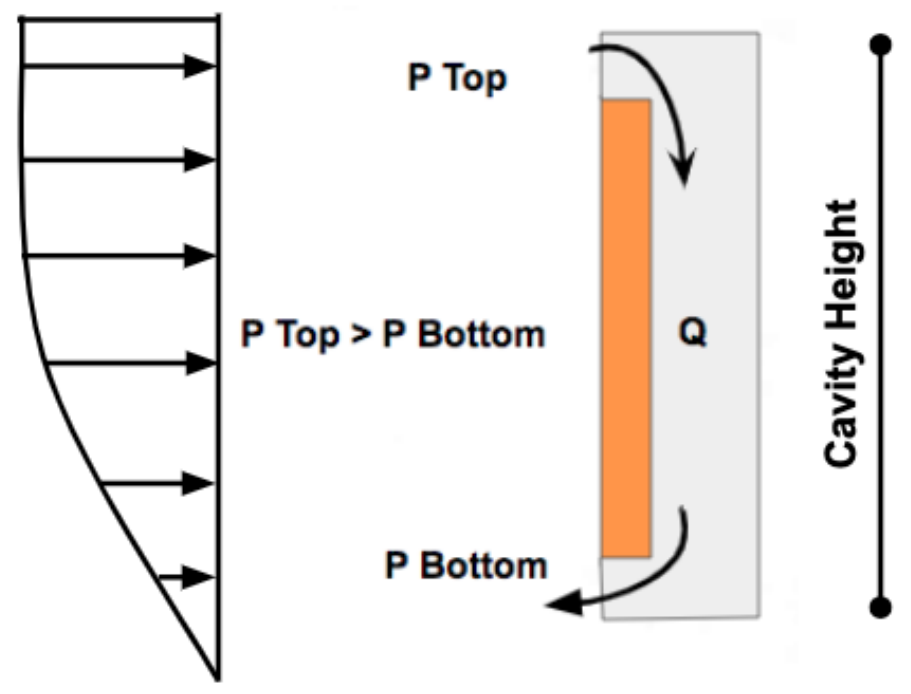

Figure 5. Ventilation Induced by Wind Pressures.

Theoretically, Pressure differences generated due to wind pressures is calculated as:

$$
\Delta P \text { wind }=1 / 2 * \rho * U^{2} \text { ref } *(C p \text { top vent }-C p \text { bottom vent })
$$

Where:

- $\triangle P \mathrm{~W}$ ind is the pressure difference generated due to wind pressures in $(\mathrm{Pa})$. 
- $\rho$ is the outdoor air density in $\left(\mathrm{Kg} / \mathrm{m}^{3}\right)$.

- Uref is the outdoor air velocity at reference height in $(\mathrm{m} / \mathrm{s})$.

- $\quad C p$ is the wind pressure coefficient relative to wind speed at desired height.

Since wind speed varies with height above grade, pressure gradients are generated along the height of the building. Thus, the wind pressure coefficient can be calculated as a function of wind velocity at a reference height as (assuming standard conditions):

$$
C p=P z / P r e f
$$

While P ref can be calculated as:

$$
\text { Pref }=0.647 * U^{2} \text { ref }
$$

And, wind pressure and speed at the desired height as:

$$
\begin{aligned}
& P_{Z}=0.647 * U^{2} z \\
& U_{Z}=(Z / Z \text { ref })^{\mathrm{a}} * U \text { ref }
\end{aligned}
$$

Where:

- $\quad P z$ is the wind pressure at the desired height in $(\mathrm{Pa})$.

- P ref is the wind pressure at the reference height of the building in $(\mathrm{Pa})$.

- $U_{Z}$ is the wind velocity at the desired height in $(\mathrm{m} / \mathrm{s})$.

- Uref is the wind velocity at the reference height in $(\mathrm{m} / \mathrm{s})$.

- $Z$ is the desired height above the ground in (m).

- Z ref is the reference height in (m).

- $\alpha$ is the exposure exponent. 
The exposure exponent is used to account for different terrains and their exposure to wind. The National Building Code of Canada assigns a value of $0.14,0.25$, and 0.36 for open country, suburban, and city center respectively. The different values for different terrains or locations arises from the fact that similar wind velocities can be achieved at different gradient heights for different terrains. For instance, a specific wind velocity can be reached at lower elevations in open country relative to a city center location as explained later in the Results section.

Rearranging Equations 6, the pressure difference between vents can be described by:

$$
C p v=(C p \text { top vent }-C p \text { bottom vent })=\frac{\Delta P \text { wind }}{\text { Pref }}
$$

Where:

- $\quad C p v$ is the difference between wind pressure coefficients of top and bottom vents.

Although, wind pressure coefficients were developed for square building shapes and could be used for static cases, they rarely represent buildings in the field. More accurate wind coefficients can be determined for a specific building with use of CFD modeling, wind tunnel studies, or field monitoring. Straube (1995) suggested that data from Atmospheric Environment Services can be used to estimate wind pressures in different Canadian cities to predict ventilation driving forces. He added that by scaling lines of equal wind pressures on building surfaces to match the size of a real building, it can be shown that larger buildings experience smaller pressure gradients over a fixed floor height. Thus, the ventilating pressures over a floor height on an exposed four-story building are expected to be greater than ventilating pressures in a forty-story building. Pressure coefficient values are typically 0.7-0.8 near the center of a typical rectangular building and when the wind direction is perpendicular to the surface of the building. Due to wind effects around buildings, pressure coefficients can drop to zero or lower at the edges. The lower the incidence angle, the lower the pressure coefficients on windward surfaces. Leeward surfaces are exposed to negative pressure coefficients. Finally, Straube argued that the average wind velocity is generally low $(3-4 \mathrm{~m} / \mathrm{s})$ at $10 \mathrm{~m}$ above grade level in most Canadian cities, however, the wind blows $90 \%$ of the time and these velocities translate to stagnation pressures ( $P$ ref $)$ ranging from 5 to $30 \mathrm{~Pa}$ 
and that average wind pressures driving ventilation in low-rise buildings are in the order of $1 \mathrm{~Pa}$, but the average falls somewhere between 0.1 and $10 \mathrm{~Pa}$, depending on building size, distance between vents, wind speed and direction.

\subsection{Ventilation Flow Mechanics}

It was explained in the previous chapter that an air pressure difference is required to drive the cavity ventilation. This pressure difference is generated due to thermal buoyancy and wind pressures acting on the enclosure. It was also explained that in vented assemblies with bottom vents only at the base of the wall, the pressure difference drives exterior air in and out of the same vent or through leaks at the top vent location. As soon as a pressure difference exist, the exterior air at the base of the wall starts to flow into the cavity and is resisted by the vents and cavity walls causing the air to lose its pressure as it enters, flows through and leaves the cavity. The whole process is initiated in attempts to achieve air pressure equilibrium between exterior and cavity air. At equilibrium, a balance between the pressure driving forces and the forces resisting the flow forces is achieved, such that:

$$
\Delta P \text { Total }=\Delta P \text { Stack }+\Delta P \text { Wind }=\Delta P \text { Resistance }
$$

While:

$$
\Delta P \text { Resistance }=\Delta \text { Pentrance }+\Delta \text { Pcavity }+\Delta \text { Pexit }
$$

Where:

- $\triangle P$ Resistance is the sum of pressure losses due to ventilation flow resistance in $(\mathrm{Pa})$.

- $\Delta P$ entrance is the pressure-drop due to flow resistance at the entrance in $(\mathrm{Pa})$.

- $\Delta P$ cavity is the pressure-drop due to flow resistance across the cavity in $(\mathrm{Pa})$.

- $\Delta P$ exit is the pressure-drop due to flow resistance at the exit in $(\mathrm{Pa})$.

In cases when the ventilation flow is upward, which is most likely to occur at low wind speeds and when the cavity air temperature is significantly higher than exterior air temperatures, as the 
air enters the cavity through the bottom vent, it loses some of its pressure due to airflow resistance by the cavity entrance. Similarly, as air flows up the cavity it loses some of its pressure due to airflow resistance by friction with cavity walls, and finally loses its remaining pressure due to airflow resistance by the cavity exit. This process is demonstrated in Figure 6, where the ventilation pressure drive is represented as the air pressure difference between exterior air at the bottom and the top vents (P4 - P1). The pressure loss at entrance, through the cavity and at the exit are represented as (P4 - P3), (P3 - P2) and (P2 - P1) respectively. When the wind pressures are more significant than stack pressures, a downward flow will occur, and the process is reversed where $(\mathrm{P} 1>\mathrm{P} 2>\mathrm{P} 3>\mathrm{P} 4)$.

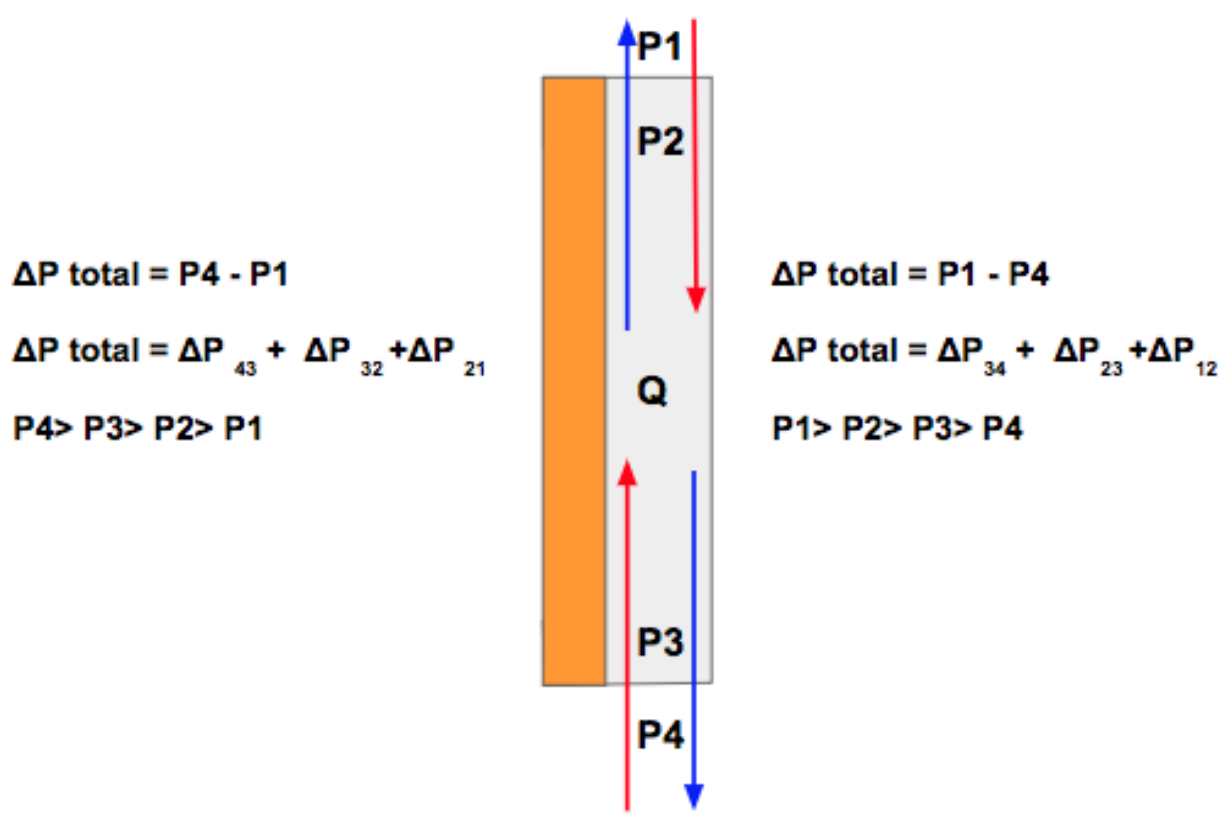

Figure 6. Cavity Ventilation Mechanics for Upward Flow (Left) and Downward Flow (Right).

The resistance to airflow through the cavity depends on the flow velocity, cavity wall roughness, cavity depth and shape. As the air velocity inside the cavity increases, friction forces with cavity walls also increase. These friction forces are dependent on the nature of airflow. When the air velocity is low, a low ratio between inertial forces of air and its viscous forces exist. This ratio is referred to as Reynolds number $(\mathrm{Re})$ and can be used to characterize the nature of the ventilation flow. At low Reynolds number, where viscous forces are dominant, the flow is characterized by 
a smooth and constant fluid motion, referred to as Laminar flow. At higher Reynold numbers, the fluid enters a transition phase and when the inertial forces of individual particles become more dominant than the viscous forces between them, the flow becomes turbulent. Straube (2004) demonstrated that ventilation flow inside the cavity can be assumed to be laminar over typical cavity air velocities ( $\operatorname{Re}<2000)$. Similarly, Stovall and Karagoizis (2004) and Pinon et al. (2004) confirmed the development of fully laminar air flows within the cavity. Thus, Reynolds number for ventilation flow can be calculated by:

$$
R e=66400 * D h * U \text { cavity }
$$

Where:

- $R e$ is Reynolds number.

- $D h$ is the cavity hydraulic diameter in (m).

- $U$ cavity is the air velocity inside the cavity in $(\mathrm{m} / \mathrm{s})$.

And:

$$
D h=4 * \text { A cavity } / P \text { cavity }
$$

Where:

- A cavity is the cross-sectional area of the cavity in $\left(\mathrm{m}^{2}\right)$.

- $P$ cavity is the perimeter of the cavity in (m).

The pressure-drop taking place through the cavity can be represented using Darcy-Weisbach equation, which is derived from Bernoulli's equation and is used to calculate pressure drop due to friction for a fluid flowing through a pipe:

$$
\Delta P \text { Cavity }=f *\left(\frac{L}{D h}\right) * P \text { stag }
$$

Where:

- $f$ is friction factor. 
- L is the cavity height in (m).

- P stag is the airflow stagnation pressure in $(\mathrm{Pa})$.

And:

$$
f=96 /(\operatorname{Re} * \gamma)
$$

Equation 17 is specific to Laminar flow in rectangular channels. The friction factor accounts for flow velocity and cavity roughness, while the blockage factor is assumed to be equal to 1 since no blockage is expected in insulation cavities (grooves) in EIFS. Re-arranging Equations 14, 15, 16 and 17, the pressure-drop across the cavity (between P2 and P3) can be calculated as:

$$
\Delta P \text { cavity }=\Delta P_{23}=(Q * h) /\left(4610 * \gamma * b * d^{3}\right)
$$

Where:

- $Q$ is the ventilation flow rate in the cavity in $\left(\mathrm{m}^{3} / \mathrm{s}\right)$.

- $h$ is the vertical distance between the top and the bottom vents in (m).

- $\gamma$ is the cavity blockage factor ( $\gamma=1$ for EPS grooves with no blockage expected).

- $d$ is the depth of the cavity in (m).

- $\quad b$ is the cavity width in (m).

Similarly, but using the standard sharp-edge orifice coefficient and assuming laminar flow through vents with a flow exponent of 0.5 and a discharge coefficient of 0.62 , the pressure-drop across a vent hole acting as an orifice is calculated as:

$$
\Delta P \text { vent }=(Q / 0.62 * \text { Avent })^{2}
$$

Where:

- Avent is the vent area in $\left(\mathrm{m}^{2}\right)$

And for discreet vents with similar types: 


$$
\Delta P \text { vent }=\Delta \text { Pentrance }=\Delta \text { Pexit }
$$

Hence, the total pressure drop experienced by the ventilation airflow can be calculated as:

$$
\Delta P \text { Total }=2 *\left(\frac{Q}{0.62 * A \text { vent }}\right)^{2}+\left(\frac{Q * h}{4611 * \gamma * d^{3} * b}\right)
$$

\subsection{Air Flow Rates \& Heat Transfer}

Minimal efforts have been put towards evaluating thermal performance impacts of vented and ventilated assemblies. Hens (1984) conducted field and laboratory studies in Belgium and showed that ventilation insignificant effects on the thermal resistance of the air cavity. Similarly, other field studies conducted in Germany by Jung (1985) showed that ventilation rates of 100 $\mathrm{ACH}$ had no effect on the thermal resistance of the air cavity. The German Institute for Brick Research conducted a field study to determine average ventilation velocities in a $40 \mathrm{~mm}$ deep vented cavity, low cavity air velocities of $0.1 \mathrm{~m} / \mathrm{s}(100 \mathrm{ACH})$ were measured when the average wind speed was $2.6 \mathrm{~m} / \mathrm{s}$. Lstiburek (2007) suggested that venting could reduce the thermal resistance of a vented EIFS assembly by about 5 percent of the thermal performance of the foam insulation (not the whole wall assembly) with a $3 \mathrm{~mm}$ deep gap.

Straube (2012) wrote a paper that helped in adopting EIFS standards into the National Building Code of Canada and the Ontario Building Code. According to Straube, small thermal losses are experienced by vented walls due to their low cavity ventilation rate and the small heat capacity of air where large amount of airflow is required to transfer significant amount of heat. Thermal losses of 3-10\% are expected when using vented EIFS assemblies against a face-sealed EIFS assembly. Straube added that for typical modern EIFS walls with (R4 - R16), limiting the ventilation flow to $0.01 \mathrm{~L} / \mathrm{s} . \mathrm{m}^{2}$ of cladding area, limits the impacts on thermal resistance to less than 3\% of whole assembly's RSI-value. However, for highly insulated (R16) assemblies, an

airflow rate of $0.03 \mathrm{~L} / \mathrm{s} \cdot \mathrm{m}^{2}$ results in $10 \%$ reduction. Hence, Straube recommended that only 
drained-vented EIFS are used since the high air flow rates of the ventilated EIFS have significant impacts on the thermal performance of the assembly. Straube added that in order to reduce the thermal impacts, only gaps of less than $3 \mathrm{~mm}$ in depth with a vent area smaller than $0.1 \%$ of the cladding area should be specified. The study concluded that for vented EIFS assemblies, limiting the cavity airflow to less than $0.1 \mathrm{~L} / \mathrm{s} . \mathrm{m}^{2}$, the thermal resistance of the exterior insulation board is compromised by less than $10 \%$.

Straube (2012) also explained the relation between airflow and heat transfer taking place in the cavity and proposed theoretical equations to predict thermal impacts of vented and ventilated assemblies by assuming that the heat flow in a vented/ventilated wall is considered as a parallel process, where airflow and conduction in the cavity cause transfer heat but do not interact, and heat transfer by airflow is a function of the ventilation rate in the cavity. The effective thermal resistance of a wall can be calculated as:

$$
\begin{aligned}
& \text { Reffective }=\frac{1}{\text { U airflow }}+\frac{1}{U \text { Conduction }} \\
& U \text { airflow }=\frac{Q * \rho * \text { Cair }}{A}
\end{aligned}
$$

Where:

- $R$ effective is the effective thermal resistance of the wall in $\left(\mathrm{m}^{2} \mathrm{~K} / \mathrm{W}\right)$.

- $U$ airflow is the thermal transmittance of the wall by airflow $\left(\mathrm{W} / \mathrm{m}^{2} \mathrm{~K}\right)$.

- $U$ conduction is the thermal transmittance of the wall by conduction $\left(\mathrm{W} / \mathrm{m}^{2} \mathrm{~K}\right)$.

- $Q$ is the ventilation flow rate in the cavity in $\left(\mathrm{m}^{3} / \mathrm{s}\right)$.

- $\rho$ is the outdoor air density in $\left(\mathrm{Kg} / \mathrm{m}^{3}\right)$.

- $C$ air is the specific heat capacity of dry air $(1 \mathrm{KJ} / \mathrm{Kg} . \mathrm{K})$.

Bassett and Mcneil (2007) measured ventilation rates driven by fluctuating wind and stack pressures for vented EIFS assemblies using a continuous emission carbon dioxide tracer method. Daily average ventilation rates were measured in the range 0.02-0.06 L/s.m of cavity height. 
Schwartz (1973) measured cavity velocities in the range of $0.2-0.6 \mathrm{~m} / \mathrm{s}$ for windward faces with wind speeds of 0 and $5 \mathrm{~m} / \mathrm{s}$ respectively, acting on an 18-story apartment building. For the leeward side, lower and more stable velocities were measured at $0.2 \mathrm{~m} / \mathrm{s}$. Finally, Straube (2012) demonstrated that ventilation rates of 0.005 to $0.05 \mathrm{~L} / \mathrm{s} . \mathrm{m}^{2}$ are expected when using claddings with limited discreet vent openings, with an area of less than $0.01 \%$ of the wall along a single line and with no clear ventilation path such as vented EIFS assemblies.

\subsection{EIFS Field Performance Testing}

Smegal (2017) conducted a full-scale wall testing near Waterloo, ON (DOE climate zone 6) for face-sealed, vented and ventilated EIFS assemblies to measure the thermal performance impacts of the air gaps. The testing also examined the effects of wind-washing at building corners. To measure the heat fluxes through the different EIFS constructions, a face-sealed assembly was utilized as a baseline to determine the effects of venting and ventilating on the thermal performance of the assembly. After all the walls were constructed and an interior temperature control was provided for the winter season, thermal and moisture monitoring were initiated by installing calibrated heat flux transducers in the OSB sheathing to measure the heat flux through the different EIFS assemblies. Two heat flux transducers were installed at the bottom and top of the OSB sheathing for each wall assembly, while five temperature sensors were installed at different assembly depths as demonstrated in Figure 7. Although not required for measuring the thermal impacts of the vented and ventilated air gaps but to better understand the hygrothermal behavior of the wall assemblies, relative humidity sensors and wooden moisture content pins were also installed as demonstrated in Figure 7. All the sensors were connected to two data acquisition units to record all the experimental data at 10 minutes intervals for a 1-year period starting in February 2016. To understand the effects of using different forms of EPS insulation, the thermal conductivity of the used EPS samples was measured and recorded at various mean

temperatures. Exterior conditions were measured by a weather station installed on the roof of the test hut and recorded ambient air temperature, solar irradiance, relative humidity, wind speed and direction at 1 -hour intervals. 


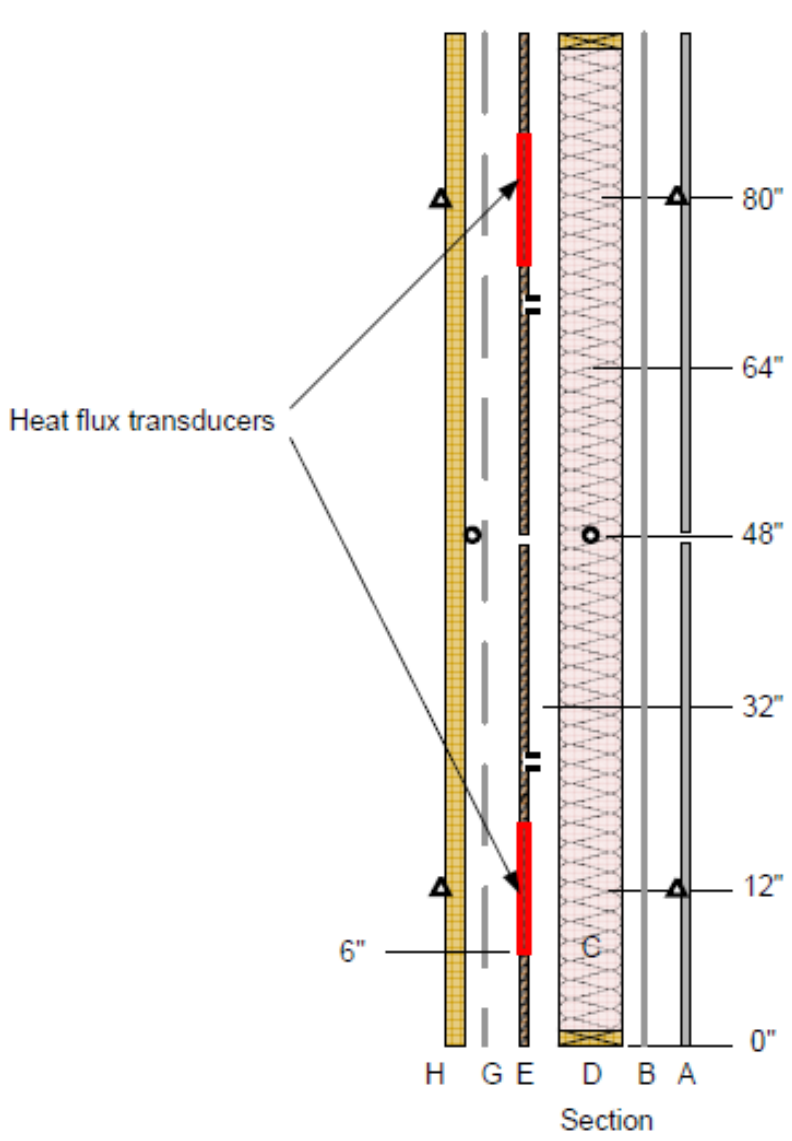

\begin{tabular}{|lll|}
\hline \multicolumn{2}{|l|}{ Assembly } & \\
Layer & Function & Description \\
A & Interior Finish & Painted gypsum board \\
B & Vapor Control & Polyethylene \\
C & Studspace & FG batt \\
D & Framing & $2 \times 6$ \\
E & Sheathing & OSB \\
& Membrane & Fluid applied AWB \\
F & Cl & 2" EIFS EPS \\
G & Drainage & Wall 2 and Wall 3 \\
H & Cladding & Finish coat on EIFS \\
\hline
\end{tabular}

Figure 7. Tested EIFS assemblies and sensor locations. (Smegal, 2007)

A year later, Smegal performed three comparisons using the collected data. In the first comparison, he compared the upper and lower heat flux plates on the face-sealed EIFS wall assembly and found that the results were very similar at high wind and low wind days. The second comparison was conducted between the upper sheathing heat flux plates on all three test walls and it was found that at low wind, the heat flux results were very similar across the three test walls. However, under windy conditions, Smegal realized that the ventilated EIFS assembly witnessed more fluctuating and higher heat fluxes than the vented and face-sealed EIFS assemblies and thus a measurable reduction in the R-value was observed. The third and final comparison was for the lower sheathing heat flux plates on all three test walls, where Smegal concluded that without wind, the results were similar between the three wall systems, although the ventilated wall assembly had the lowest heat flux due to air in the ventilated cavity warming as it was falling. Under windy conditions, the results were fluctuating and inconsistent. 


\subsection{Methodology \& Approach}

Although EIFS manufacturers provide different configurations for drained EIFS assemblies (Dryvit Systems Inc., 2019), it was found throughout the literature review that the impacts of theses cavities on the thermal performance of the wall assembly have not been well-studied. In addition, field tests conducted to evaluate those impacts are limited to one-story height test setups and to local climates where the tests were conducted, thus ignoring the escalating wind velocities across a building's height and providing little insight on the thermal performance of these EIFS drained assemblies in different climates. As discussed earlier, this research aims to create and calibrate simulation models for two EIFS wall assemblies (face-sealed and vented) against the experimental data collected by Smegal (2007), as described in the previous section.

COMSOL Multiphysics was utilized to simulate the wall assemblies and to evaluate their thermal performances. COMSOL was selected as it is commonly used for modelling and solving various scientific and engineering problems based on solving Partial Differential Equations using the Finite Element Method. Kersten (2013) modelled the heat exchange in cavities of building constructions using COMSOL's conjugate heat transfer module to determine the thermal resistance properties of the air cavity in a double wall construction under different variations, including 1) Substituting cavity air with vacuum, 2) Increasing the cavity ventilation flow by increasing wind speeds, 3) Various cavity depths and construction heights and 4) Addition of reflective foil paper on materials making up the cavity walls. A laminar cavity flow was assumed, and the simulation results were verified against tabulated values of the cavity's thermal resistance in NEN-EN-ISO 6946 and were checked by the means of hand calculations. Kersten (2013) concluded that COMSOL is useful for modeling the heat transfer in cavities as it provides the ability to integrate different kinds of physics phenomena into a single model to provide flexibility in approaching the problem from the perspective of thermal energy transfer.

In this research, the main steps carried out using COMSOL are demonstrated in Figure 8. 


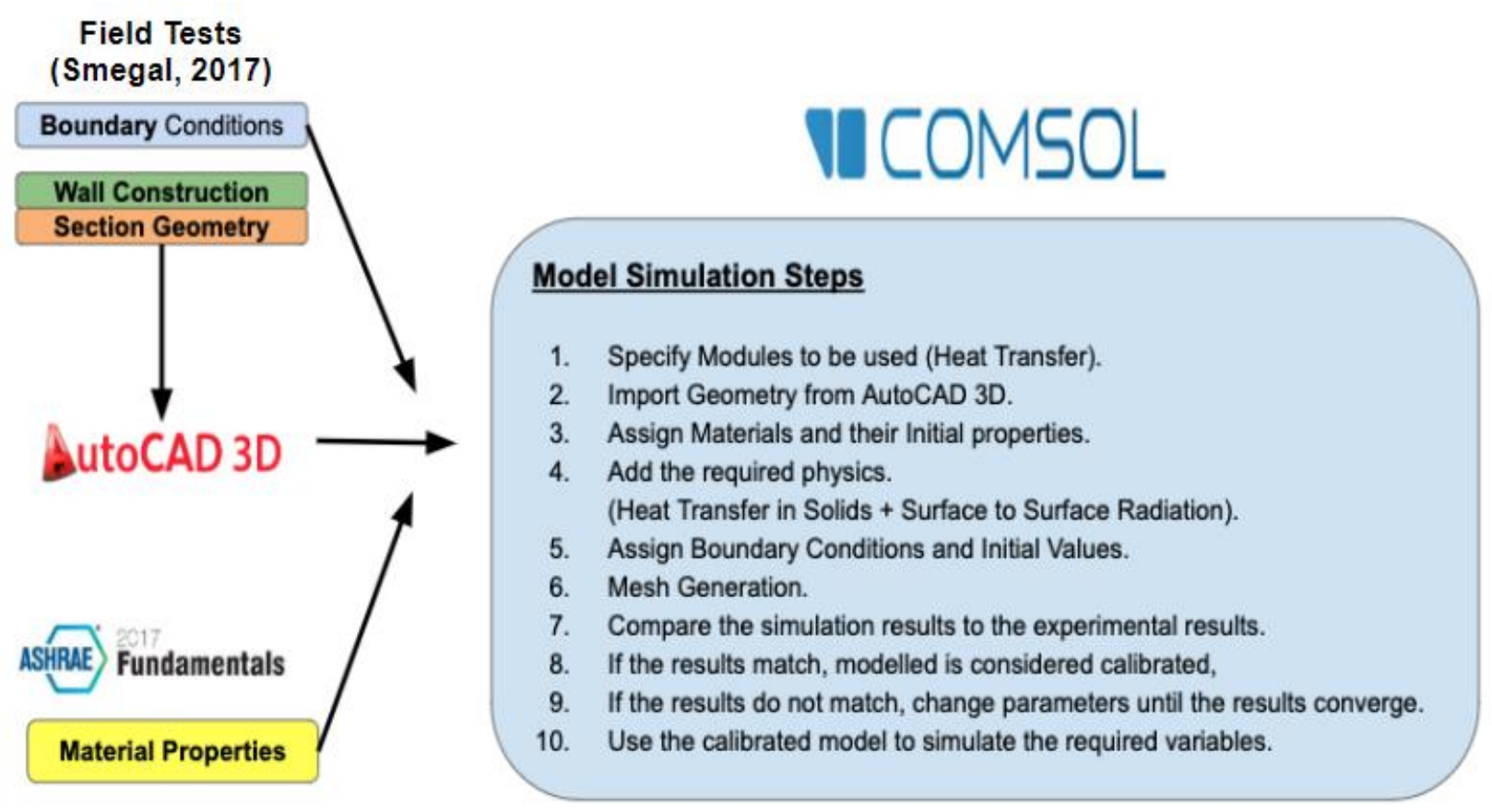

Figure 8. Problem Solving Steps.

\subsection{Model Geometry \& Material Properties}

The walls' geometries were constructed in AutoCAD 3D and imported into COMSOL. The modelled walls are demonstrated in Figure 9 and are based on the experimental wall constructions tested by Smegal (2017). Both the interior vapor barrier and the exterior WRB were not modelled due to their negligible thermal resistances and to simplify the modelled geometry, the physics involved and the mesh generation process. Both walls were modelled to set on a concrete foundation as demonstrated in Figure 9. Table 1 provides a legend for the materials making up the wall assembly and found in Figure 9, and the initial material properties used for the initial run before model calibration was carried out. Initial material properties found in Table 1 are mostly based on ASHRAE (2013) and the COMSOL database.

The vented EIFS model design includes four $2.1 \mathrm{~m}$ geometrically defined air cavities in the EPS insulation with vent holes located at the bottom edge of the wall. Near the top of the cavity, $0.3 \mathrm{~m}$ EPS enclosure blocks seal the top edge. The $2.1 \mathrm{~m}$ air cavity height was selected based on the 
constructions tested by Smegal (2017) to represent one-story height air compartments. Compartmentalization of the air cavity reduces stack pressures inside the cavity and aids in reducing the air pressure difference between the cavity and the exteriors. Pressure-equalization attempts to eliminate the driving force for pressure-induced water penetration, thus reducing the amount of water entering the cavity by the means of air. For pressure equalization to be achieved, the cross-sectional area of the vent holes must allow for sufficient air to be exchanged with each of the compartments under the applied air pressures. Both static air pressure differences induced by stack effect and mechanical systems, and dynamic air pressure differences induced by wind gradients over the building facade must be equalized. Since pressure equalization always requires a zero-pressure difference between cavity and exteriors, dynamic wind pressure differences are hard to eliminate due to the wall assembly's inability to quickly respond to the dynamic nature of wind. Thus, EIFS are typically designed as pressure moderation cladding systems with an air pressure difference limit of $25 \mathrm{~Pa}$ between the cavity and exteriors, and air cavities are divided into compartments by the use of the enclosure blocks at each floor level.

Thermal conductivity testing was conducted by Smegal (2017) for the EPS insulation board profiles used in both the face-sealed and the vented assemblies. Since thermal conductivity for some building insulation materials changes with respect to mean temperature (i.e. the colder the temperature, the lower thermal conductivity for EPS insulation), the thermal conductivity tests were conducted over a range of mean temperatures, and the conductivity measurements were input as temperature functions into COMSOL in this research. Similarly, air properties were made dependent on the air pressure and temperature. All other material properties were unknown and thus became part of the calibration process. In some cases, the material species were assumed, as an example, the lumber type used for wall framing is unknown and was assumed to be made of Spruce. Material properties were significantly altered and the combination producing the closest results between the simulation and experimental data were chosen as discussed later in this section. 
-Note: The mesh was generated automatically by COMSOL based on the physics involved and the size setting was set to "Finer". It is important to note that reducing the mesh size further did not affect the results of the simulation, thus a "finer" mesh was considered adequate and produced accurate results in a timely manner. The mesh was generated using tetrahedral and triangular elements as recommended for heat transfer simulations.

Table 1. Initial Material Properties and Color Legend

\begin{tabular}{|c|c|c|c|c|c|c|}
\hline Legend & Material & $\begin{array}{c}\text { Thickness } \\
(\mathrm{mm})\end{array}$ & $\begin{array}{l}\text { Density } \\
\left(\mathrm{Kg} / \mathrm{m}^{3}\right)\end{array}$ & $\begin{array}{c}\text { Specific Heat } \\
\text { Capacity } \\
\text { (J/Kg. K) }\end{array}$ & $\begin{array}{c}\text { Thermal } \\
\text { Conductivity } \\
(\mathrm{W} / \mathrm{m} . \mathrm{K})\end{array}$ & Remarks \\
\hline & EIFS Lamina & 12.7 & 1800 & 850 & 0.37 & - \\
\hline & EPS Insulation & 50.8 & 15 & 1500 & $k(T)$ & - \\
\hline & OSB Sheathing & 12.7 & 574 & 1100 & 0.16 & - \\
\hline & Spruce Studs & 152.4 & 532 & 2700 & 0.1 & $16 "$ O.C. \\
\hline & Fiberglass Batt & 152.4 & 22 & 850 & 0.033 & - \\
\hline & Gypsum Board & 12.7 & 574 & 1100 & 0.16 & - \\
\hline & EPS Closure Blocks & 12.7 & 14.8 & 1470 & $k(T)$ & $0.3 m$ Length \\
\hline & Air Cavity & 12.7 & $\rho(P, T)$ & $C p(T)$ & $k(T)$ & 2.1m Length \\
\hline
\end{tabular}




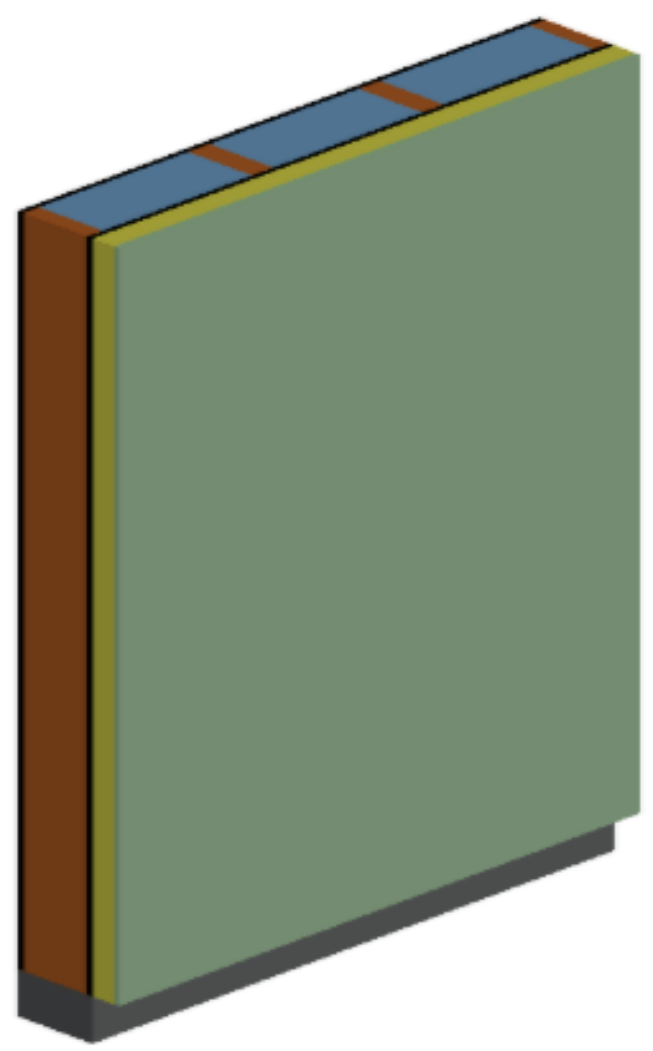

Face-Sealed EIFS Isometric View

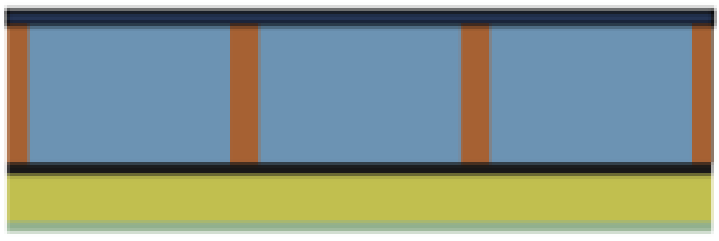

Face-Sealed EIFS Top View

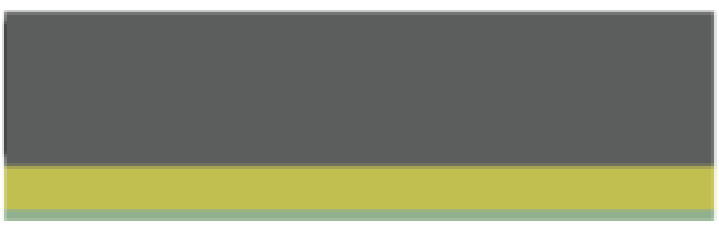

Face-Sealed EIFS Bottom View

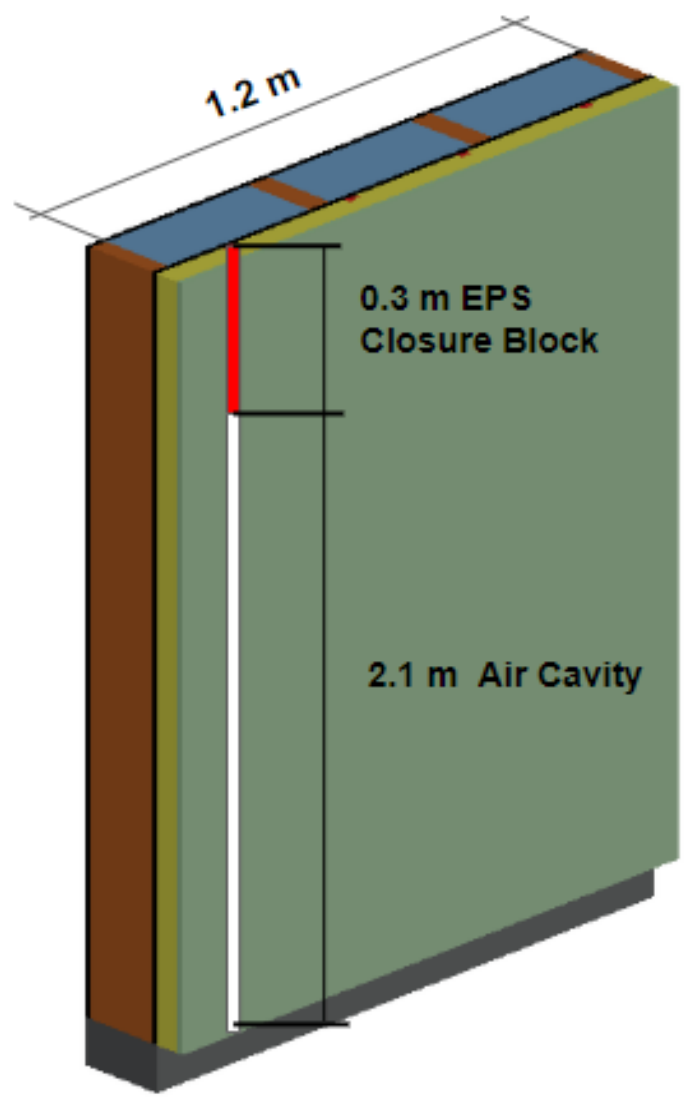

Vented EIFS Isometric View

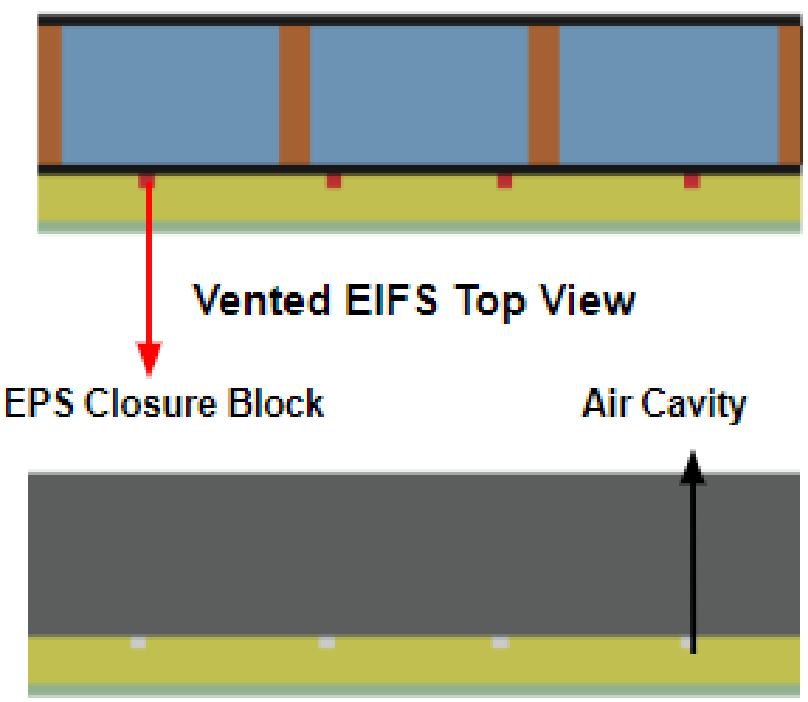

Vented EIFS Bottom View

Figure 9. Geometry Details. (COMSOL, 2018) 


\subsection{Boundary \& Initial Conditions}

Both interior and exterior weather conditions were recorded by Smegal (2017) during the field test and were imported as hourly functions into COMSOL. Exterior conditions included ambient temperature, solar irradiance, wind velocity, and ambient relative humidity, while interior conditions included temperature and relative humidity values. The interior conditions were modelled using the Isothermal Domain feature in COMSOL, implying that the interior air is well-mixed, and its temperature is spatially uniform. This resulted in heat flux and temperature simulation results that are more consistent with the field test results.

Convective heat flux correlations were assigned as boundary conditions to the interior and exterior surfaces of the wall assembly. A Plate Averaged External Forced Convection (EFC) coefficient was assigned to the exterior surface, where the exterior convective heat flux coefficient was made dependent on the wind speeds acting on the wall and driving the flow. Additionally, a surface-to-ambient radiation and a boundary heat source were assigned to the exterior surface to account for solar irradiance and ambient radiation effects. Similarly, a Vertical Wall External Natural Convection (ENC) coefficient and a surface-to-ambient (interiors) radiation heat flux boundary conditions were assigned to the interior surface of the assembly such that the interior convective and radiative heat transfer coefficients vary with the imposed interior temperatures. In natural convection, buoyancy forces induced by temperature differences together with the thermal expansion of the fluid drive the flow. The EFC correlation is based on the fluid's Reynolds and Prandtl numbers, while the ENC correlation is based on the fluid's Rayleigh number. Both correlations require the definition of a length scale and can experience laminar or turbulent flow conditions. Figure 10 demonstrates schematic representations of geometry and parameters for the heat transfer coefficient correlations taken directly from COMSOL. It is important to note that the convective correlations described above were used based on the trial and error approach described in the next section and produced the minimum bias between simulation and field results. 
Finally, For the vented assembly, an open boundary condition was applied at the air cavity entrance, allowing for heat to enter and leave the fluid domain (cavity) based on the exterior conditions including ambient temperatures and wind speeds. Surface-to-surface diffuse radiation boundary conditions were also assigned to the boundary surfaces making up the cavity walls.

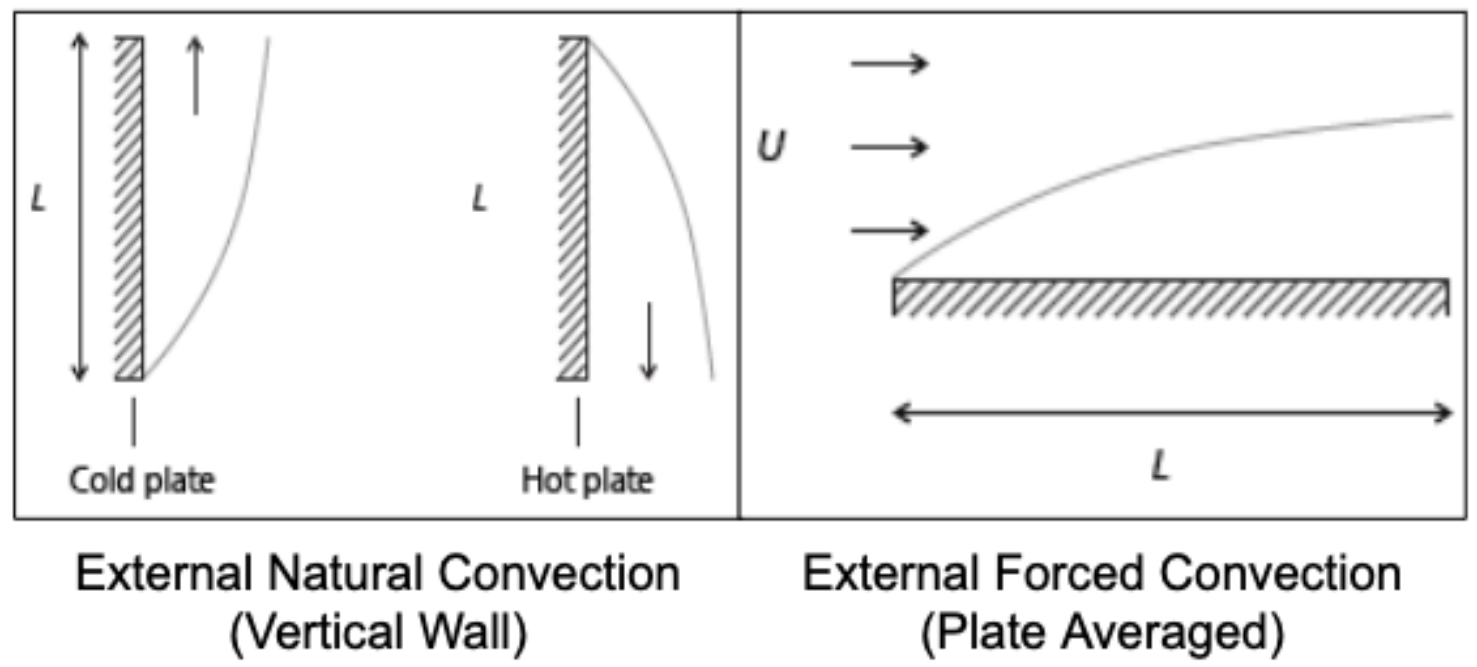

Figure 10. Schematic Representations of ENC, EFC correlations (COMSOL, 2018)

Initial conditions were required as simulation model inputs and included each domain's mean temperature and relative humidity. As explained earlier, the relative humidity measurements are not vital for evaluating the thermal performance of the wall assemblies, however, the data was made available during Smegal's field tests and was input in the simulation models for future work. Temperature initial values were also calculated using the sensors' data and Fourier's Law of Conduction was used to estimate the average domain temperature values. Table 2 demonstrates the assumed initial conditions for different domains used for both the face sealed and vented EIFS models.

Table 2. Domain Initial Conditions

\begin{tabular}{|c|c|c|c|c|c|c|c|}
\hline Boundary & EIFS Lamina & EPS & Air Cavity & OSB & Studs & Fiberglass & Gypsum Board \\
\hline Temperature $(K)$ & 267 & 277 & 285 & 288 & 290 & 290 & 293 \\
\hline
\end{tabular}


Finally, the experimental heat flux calculations from Smegal (2017) were only made available for specific short periods although the monitoring period continued for a full year. These specific periods were chosen to be representative of the winter season and were classified into high and low wind periods by Smegal. The model calibration was carried out for the day of February 12, 2016. This period was selected for several reasons. Firstly, heat flux experimental calculations are available over a 24-hour period starting at 5:00 PM, thus the results are representative for a full day temperature cycle in the winter season and captures the effects of solar radiation and night-time irradiation on the heat flux. In addition, Feb 12, 2016 was one of the coldest days throughout the monitoring period and witnessed the highest range of exterior ambient temperatures and wind speeds out of all other periods, as demonstrated in Table 3. Furthermore, this day witnessed the largest heat flux magnitudes sustained for a period due to large temperature difference between the interiors and exteriors, thus can be considered as a "Winter Design Day”. Finally, this day represented one of the longest periods where heat flux calculations were made available by Smegal. It is important to note that simulations were initiated 8-hours before the beginning of the calibration period to allow the simulation solution to converge while avoiding high computational costs due to the selection of prolonged periods.

Table 3. Calibration Period Conditions

\begin{tabular}{|c|c|c|c|c|c|}
\hline Start Date-Time & $\begin{array}{c}\text { Monitoring } \\
\text { Hours }\end{array}$ & $\begin{array}{c}\text { High Temp } \\
\left({ }^{\circ} \mathbf{C}\right)\end{array}$ & $\begin{array}{c}\text { Low Temp } \\
\left({ }^{\circ} \mathbf{C}\right)\end{array}$ & $\begin{array}{c}\text { High Wind } \\
\text { Speed }(\mathbf{m} / \mathbf{s})\end{array}$ & $\begin{array}{c}\text { Low Wind } \\
\text { Speed }(\mathbf{m} / \mathbf{s})\end{array}$ \\
\hline $2 / 12 / 2016-17: 00: 00$ & 24 & -9 & -24 & 6 & 3 \\
\hline
\end{tabular}

\subsection{Theory of COMSOL's Heat Transfer Module}

The Heat Transfer in Solids module was used to simulate the whole face-sealed wall assembly, and a fluid domain was added to the vented assembly model to represent the cavity spaces. The Heat Transfer in Solids COMSOL module solves: (COMSOL, 2018)

$$
\rho \cdot C p \cdot\left(\frac{\partial T}{\partial t}+\text { utrans } \cdot \Delta T\right)+\Delta \cdot(q+q r)=-\alpha T: \frac{d S}{d t}+Q
$$


Where:

- $\rho$ is the density in $\left(\mathrm{Kg} / \mathrm{m}^{3}\right)$.

- Cpis the specific heat capacity in $(\mathrm{J} / \mathrm{Kg} . \mathrm{K})$.

- $\quad T$ is the absolute temperature in $(\mathrm{K})$.

- utransis the velocity vector of translational motion in $(\mathrm{m} / \mathrm{s})$.

- $q$ is the heat flux by conduction in $\left(\mathrm{W} / \mathrm{m}^{2}\right)$.

- qris the heat flux by radiation in $\left(\mathrm{W} / \mathrm{m}^{2}\right)$.

- $\alpha$ is the thermal expansion coefficient in $(1 / \mathrm{K})$.

- $\mathrm{S}$ is the second Piola-Kirchhoff stress tensor in (Pa).

- $\mathrm{Q}$ is additional heat sources in $\left(\mathrm{W} / \mathrm{m}^{3}\right)$.

While the Heat Transfer in Fluids Module solves: (COMSOL, 2018)

$$
\rho \cdot C p \cdot\left(\frac{\partial T}{\partial t}+u \cdot \Delta T\right)+\Delta \cdot(q+q r)=\alpha p T\left(\frac{\delta P}{\delta t}+u \cdot \Delta p\right)+\tau: \Delta u+Q
$$

Where:

- $\rho$ is the density in $\left(\mathrm{Kg} / \mathrm{m}^{3}\right)$.

- Cpis the specific heat capacity in $(\mathrm{J} / \mathrm{Kg} . \mathrm{K})$.

- $\quad T$ is the absolute temperature in $(\mathrm{K})$.

- $u$ is the velocity vector in $(\mathrm{m} / \mathrm{s})$.

- $q$ is the heat flux by conduction in $\left(\mathrm{W} / \mathrm{m}^{2}\right)$.

- qris the heat flux by radiation in $\left(\mathrm{W} / \mathrm{m}^{2}\right)$.

- $\alpha p$ is the thermal expansion coefficient in $(1 / \mathrm{K})$.

- $p$ is the pressure in $(\mathrm{Pa})$.

- $\tau$ is the viscous stress tensor in $(\mathrm{Pa})$.

- $\mathrm{Q}$ is heat sources other than viscous dissipation in $\left(\mathrm{W} / \mathrm{m}^{3}\right)$. 


\subsection{Model Calibration}

Energy simulation models are complex as they are dependent on a large input data sets, which its accuracy is based on the user knowledge and the approach used for determining the input data. Fine tuning of input parameters, referred to as calibration, is often required to gain confidence in the results produced by a simulation model, which must closely match the experimental results. This section aims to calibrate two simulation models, face-sealed and vented EIFS wall assemblies, to match the output of the simulation to the experimental data provided by Smegal (2017). The experimental data includes measurements of the total heat flux through the lower and upper parts of OSB sheathings, measured at 10 minutes intervals, and hourly temperature data relative to sensor locations (See Figure 7). The calibration procedure followed is comprised of:

1- Screening Analysis, that identifies the input parameters with the most influence on the simulation results. The "Sensitivity Index" was calculated once for each input unknown parameter by inputting two extreme values (high and low) of a specific parameter and evaluating the percentage difference. A higher Sensitivity Index indicates that a parameter is more influential on the results. The Sensitivity Index is calculated as:

$$
S I=\frac{\sum(E \max -E \min )}{\sum(\operatorname{Emax})} \cdot 100 \%
$$

Where:

- $E \max =$ Maximum Output Value (by inputting the high extreme parameter value).

- $\quad E m i n=$ Minimum Output Value (by inputting the low extreme parameter value).

2- Manual Calibration "trial and error" approach, based on an iterative manual tuning of the model input parameters;

3- Post-Processing Graphical Techniques, consisting of time-series and scatter plots; 
4- Evaluating Criteria for Model Goodness-of-Fit that determine if a model could be considered calibrated and how well the simulation results represent the experimental data for a selected time interval. Both indices, the Mean Bias Error (MBE) and the Coefficient of variation of the Root Mean Square Error (Cv (RMSE)) were calculated for each simulation undertaken. Using both indices allows for preventing any calibration error due to errors compensation. MBE is an overall measure of how biased the data is and could be a positive or a negative value. A value closer to zero indicates a better matching between simulation and experimental data. $\mathrm{MBE}$ is calculated by:

$$
M B E=\frac{\text { speriod } \cdot(S-M) \text { interval }}{\text { speriod } \cdot \text { Minterval }} \cdot 100 \%
$$

Where:

- $\mathrm{M}$ is the measured data during the time interval;

- $\mathrm{S}$ is the simulated data during the same time interval.

$\mathrm{Cv}$ (RMSE) is a normalized measure of the variability between measured and simulated data and a measure of the goodness-of-fit of the model that always has a positive value. A lower $\mathrm{Cv}$ (RMSE) value indicates better calibration, and is calculated by:

$$
\begin{aligned}
& C v(R M S E \text { period })=\frac{R M S E \text { period }}{\text { A period }} \cdot 100 \% \\
& R M S E \text { period }=\sqrt{\frac{\Sigma(S-M)^{2} \text { interval }}{\text { Ninterval }}} \\
& \text { A period }=\frac{\text { speriod } \cdot \text { M interval }}{\text { Ninterval }}
\end{aligned}
$$

Where:

- Ninterval is the number of time intervals considered for the monitored period. 
Thresholds of MBE and Cv (RMSE) must be achieved to consider a model calibrated. The thresholds for hourly simulations that must be met are documented in Table 4.

Table 4. Statistical Indices Thresholds Criteria

\begin{tabular}{|c|c|c|c|}
\hline Statistical Index & MBE\% & Cv (RMSE)\% & Reference \\
\hline ASHRAE 14 & \pm 10 & 30 & ASHRAE (2002) \\
\hline IPMVP & \pm 5 & 20 & IPMVP (2003) \\
\hline FEMP & \pm 10 & 30 & FEMP (2008) \\
\hline
\end{tabular}

\subsection{Model Limitations}

As will be explained in the next section, the simulation models were calibrated by identifying the values of the unknown parameters that produced the closest results between the experimental and simulation data. This data included exterior and interior surface temperatures and the midsheathing temperatures for the face-sealed and vented EIFS assemblies. The calibration carried out is exclusive to the wall assemblies tested in terms of geometry, constructions, interior and exterior conditions experienced during the selected calibration. It is believed that the calibrated models produced in this research can be used to simulate wall assemblies with similar constructions during the winter period. Models may need to be recalibrated when used to represent summer periods. Furthermore, the calibration was carried out for a north-facing wall that experiences lower wind pressures than a south-facing wall and only diffuse solar radiation is received by the wall. A north-facing wall was modelled to mimic the conditions experienced during the field test by Smegal (2017). Thus, it is expected that the calibrated models produced during this research cannot be used to carry out thermal simulations that represent a non-north facing wall for a location in the northern hemisphere. This is because specific procedures that are outside the scope of this research must be carried out to calibrate a southern facing wall that is receiving both direct and diffuse solar radiation. Finally, the models produced in this research neither attempt to solve for pressure and velocity fields experienced by the walls, nor to find the relationship between the air velocity inside the cavity and the applied wind speeds. 


\subsection{Results \& Discussion}

This Section is divided into two parts. The first part provides the model calibration results, while the second part mainly provides results, discussions and answers for the research questions noted earlier in the report by conducting thermal simulations using the calibrated models.

\subsection{Calibration Results}

As explained earlier, the experimental data included heat flux and temperature measurements for the sensor and heat flux plates locations as demonstrated earlier in Figure 7. Theoretically, for a face-sealed EIFS assembly, the heat fluxes at the higher and lower flux plates are very similar over a 1-story height wall with a slight increase in the heat flux at the top plate. This occurs since warm interior air rises, and slightly colder air is left at the lower part of the test hut, reducing the temperature difference through the envelope at the lower part of the wall. In addition, higher wind pressures are experienced at the top of the wall increasing the amount of heat lost by the envelope due to convection at the top part of the wall. Similarly, for a vented EIFS assembly with low exposure to solar radiation, the cavity air is forced down the cavity due to higher wind pressures at the top of the wall, and heat is transferred to the falling air from the upper cavity surfaces resulting in lower heat fluxes at the lower flux plate due to lower temperature difference between cavity and interior air. To calibrate the simulation models more accurately against a single set of measurements, the lower and higher heat flux plate measurements were averaged assuming a mid-height plate placement at 48-inches elevation as shown in Figure 7 representing the average interior temperature stratification plane. Similarly, data from lower and higher temperature sensors were averaged, and included temperature measurements behind the interior drywall, EIFS top coat exterior surface, and mid-sheathing depth for both the face-sealed and vented wall assemblies.

The Screening Analysis was conducted for each unknown parameter input, and a Sensitivity Index was computed using the simulation results and the experimental values corresponding to: 
1. Heat Flux $\left(\mathrm{W} / \mathrm{m}^{2}\right)$ at mid-sheathing.

2. Temperature $\left({ }^{\circ} \mathrm{K}\right)$ at the exterior surface of the interior gypsum board.

3. Temperature $\left({ }^{\circ} \mathrm{K}\right)$ at mid-sheathing.

4. Temperature $\left({ }^{\circ} \mathrm{K}\right)$ at the exterior surface of the wall assembly.

The sensitivity study results can be found in Appendix A. There are 19 unknown input parameters including thermal conductivity $(\mathrm{W} / \mathrm{m} . \mathrm{K})$, specific heat capacity $(\mathrm{J} / \mathrm{kg}$.) and density $\left(\mathrm{kg} / \mathrm{m}^{3}\right)$ of interior gypsum board, fiberglass insulation, wood studs, OSB sheathing, EPS insulation and the EIFS base and top coats (modelled as one component); and the interior and exterior convective heat transfer coefficients (multiple heat transfer coefficients were input in lieu of ENC and EFC for trial and error purposes). Only the thermal conductivity of the EPS insulation was known and was input as a temperature dependent function into COMSOL as explained earlier. The sensitivity analysis revealed that the heat flux of the wall assembly is sensitive primarily to the thermal conductivity of the fiberglass insulation followed by the material properties of the EPS insulation, implying the validity of the calibration approach since the fiberglass insulation is the highest contributor to the assembly's thermal resistance, followed by EPS insulation. To ensure the validity of this approach, the fiberglass cavity insulation was replaced by air spaces between the wood studs and the sensitivity index was recalculated for the modified wall and heat flux was found to be mostly sensitive to the thermal conductivity of the EPS insulation.

The temperature at the interior gypsum board was found to be mostly sensitive to the thermal conductivity of the fiberglass insulation followed by the specific heat capacity and density of the EPS insulation, the internal convective heat transfer coefficient, and the material properties of the gypsum board itself. The mid-sheathing temperature was found to be mostly sensitive to the thermal conductivity of the fiberglass at a higher extent than the value's influence on the gypsum board temperature. The mid-sheathing temperature was also strongly affected by the wood studs and OSB properties. Finally, the assembly's exterior surface temperature was found to be mostly sensitive to the exterior convective heat transfer coefficient value and the properties of fiberglass and EIFS top coat. Based on the results found from the values of the sensitivity indices, and to 
achieve a more precise material properties calibration by avoiding the input of irrelevant values, it was decided to calibrate all unknown parameters against temperature sensors rather than heat flux measurements, while the heat flux was later simulated based on the surface temperaturecalibrated parameters as will be shown later in this section. In addition, it was verified that the final calibrated values are within the common range of material property values, based on ASHRAE (2013). It is important to note that calibration of highly influential parameters such as the fiberglass and EPS properties was emphasized during the calibration process on other parameters. Table 5 demonstrates the calibration procedure undertaken and the final values of the unknown parameters. Exterior and interior convective heat transfer coefficients were initially calibrated, each against the temperature measurements of the surface with higher sensitivity to the variation of each of the parameters, followed by the fiberglass thermal conductivity (against mid-sheathing temperature) and material properties of the assembly components. The model parameters were calibrated against temperature rather than heat flux measurements to achieve more precise results since altering most of the parameters in the trial and error approach did not affect the heat flux results significantly, while the same values resulted in significant changes in surface temperature results. Furthermore, calibrating the interior and exterior heat transfer coefficients against the interior and exterior surface temperatures respectively produced temperature results that are dependent and affected by the interior and exterior conditions including ambient temperatures, solar irradiance and wind speeds.

Modifications to the initial material properties and boundary condition variables were completed through an iterative process until the best combination of input parameters was identified, representing the closest match between the simulation output and the field data, based on graphical representations, MBE and Cv (RMSE) calculated values. More than 200 iterations were completed before calibration was considered achieved. Calibration was completed individually for each parameter, starting with parameters with the highest influence on the results as per the screening analyses, and calibration was considered achieved when further modifying a parameter's magnitude has caused an increase in the $\mathrm{Cv}(\mathrm{RMSE}$ ) values (when the parameter value with the lowest $\mathrm{Cv}(\mathrm{RMSE})$ was identified) and/or are when the $\mathrm{Cv}(\mathrm{RMSE})$ values were found to be within the threshold criteria limits presented previously in Table 4. 
Table 5. Calibration Procedure Based on Sensitivity Analyses.

\begin{tabular}{|c|c|c|c|c|c|}
\hline Parameter & Description & Unit & $\begin{array}{l}\text { Initial } \\
\text { Value }\end{array}$ & Final Value & Calibrated Against \\
\hline$H$ in & $\begin{array}{l}\text { Interior Convective Heat } \\
\text { Transfer Coefficient }\end{array}$ & $W / m^{2} \cdot K$ & 8.3 & $\begin{array}{l}\text { External Natural } \\
\text { Convection Coef. }\end{array}$ & Gypsum Board Surf. Temp. \\
\hline$k G B$ & $\begin{array}{l}\text { Gypsum Board Thermal } \\
\text { Conductivity }\end{array}$ & $W / m . K$ & 0.16 & 0.068 & Gypsum Board Surf. Temp. \\
\hline$P G B$ & Gypsum Board Density & $\mathrm{Kg} / \mathrm{m}^{3}$ & 574 & 620 & Gypsum Board Surf. Temp. \\
\hline$C p G B$ & $\begin{array}{l}\text { Gypsum Board Specific Heat } \\
\text { Capacity }\end{array}$ & $J / K g . K$ & 1100 & 850 & Gypsum Board Surf. Temp. \\
\hline k Spruce & Studs Thermal Conductivity & $W / m . K$ & 0.1 & 0.087 & Mid-Sheathing Temperature \\
\hline P Spruce & Studs Density & $\mathrm{Kg} / \mathrm{m}^{3}$ & 532 & 400 & Mid-Sheathing Temperature \\
\hline Cp Spruce & Studs Specific Heat Capacity & $J / K g . K$ & 2700 & 1630 & Mid-Sheathing Temperature \\
\hline k Fiberglass & $\begin{array}{l}\text { Fiberglass Thermal } \\
\text { Conductivity }\end{array}$ & $W / m . K$ & 0.033 & 0.044 & Mid-Sheathing Temperature \\
\hline P Fiberglass & Fiberglass Density & $\mathrm{Kg} / \mathrm{m}^{3}$ & 22 & 9 & Gypsum Board Surf. Temp. \\
\hline Cp Fiberglass & $\begin{array}{l}\text { Fiberglass Specific Heat } \\
\text { Capacity }\end{array}$ & $J / K g . K$ & 850 & 860 & Gypsum Board Surf. Temp. \\
\hline$k O S B$ & OSB Thermal Conductivity & $W / m . K$ & 0.16 & 0.092 & Mid-Sheathing Temperature \\
\hline$P$ OSB & OSB Density & $\mathrm{Kg} / \mathrm{m}^{3}$ & 574 & 650 & Mid-Sheathing Temperature \\
\hline $\operatorname{COS} B$ & OSB Specific Heat Capacity & $J / K g . K$ & 1100 & 1880 & Mid-Sheathing Temperature \\
\hline$P E P S$ & EPS Density & $\mathrm{Kg} / \mathrm{m}^{3}$ & 15 & 16 & Gypsum Board Surf. Temp. \\
\hline$C p E P S$ & EPS Specific Heat Capacity & $J / K g . K$ & 1500 & 1470 & Gypsum Board Surf. Temp. \\
\hline k Lamina & Lamina Thermal Conductivity & $W / m \cdot K$ & 0.37 & 0.31 & Top Coat Surf. Temp. \\
\hline P Lamina & Lamina Density & $\mathrm{Kg} / \mathrm{m}^{3}$ & 1800 & 1600 & Top Coat Surf. Temp. \\
\hline Cp Lamina & Lamina Specific Heat Capacity & $J / K g . K$ & 850 & 870 & Top Coat Surf. Temp. \\
\hline Hout & $\begin{array}{l}\text { Exterior Convective Heat } \\
\text { Transfer Coefficient }\end{array}$ & $W / m^{2} \cdot K$ & 24 & $\begin{array}{l}\text { External Forced } \\
\text { Convection Coef. }\end{array}$ & Top Coat Surf. Temp. \\
\hline
\end{tabular}


Figures 11 through 21 demonstrate graphical representations for the initial and final surface temperatures after calibration of each parameter, against the experimental data for each sensor location for the face-sealed and vented EIFS assemblies. The parameters were calibrated only for the face-sealed assembly since it is believed that the same material species were used during the field tests for both the vented and the face-sealed EIFS assemblies.

Figure 11 demonstrates the average temperature of the exterior surface of the gypsum board in the face-sealed EIFS assembly. The monitored surface temperatures (EXP) showed a general reduction in the surface temperature throughout the calibration period while the average interior temperature lies between $293.5^{\circ} \mathrm{K}-294.5^{\circ} \mathrm{K}$ with a slight increase in the second half of the calibration period as demonstrated in Figure 12 below. In addition, the interior temperature can be seen to significantly fluctuate every hour at $3^{\circ} \mathrm{K}$, explaining the fluctuations that can be seen in the EXP surface temperatures in Figure 11. The initial run produced results that deviate at a maximum of $4^{\circ} \mathrm{K}$ from the experimental results. As mentioned earlier, the sensitivity index revealed that the exterior surface temperature of the gypsum board is mostly affected by the value of interior convective heat transfer coefficient and the physical material properties of the EPS and fiberglass insulation, followed by the properties of the gypsum board itself. As the fiber glass thermal conductivity, the EPS density and the interior convective heat transfer coefficient were calibrated, calibrating the other material properties did not create significant changes in results. The final calibrated gypsum board temperature, labelled as "Final" in Figure 11 deviates slightly at a maximum of $1^{\circ} \mathrm{K}$ from the monitored filed data, and represents the final calibrated surface temperature after the calibration of all 19 parameters was completed. 


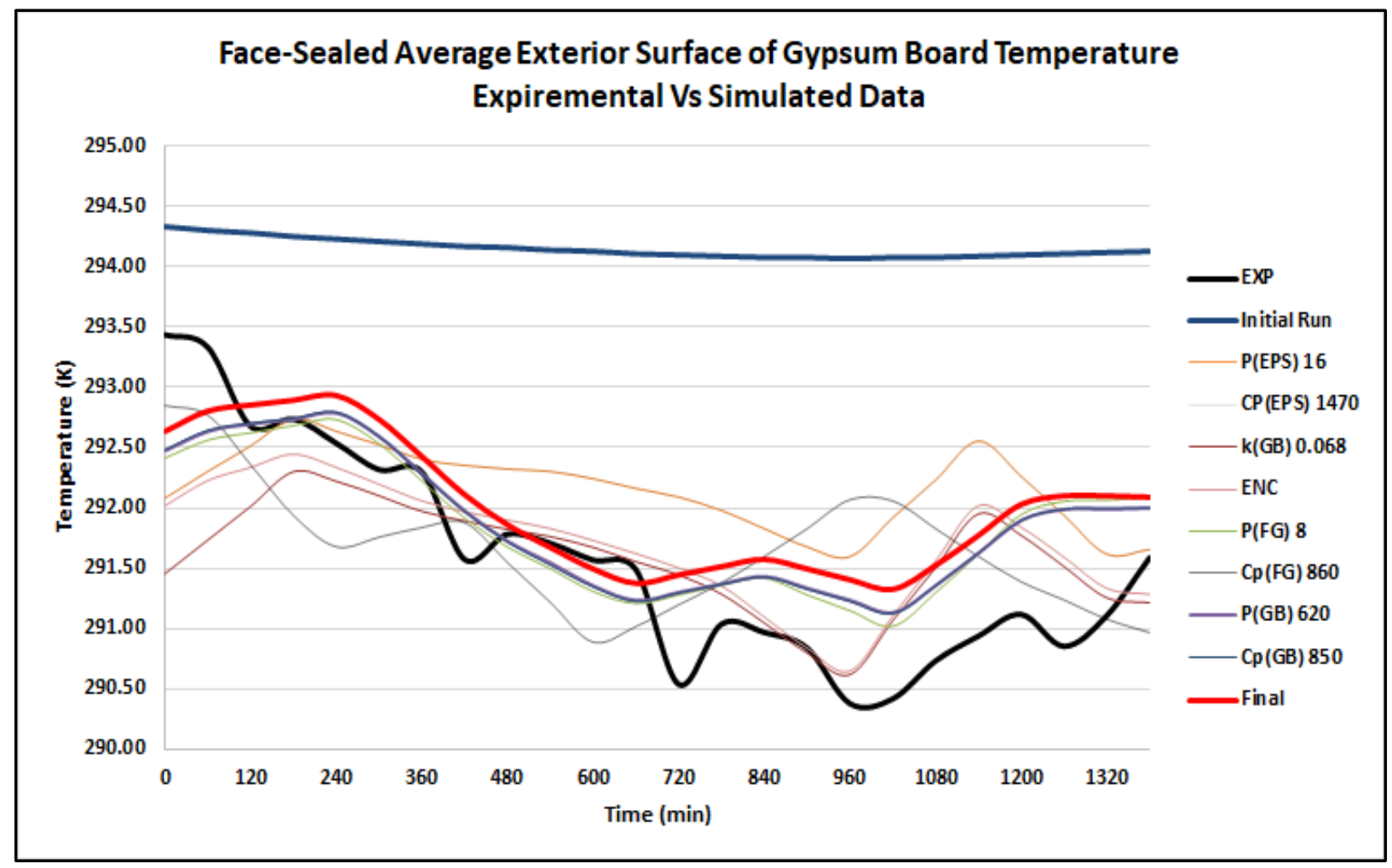

Figure 11. Average Temperature of Exterior Surface of Interior Gypsum Board.

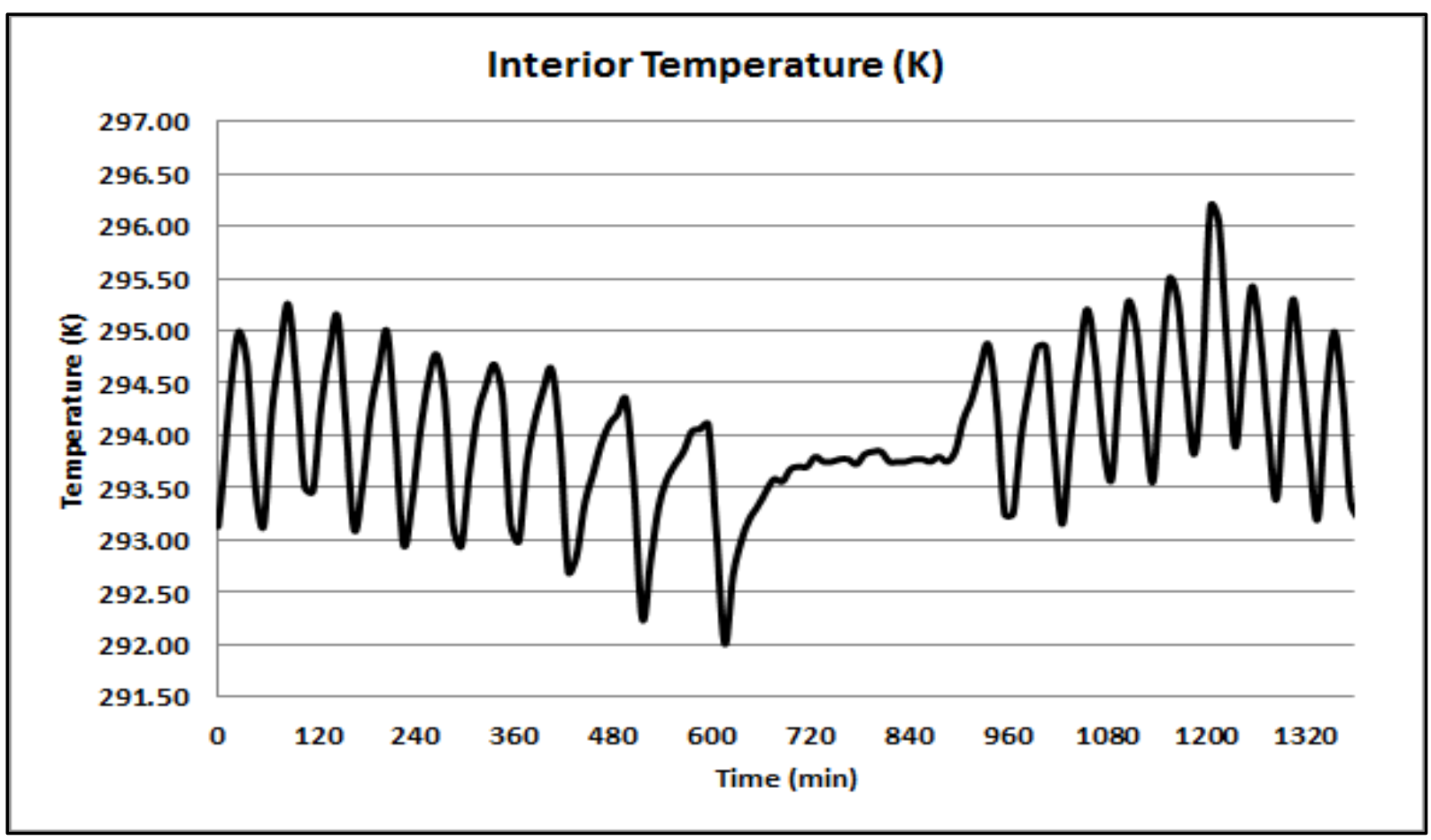

Figure 12. Monitored Interior Temperature Throughout Calibration Period. 
As mentioned earlier, the calibration of the parameters was only completed for the face-sealed assembly since it is believed that the same material species were used during the field tests for both the vented and the face-sealed EIFS assemblies. Figure 13 demonstrates a comparison between the average exterior surface temperature of the gypsum board as measured in the vented EIFS assembly, and the simulation results after the calibration of all parameters was completed. Although, the face-sealed calibration results align more closely with their experimental results when compared with the vented assembly simulation and experimental data, the maximum surface temperature difference between the simulation and experimental results for the vented assembly is only $1.5{ }^{\circ} \mathrm{K}$ as demonstrated in Figure and is within the accuracy range of the temperature sensor.

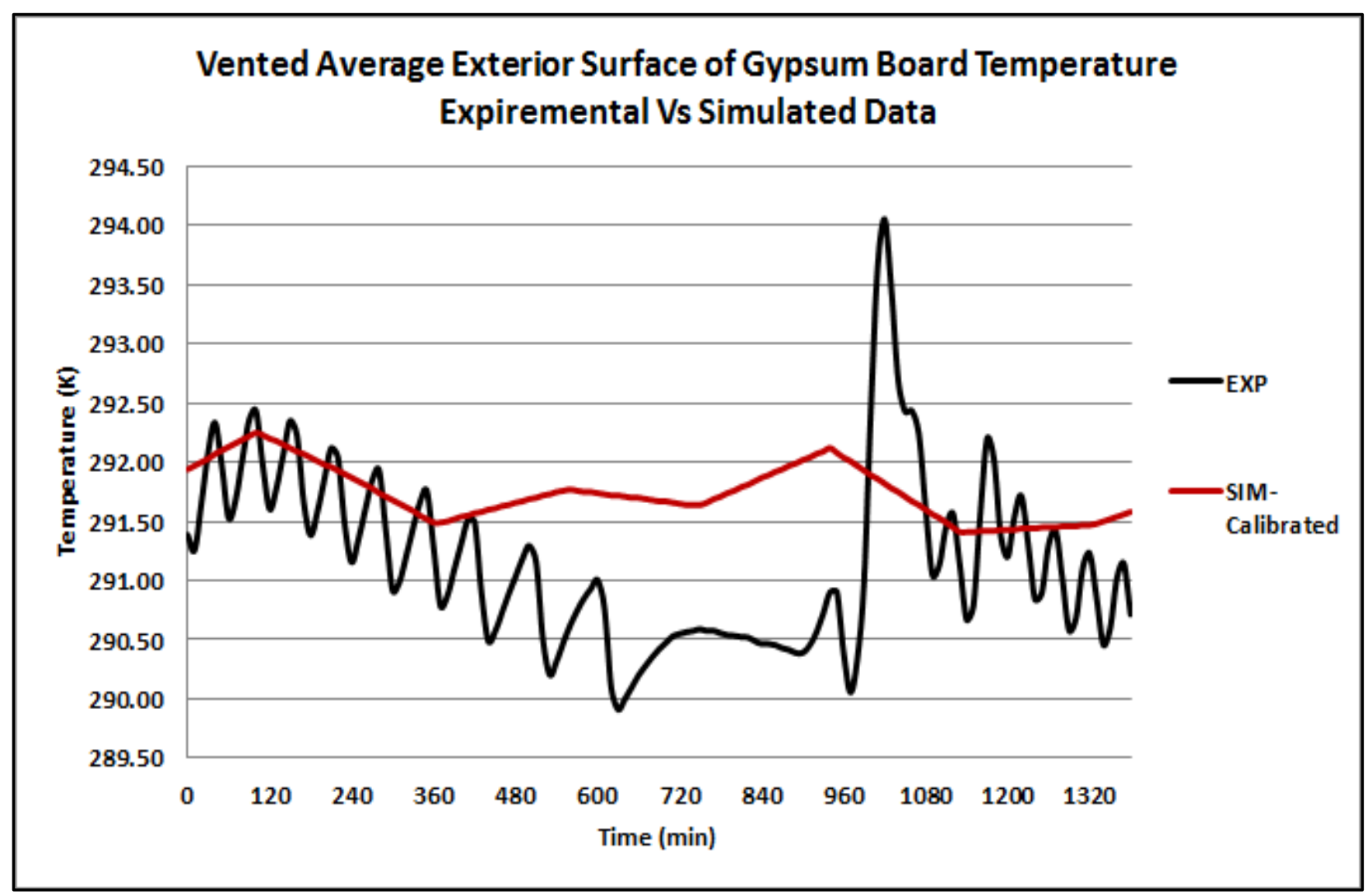

Figure 13. Average Temperature of Exterior Surface of Interior Gypsum Board (Vented). 
As demonstrated in Figure 14, the exterior convective heat transfer coefficient and the material properties of the EIFS lamina were calibrated against the sensor measuring the exterior surface temperature. The initial run produced results that significantly deviate from the experimental values at a maximum difference of $22^{\circ} \mathrm{K}$, however, after calibrating the gypsum board temperature, followed by the fiberglass thermal conductivity (against mid-sheathing temperature), exterior convective heat transfer coefficient and the lamina thermal conductivity, the results marked as "Final" in Figure 14 demonstrate a significant improvement over the initial run values, with a maximum temperature difference of $3^{\circ} \mathrm{K}$ from the experimental values.

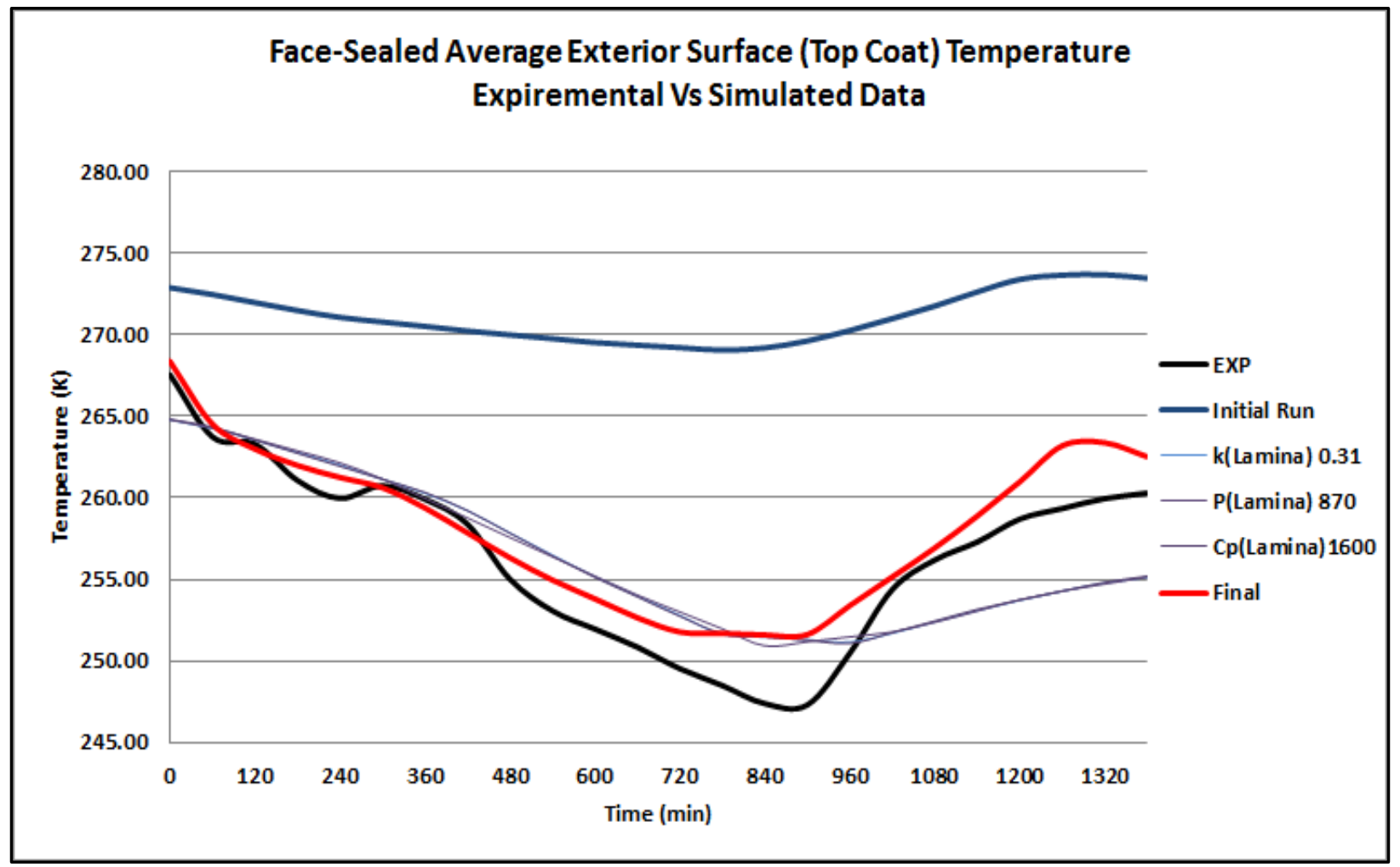

Figure 14. Average Temperature of EIFS Top Coat (Face-Sealed).

Similarly, Figure 15 demonstrates the simulation results for the vented EIFS assembly after the calibration of all parameters was completed against the experimental data, and a maximum temperature difference of $4.5^{\circ} \mathrm{K}$ can be seen, however, the simulation results are closely aligned (graph shape) with the experimental results indicating that the simulation results are able to predict the performance of the assembly when exposed to exterior conditions variations, thus 
indicating the validity of the model. Figure 16 demonstrates the exterior ambient temperature profile experienced throughout the calibration period. When compared to the simulation results from Figures 14 and 15, during the second half of the calibration period, the surface temperature of the top coat increases by $12^{\circ} \mathrm{K}$, while only a $5^{\circ} \mathrm{K}$ increase in the ambient temperature is witnessed during the same period. However, when looking at Figure 17, representing the amount of diffuse solar irradiance received by the exterior surface of the wall assembly, it becomes clearer that the additional $7^{\circ} \mathrm{K}$ increase is caused by solar radiation, indicating that the simulation results takes solar radiation into account.

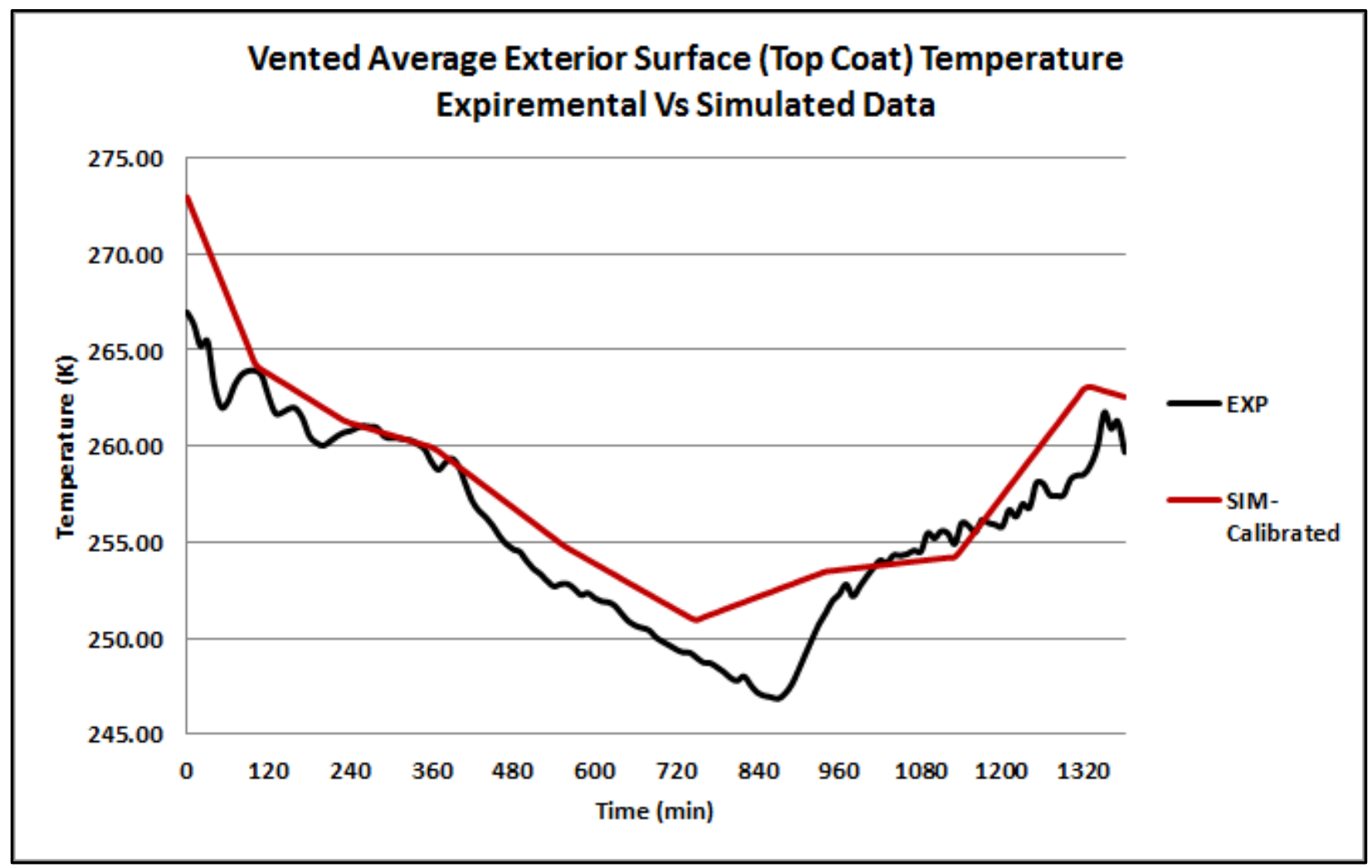

Figure 15. Average Temperature of EIFS Top Coat (Vented). 


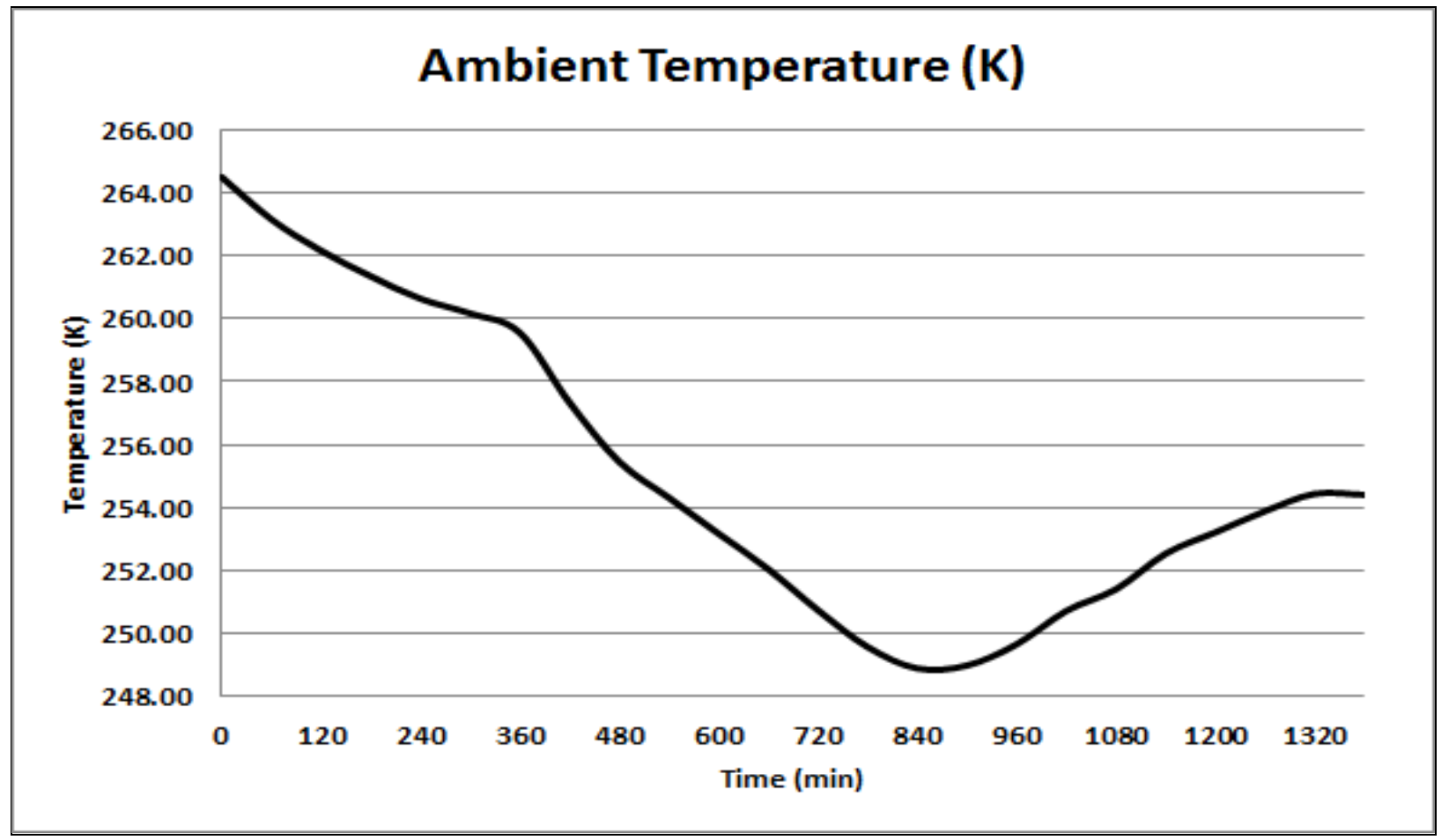

Figure 16. Monitored Exterior Ambient Temperature Throughout Calibration Period.

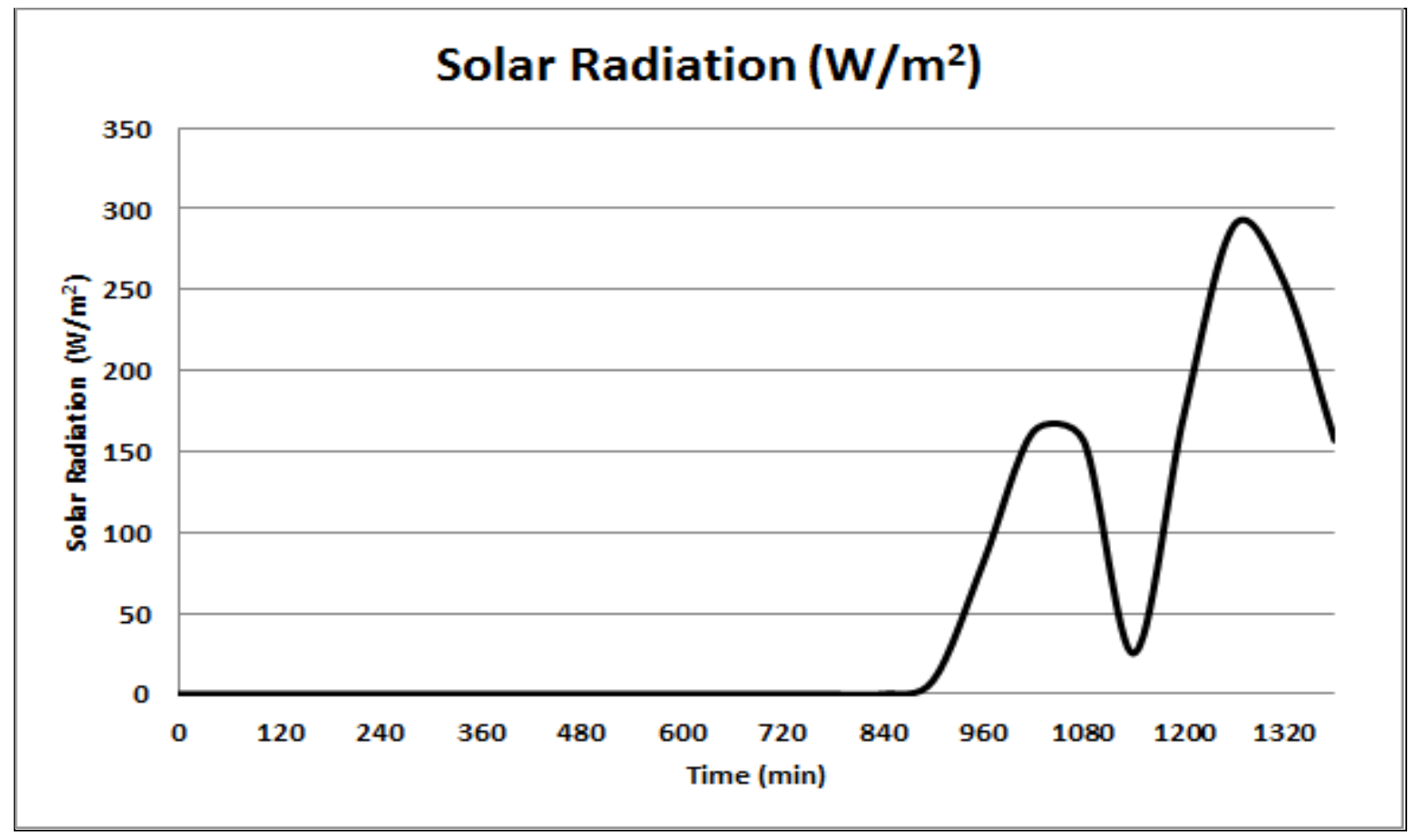

Figure 17. Solar Radiation Received by The Experimental Wall Models. 
As demonstrated in Figure 18, the mid-sheathing temperature was found to be mostly sensitive to the thermal conductivity of the fiberglass insulation, OSB sheathing and wood studs' properties. It is important to note that the screening analyses revealed that the thermal conductivity of fiberglass is the most influential parameter on the results of the simulations, including the previous results of gypsum board and top coat surface temperatures. However, it was decided to calibrate the fiberglass conductivity against the mid-sheathing sensor as it resulted in a higher sensitivity index for this sensor location than others. Thus, after calibrating the boundary conditions (interior/exterior heat transfer coefficients), the thermal conductivity of the fiberglass was calibrated ahead of all remaining 16 parameters. This contributed to easier and more accurate model calibration. As demonstrated in Figure 18, a significant improvement can be seen between the results of the initial run and the final calibration curves. The initial run had results that deviated from the experimental data at a maximum difference of $24^{\circ} \mathrm{K}$, while the "Final" calibrated values deviate at a maximum of $3^{\circ} \mathrm{K}$ from experimental values. Furthermore, the final simulated values represent the average of experimental values throughout the calibration period (See Period of 480-1380 min), thus giving confidence in the simulated results.

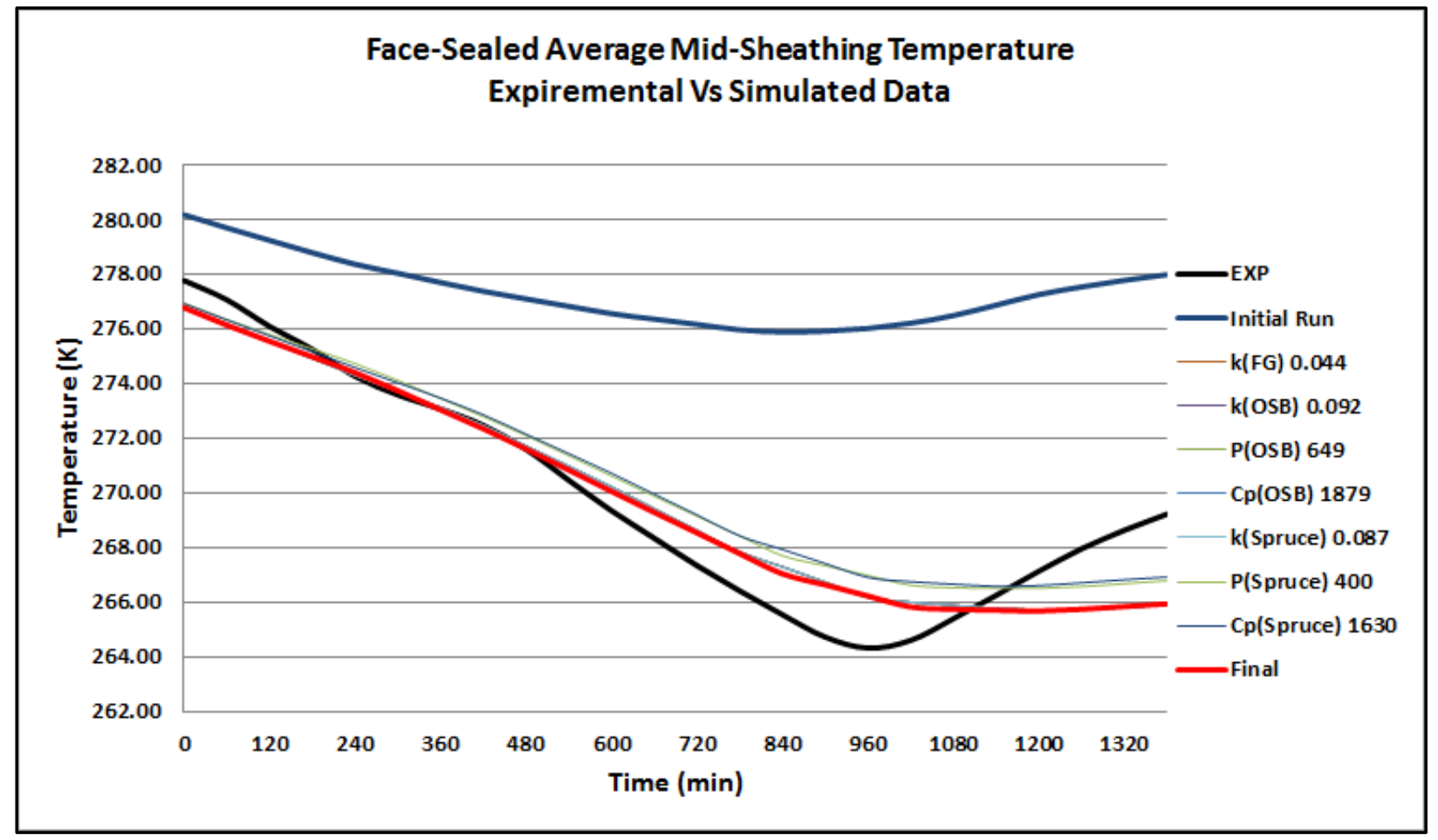

Figure 18. Average Mid-Sheathing Temperature (Face-Sealed). 
Figure 19 demonstrates the simulation results for the vented EIFS assembly with a similar $3^{\circ} \mathrm{K}$ temperature difference.

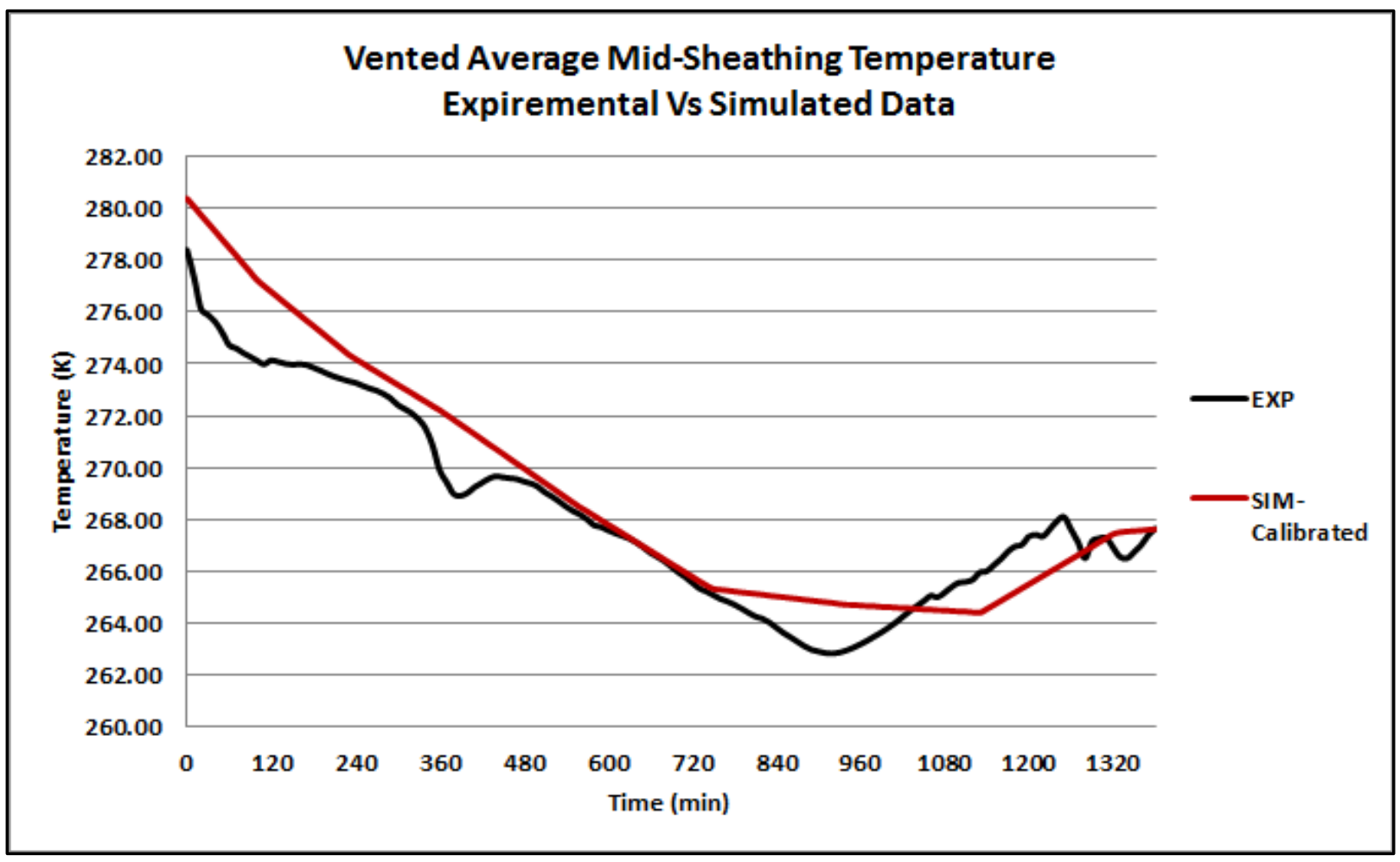

Figure 19. Average Mid-Sheathing Temperature (Vented).

Finally, after identifying all the unknown parameters, the total heat flux through the mid sheathing was validated against the average experimental data produced by the heat flux plates. Figure 20 demonstrates the improvement between the results of the initial run and the heat flux magnitudes after the calibration of the boundary conditions and material properties were completed. Although a significant improvement can be observed and the results of the "final" values after calibration match closely to the experimental heat flux during the period of 0-900 min (0 represents 5:00 PM, 900 represents 8:00 AM next day), the experimental heat flux starts to decline at a faster rate than the simulated results until the end of the calibration period (900$1380 \mathrm{~min})$. A trial and error approach was undertaken to identify the source of the discrepancy between the simulated and experimental values by attempting to re-calibrate some of the parameters against the flux curve and it was found out that in order for the simulation results to 
match the experimental values during the discrepancy period, several unrealistic material properties have to be input, such as a $10 \mathrm{~kg} / \mathrm{m}^{3}$ and $100 \mathrm{~J} / \mathrm{kg} . \mathrm{K}$ in lieu of realistic, tabulated and calibrated values of $400 \mathrm{~kg} / \mathrm{m}^{3}$ density and $1630 \mathrm{~J} / \mathrm{kg} . \mathrm{K}$ for the wood studs. The species of lumber used for studs during the field test are unknown but were assumed to be spruce for this research. Other source of this discrepancy could be the result of an exposure to diffuse solar radiation reflected from the ground surface covered with reflective snow during the month of February and causing an increase in the temperature of the EIFS top coat, which warms up the air besides it and produces a reduction in the heat flux magnitude. However, as neither the ground nor the sun position was modelled for this research due to software limitations, there were no means by which this source of discrepancy could be confirmed. Solar radiation was identified as a source of discrepancy since the discrepancy period starts at the same time when solar radiation effects start to take place around 8:00 AM (900 min). Note that both the tested and simulated walls were oriented towards the north, thus a direct source of radiation is not expected, and only diffuse radiation could be considered for most of the day.

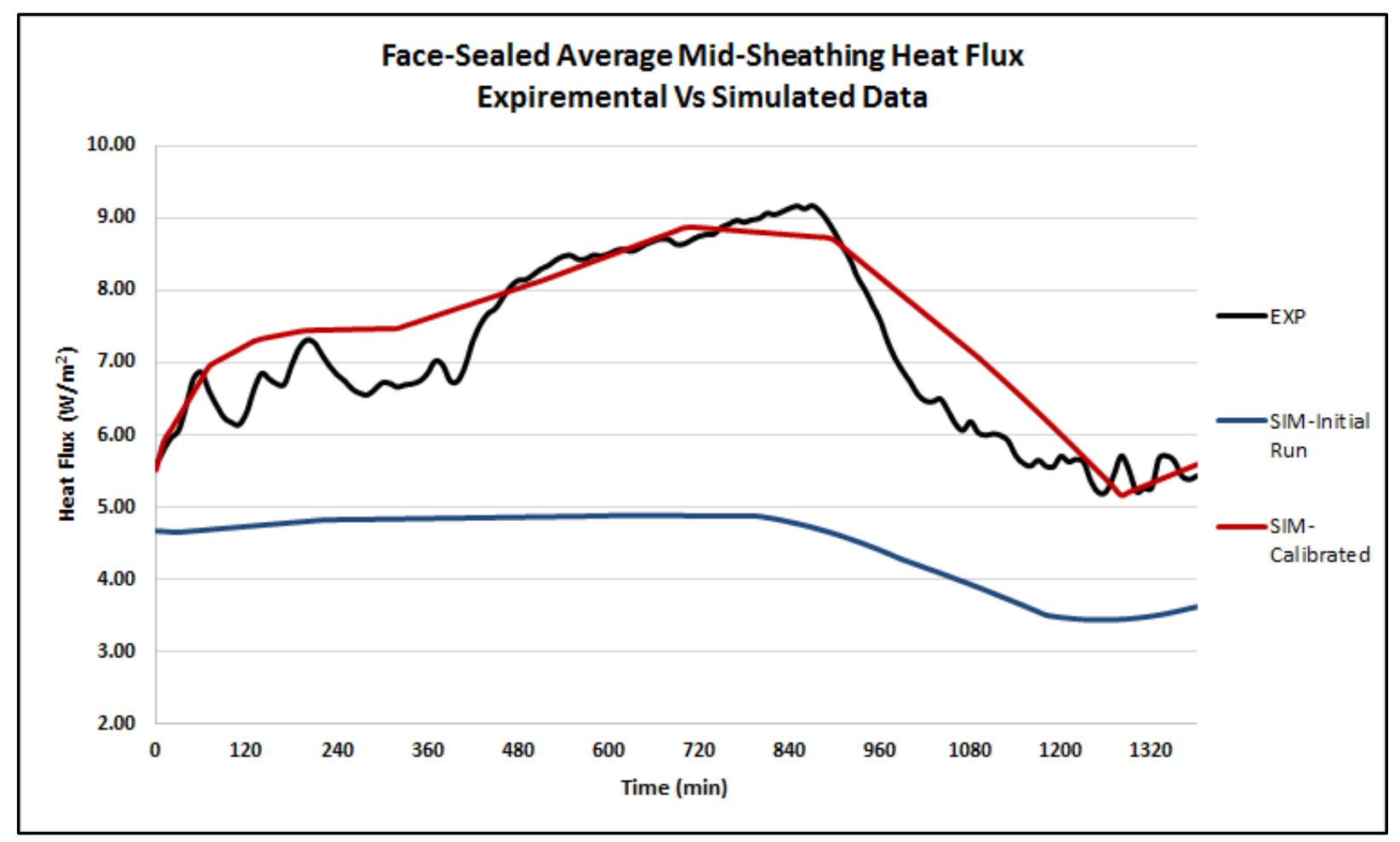

Figure 20. Heat Flux through Mid-Sheathing (Face-Sealed). 
Nevertheless, for the calibrated parameters to have realistic values and since the simulation results fall in the calibration statistical criteria by all bodies presented previously in Table 4 , the model was considered sufficiently calibrated. Figure 21 demonstrates a graphical comparison between the simulated heat flux through the EIFS vented assembly, after the calibration of all parameters was completed, against the experimental results for the same period. The discrepancy between both curves is due to the same reasons as explained above for the face-sealed assembly. Since the aim of this paper to find the difference of the heat flux between the vented and facesealed assemblies caused by different EPS profile, a separate calibration of the input parameters for the vented assembly was not conducted and the results demonstrated in Figure 21 are based on the calibration of parameters against surface temperatures in the face-sealed EIFS assembly.

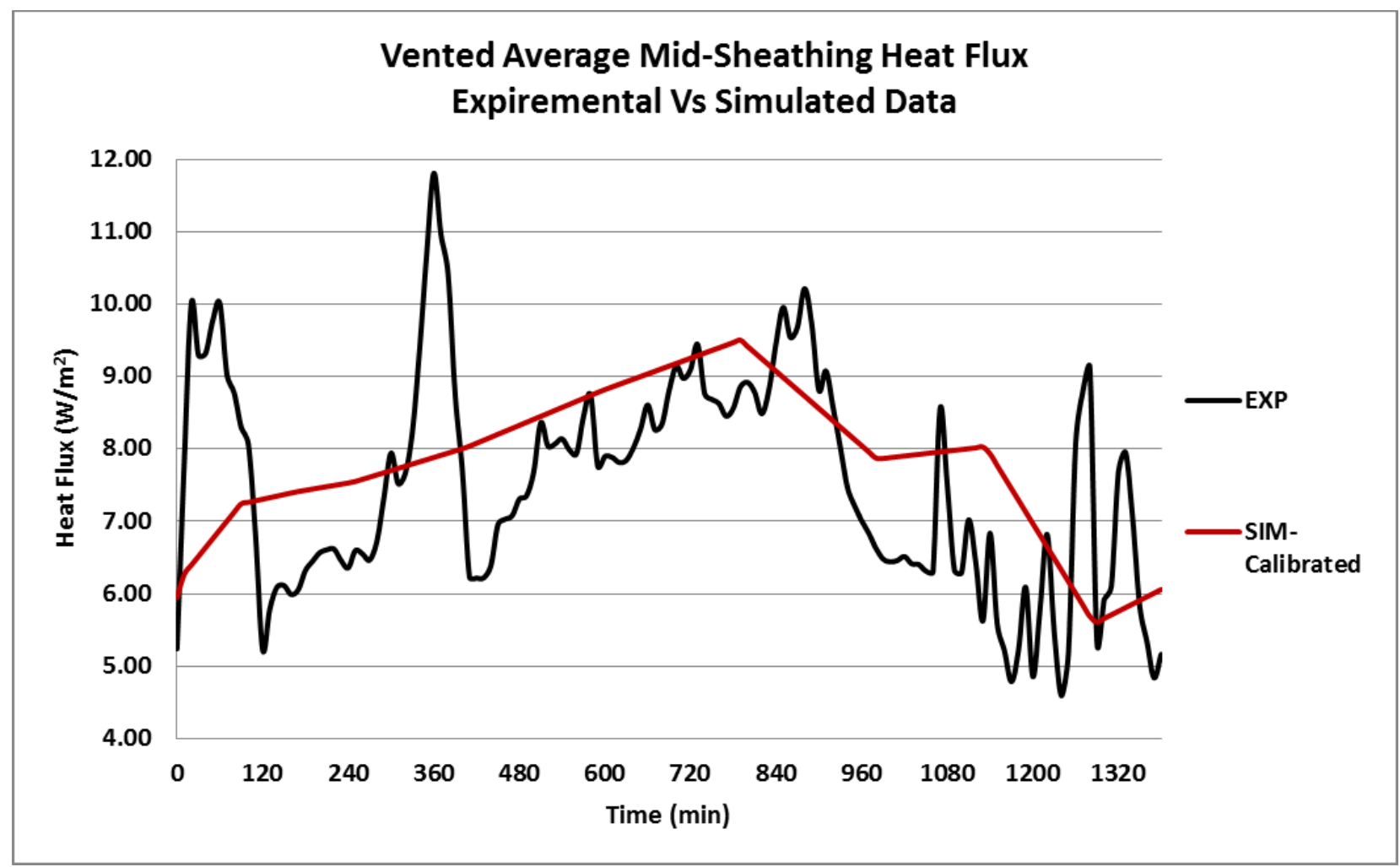

Figure 21. Heat Flux through Mid-Sheathing (Vented). 


\subsection{Simulation Results}

In this Section, the calibrated models were used to evaluate the thermal performance impacts of venting EIFS assemblies. Furthermore, the thermal performance impacts of increasing wind speeds caused by applying EIFS on higher elevations, were evaluated for both the face-sealed and vented EIFS assemblies. Measured wind speeds were input in COMSOL as time functions assuming a reference height of $2.4 \mathrm{~m}$ since a weather station was installed on the test hut's roof during Smegal's field testing. Hence, the measured wind speeds correspond to a single-story building height at an open country site, referred to as "low-rise" in this research. Wind speeds acting on higher building elevations were calculated using the boundary layer theory as outlined in Equations 8 through 10 above.

A "mid-rise" building was assumed to have a height of $36 \mathrm{~m}$ (12-stories) with a suburban exposure. A building height of $36 \mathrm{~m}$ was selected to represent the maximum allowed height for a mid-rise building in Ontario. Finally, a "high-rise" building was assumed to have an arbitrary height of $99 \mathrm{~m}$ (33-Stories) with a city-center terrain. A height of $99 \mathrm{~m}$ was selected as most existing buildings with EIFS construction and buildings to be renovated by EIFS over cladding are generally 12-33 stories in height in North America, and thus the results of this research could be interpolated to find the impacts (if any) of applying vented EIFS at any height in between. Figure 22 demonstrates buildings with varying heights utilizing EIFS. 


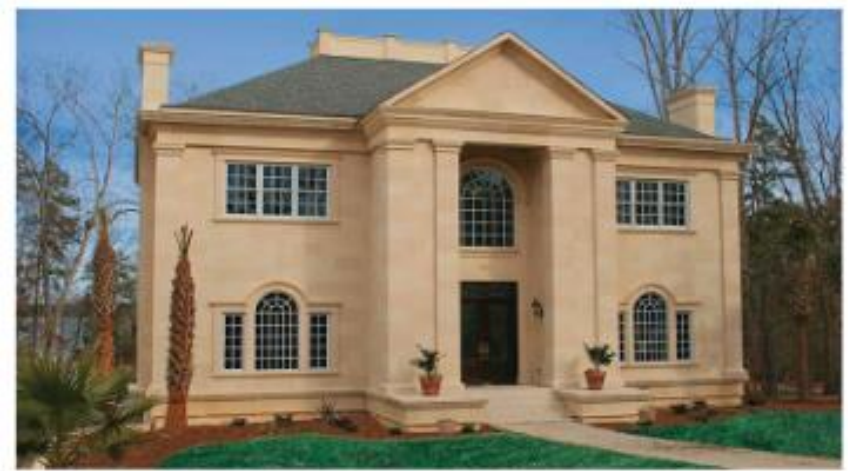

EIFS Applied on a Low-rise Residential Building in Lexington, South Carolina.

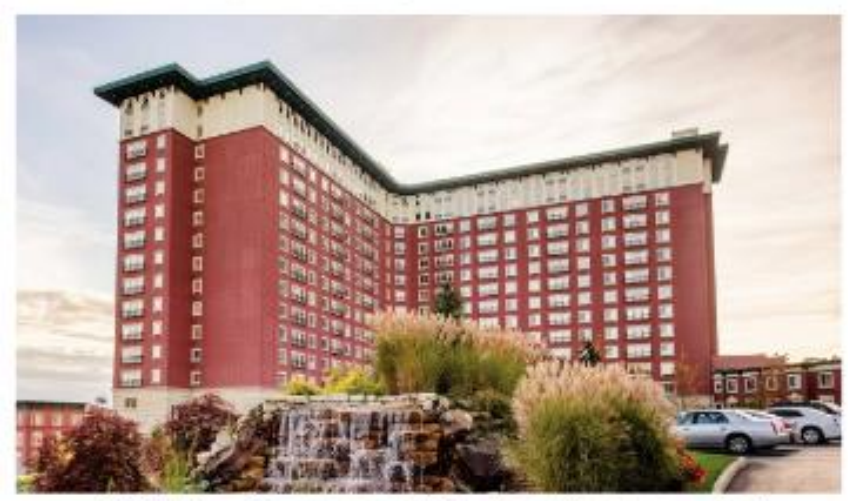

EIFS Applied on a Mid-rise Commercial Building in Cincinnati, $\mathrm{OH}$.

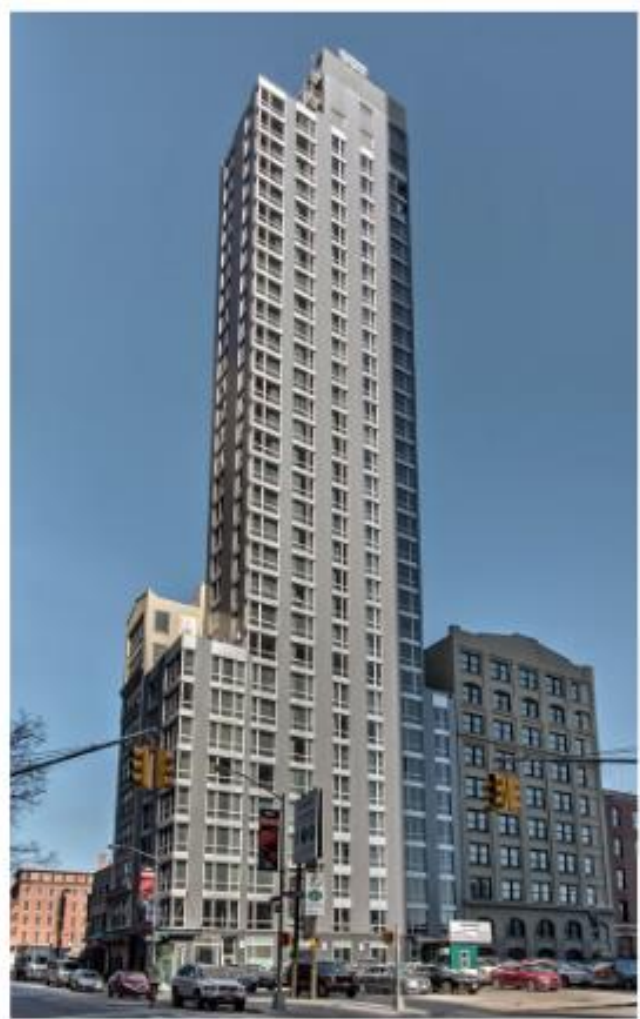

EIFS Applied on a High-rise Commercial Building in NYC.

Figure 22. EIFS Installed at Different Building Heights and Types. (EIMA, 2019)

As demonstrated in Figure 23, wind speed increases with height from grade level due to several reasons. Firstly, at great heights from grade, air movements are driven by pressure gradients in the atmosphere caused by variable solar heating of the earth. At higher altitudes, the pressure gradient between warm and cold air increases producing greater wind speeds. Secondly, near grade level, wind speeds tend to be lower due to friction with ground surfaces and objects such as buildings, vegetation and mountains. At higher amplitudes, these friction forces depreciate gradually until they become negligible causing greater wind speeds. It is important to note that friction forces increase at rough terrains such as city center locations, where the atmospheric boundary layer is fully developed at higher levels above grade than in a flat area with low surface roughness. The wind velocity variation versus the height above ground exhibits a parabolic shape, reaching a maximum value at 100-1000 $\mathrm{m}$ above ground, depending on the ground roughness (Bassett and Mcneil, 2005). 


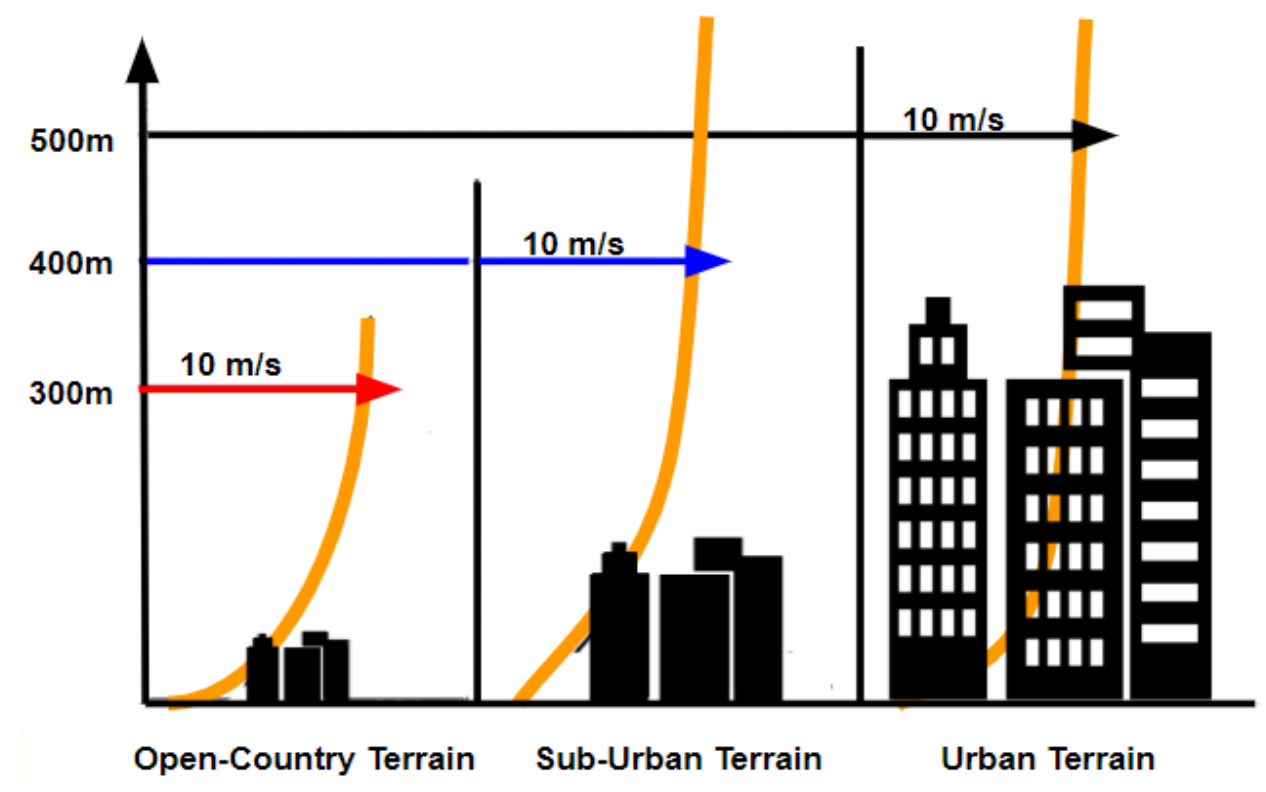

Figure 23. Wind Velocity Variation with Height and Terrain.

Figure 24 demonstrates the wind speeds applied on the wall models during the simulation period based on building heights and their sites terrains. The graphs' amplitudes are magnified at higher elevations as wind speed increases exponentially with height above the ground.

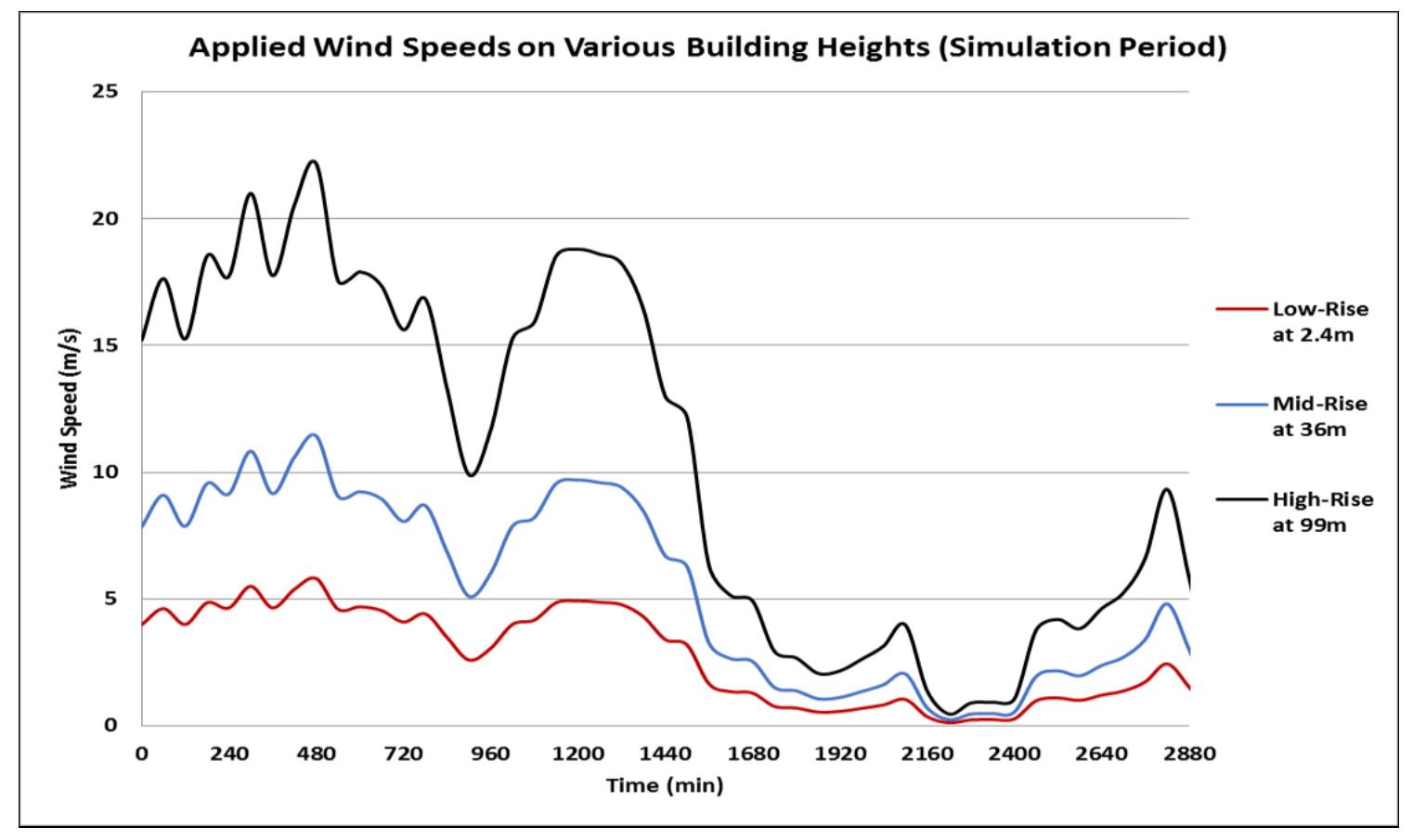

Figure 24. Applied Wind Speeds Corresponding to Different Building Heights. 
The purpose of this subsection is to compute the effective thermal resistances of the face-sealed and vented EIFS assemblies at different construction heights and using the calibrated models created during this research. ASTM-C1155 (2013), Standard Practice for Determining Thermal Resistance of Building Envelope Components from the In-Situ Data, is a procedure commonly used to obtain and use data from in-situ measurements of temperatures and heat fluxes on building envelopes to compute thermal resistances that are functions of mean temperatures. ASTM-C1155 requires the measurement of heat flux and the interior and exterior surface temperatures, as conducted by Smegal (2017) during the EIFS field test. Since the simulation models are based on the field experiments conducted by Smegal (2017), it was decided to compute the thermal resistances of the simulated assemblies in accordance with the summation technique outlined and recommended by ASTM-C1155. The thermal resistances were calculated using:

$$
R e=\frac{\Sigma \operatorname{period} \Delta T s}{\Sigma \operatorname{period} q}
$$

Where:

- $R e$ is the estimated effective thermal resistance for the simulation period in $\left(\mathrm{m}^{2} \mathrm{~K} / \mathrm{W}\right)$.

- $\Delta T s$ is the difference between the exterior and interior surface temperatures in $\left({ }^{\circ} \mathrm{K}\right)$.

- $q$ is the heat flux in $\left(\mathrm{W} / \mathrm{m}^{2}\right)$.

While the corresponding mean temperatures were calculated using:

$$
T e=\frac{\Sigma \text { period } \Delta T(T i s-0.5(\Delta T))}{\Sigma \text { period } \Delta T}
$$

Where:

- $\quad T e$ is the estimated mean temperature corresponding to calculated thermal resistance in $\left({ }^{\circ} \mathrm{K}\right)$.

- $\Delta T$ is the difference between the exterior and interior ambient temperatures in $\left({ }^{\circ} \mathrm{K}\right)$.

- $\quad$ Tis is the interior surface temperature in $\left({ }^{\circ} \mathrm{K}\right)$. 
As required by ASTM-C1155, calculations of thermal resistances were conducted over two periods of 24 hours since a 24-hour period is a dominant temperature cycle. To ensure that enough data was produced using simulations for accurate assessment, the convergence factor requirements in ASTM-C1155 were satisfied. ASTM-C1155 requires that three continuous periods of (12hr) meet the maximum convergence factor requirement of 0.1 (a zero-convergence factor indicates higher calculation accuracy) before initiating the thermal resistance calculations for the next two 24-hour periods. ASTM-C1155 also recommends that thermal resistance calculations are conducted at a minimum temperature difference of $10^{\circ} \mathrm{C}$ between interior and exterior environments, a maximum interior temperature variation of $3^{\circ} \mathrm{C}$ over the calculation period, and to limit exposure to solar radiation to further increase the accuracy of the calculations. Thus, it was verified that that selected simulation period satisfied the temperature recommendations, while solar irradiance values were set to zero over the simulation period, thus ignoring the effects of solar radiation on the estimated effective thermal resistances of the modelled EIFS assemblies.

Figures 25 through 29 provide time-series plots of the simulated heat fluxes magnitude throughout the simulation period for the face-sealed and vented EIFS assemblies applied on lowrise, mid-rise and high-rise buildings as defined earlier. The first comparison, as demonstrated in Figure 25, was conducted between a face-sealed and a vented EIFS assembly applied on a lowrise building with a wall cavity height of $2.1 \mathrm{~m}$. The heat flux through the face-sealed assembly can be seen to be slightly lower than the vented assembly's heat flux throughout the simulation period. The calculated RSI-values for the face-sealed and vented EIFS assembly are RSI-4.80 at 271.52 ${ }^{\circ} \mathrm{K}$ and RSI-4.63 at $271.65{ }^{\circ} \mathrm{K}$ respectively, implying a 3.6\% reduction in the effective RSI-value of the whole assembly due to venting. 


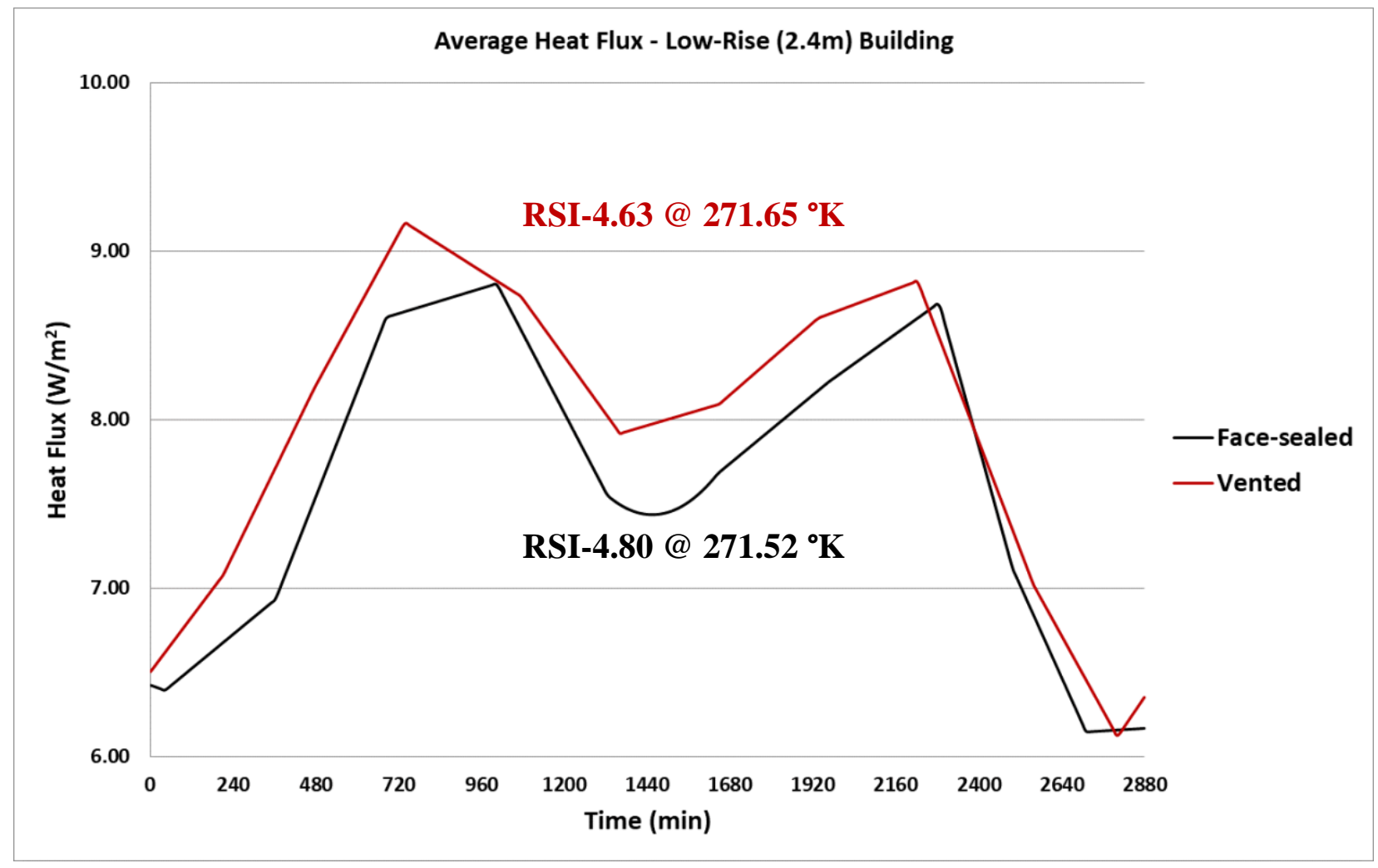

Figure 25. Thermal Performance of (FS VS. Vented EIFS) on Low-Rise Buildings.

Figures 26 and 27 demonstrate the heat flux through the face-sealed and vented and EIFS assemblies when applied on mid-rise $(36 \mathrm{~m})$ and high-rise $(99 \mathrm{~m})$ buildings throughout the same simulation period. Increasing the wind speeds did not cause a significant reduction in the thermal resistances for neither the face-sealed nor the vented EIFS assemblies. The calculated RSI-values for the face-sealed and vented EIFS assemblies applied on mid-rise buildings are RSI-4.82 at 271.73 ${ }^{\circ} \mathrm{K}$ and RSI-4.63 at $271.65{ }^{\circ} \mathrm{K}$ respectively, implying a 3.8\% reduction in the effective RSI-value of the whole assembly due to venting. Finally, the calculated RSI-values for the facesealed and vented EIFS assemblies applied on mid-rise buildings are RSI-4.83 at $271.78{ }^{\circ} \mathrm{K}$ and RSI-4.63 at $271.88{ }^{\circ} \mathrm{K}$ respectively, implying a $\mathbf{4 \%}$ reduction in the effective RSI-value of the whole assembly due to venting. 


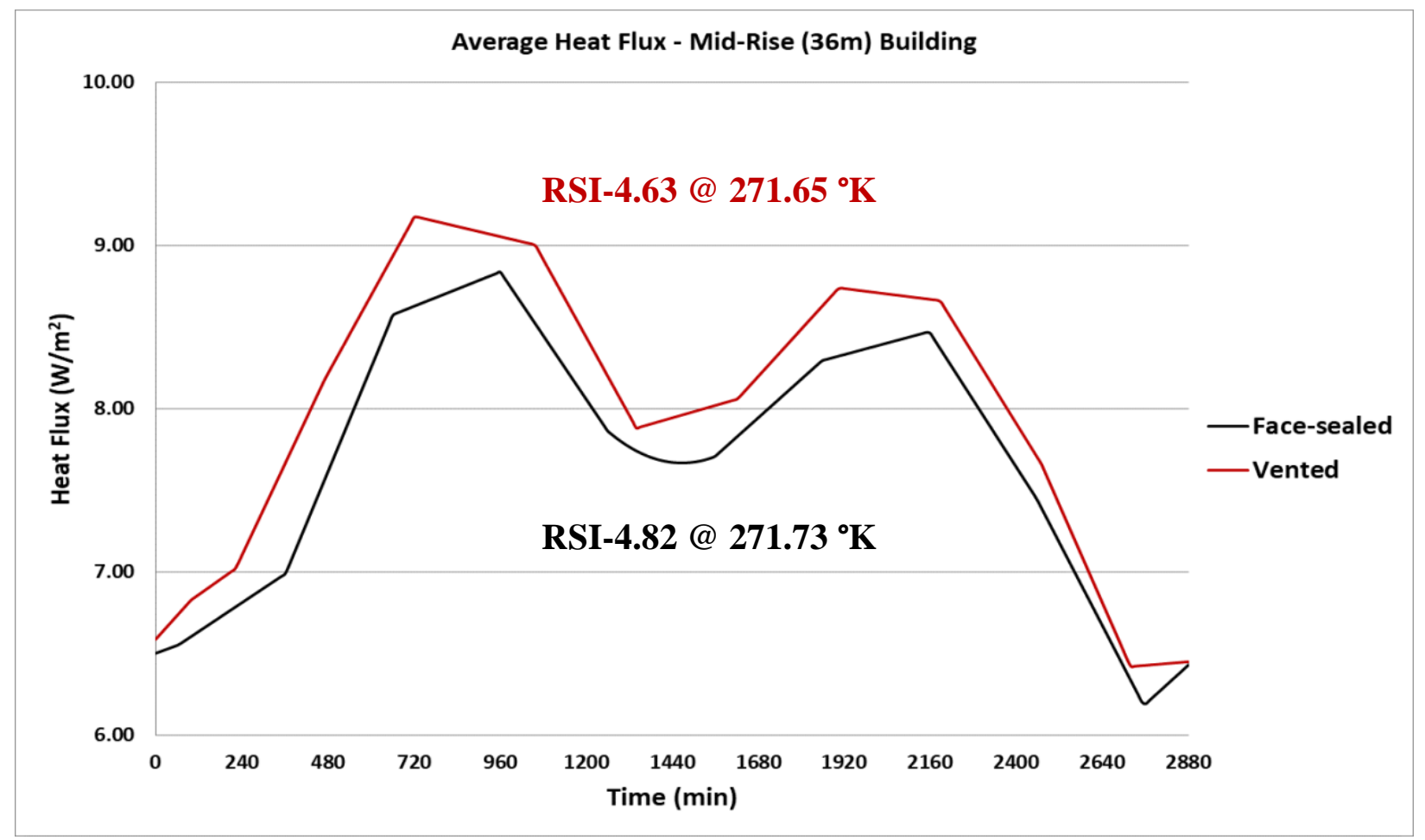

Figure 26. Thermal Performance of (FS VS. Vented EIFS) on Mid-Rise Buildings.

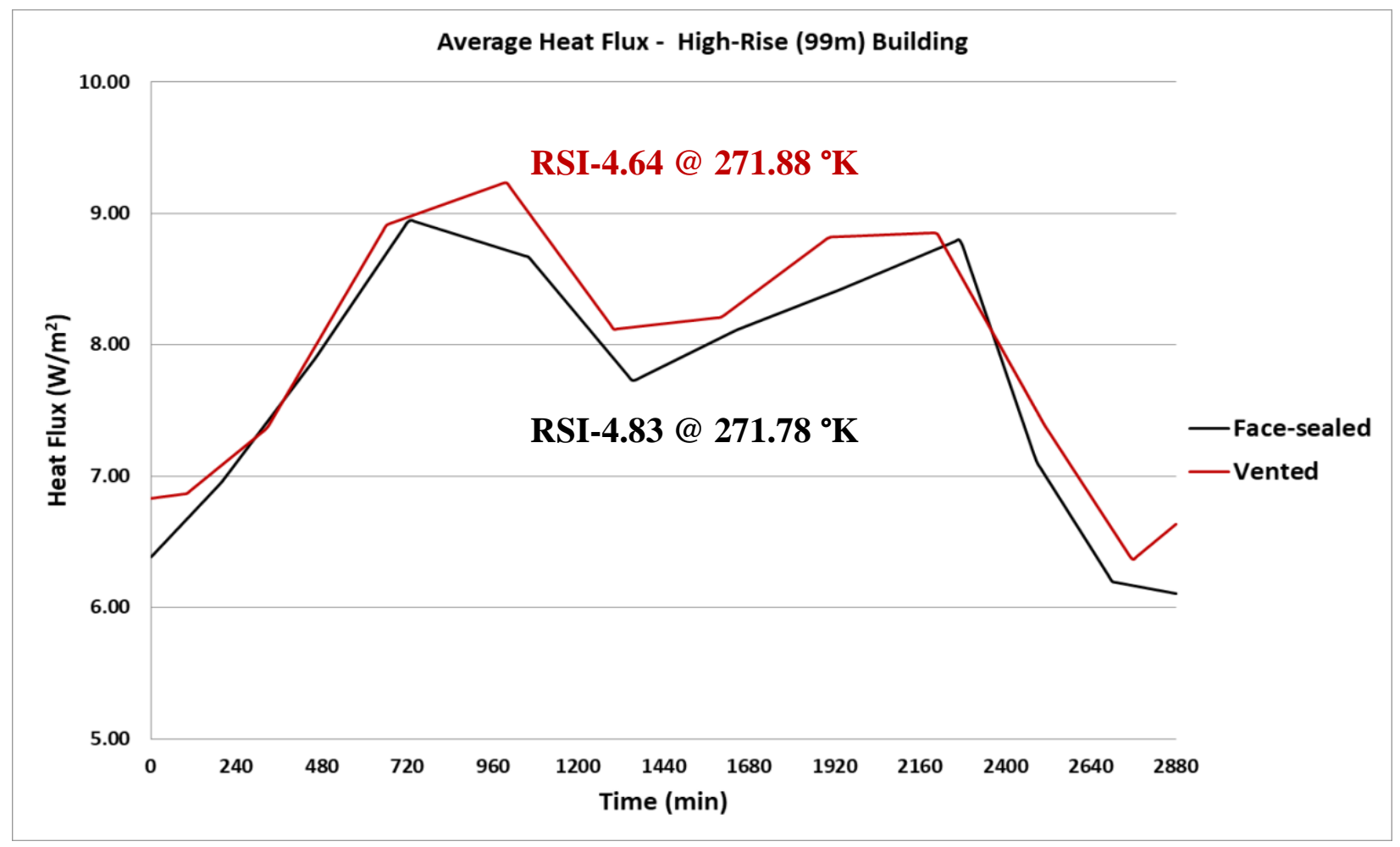

Figure 27. Thermal Performance of (FS VS. Vented EIFS) on High-Rise Buildings. 
Comparisons of heat fluxes at different building heights are further demonstrated in Figures 28 and 29, where wind influenced the heat flux results. The mid-rise and high-rise assemblies show slightly greater fluctuations and higher heat fluxes over the simulation period. However, the increased wind speeds at these heights caused a reduction in the exterior surface temperatures due to higher heat transfer by convection, which resulted in stabilizing the calculated thermal resistances of the wall assemblies across all construction heights for both the face-sealed and vented EIFS assemblies.

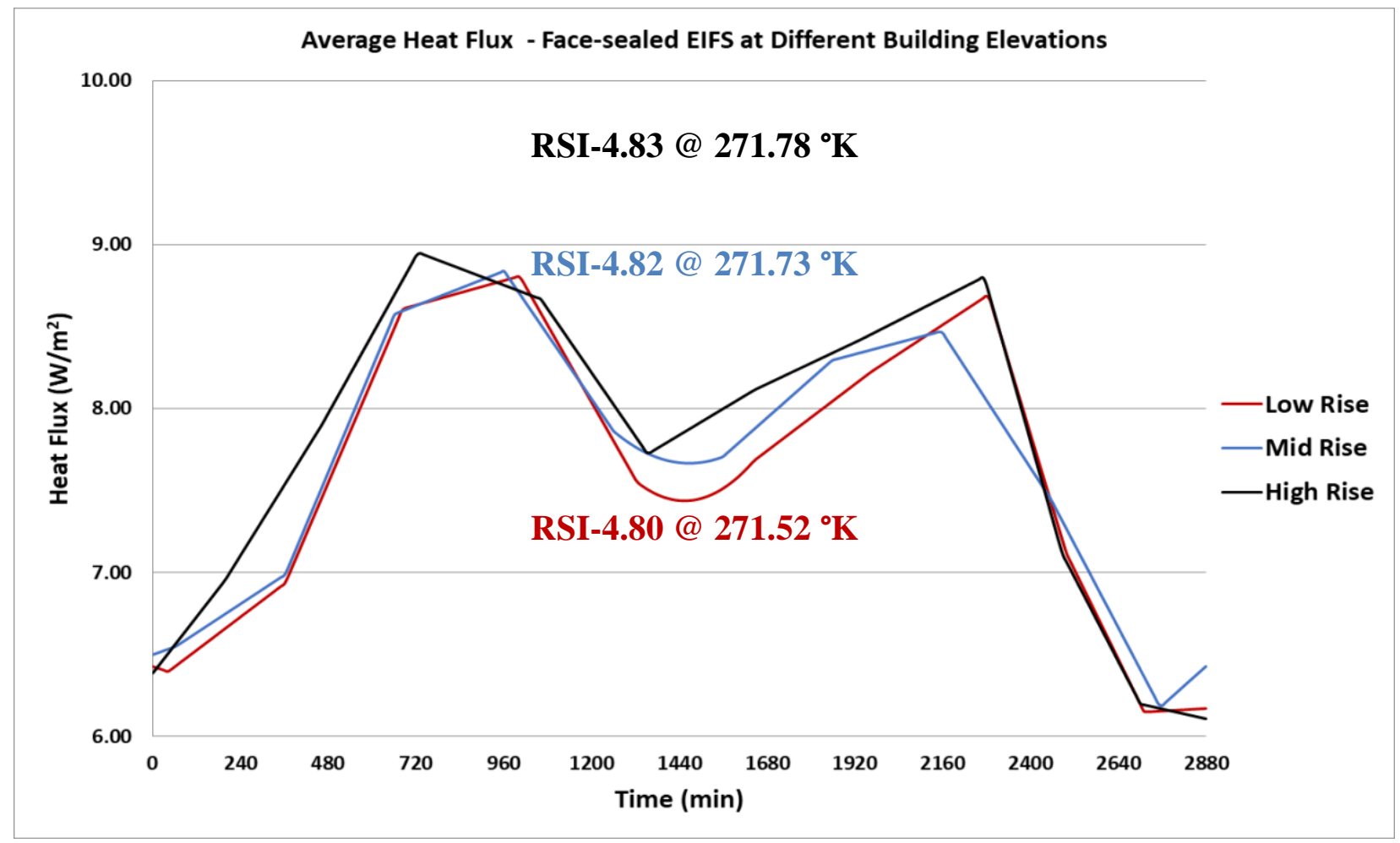

Figure 28. Thermal performance of the Face-Sealed EIFS Against Building Height. 


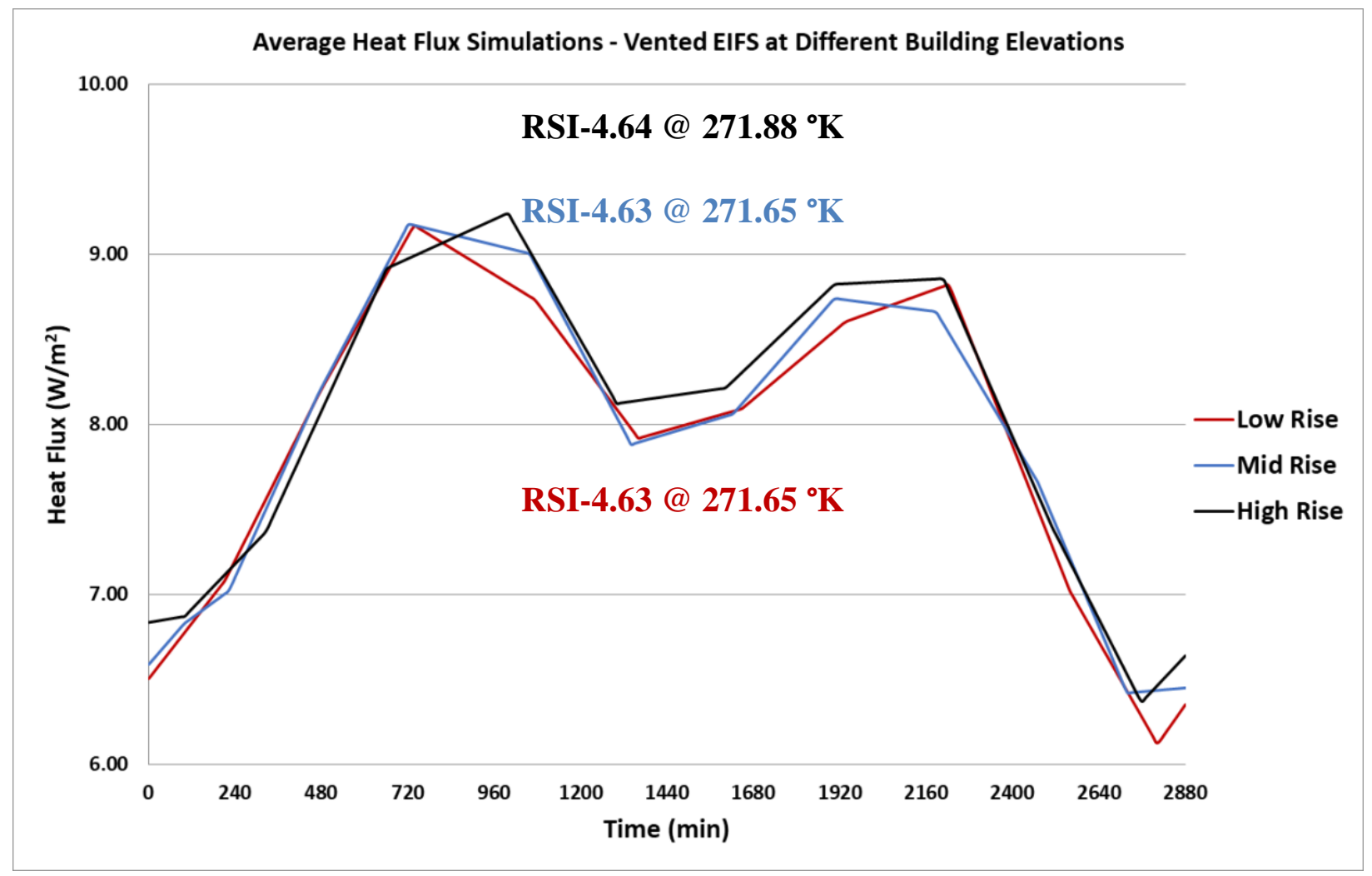

Figure 29. Thermal performance of the Vented EIFS Against Building Height.

Thus, it can be concluded from the results that a vented EIFS assembly constructed of 2-inches of EPS insulation board and 6-inches of fiberglass cavity insulation, experiences a reduction of 3.5 - 4\% in its effective RSI-value compared to a face-sealed EIFS. Furthermore, increased wind speeds, caused by installing EIFS at higher elevations from the grade had negligible effects on the thermal resistances of the face-sealed and vented EIFS assemblies when calculated according to ASTM-C1155. The results of this research agree with the results of other studies by Straube (2012) and Lstiburek (2007), suggesting that venting an EIFS assembly, constructed of with 2inch EPS insulation, causes a reduction of 3\% in its effective thermal resistance when compared to a face-sealed EIFS assembly, as discussed earlier. 


\subsection{Conclusion}

In this research, the thermal performance impacts of applying vented EIFS assemblies were studied and evaluated. A literature review was conducted and included studying forces driving ventilation including stack and wind pressures, their effects on the thermal performance of EIFS assemblies, and the need for vented cavities in improving the moisture management of modern wall assemblies. Thermal simulations of the face-sealed and vented EIFS assemblies were built and calibrated against experimental and monitoring data collected by previous works. The process of model calibration was completed by evaluating statistical indices including sensitivity analyses, MBE and Cv (RMSE). Simulations were conducted using COMSOL Multiphysics, for which its ability to perform accurate thermal simulations was verified.

The calibrated models were used to evaluate the heat flux through the vented EIFS assembly in response to increased wind speeds and/or building elevations, to which EIFS are applied. A facesealed EIFS model was used as a baseline to evaluate the thermal performance impacts of venting EIFS during a winter design day. It can be concluded from the results that a vented EIFS assembly constructed of 2-inches of EPS foam insulation and 4-inches of fiberglass cavity insulation, experiences a maximum reduction of $4 \%$ in the whole assembly's RSI-value compared to a face-sealed assembly. Furthermore, increased wind speeds, caused by installing EIFS at higher elevations from the grade had negligible effects on the thermal resistances of the face-sealed and vented EIFS assemblies when calculated in accordance with ASTM-C1155. Model-applied wind speeds were chosen to represent wind speed effects of low-rise buildings with a $2.4 \mathrm{~m}$ wall height at an open country terrain, mid-rise buildings with a wall height of $36 \mathrm{~m}$ (12-stories) at a suburban terrain, and high-rise buildings with a 99m (33-stories) at an urban city center. 


\subsection{Future Work}

This paper only studied the negative thermal performance impacts of applying "vented" in lieu of "face-sealed" EIFS assemblies, ignoring the positive impacts of improving the wall's moisture and hygrothermal performance when vented EIFS are applied. It is believed that studying the hygrothermal performance of vented EIFS would provide valuable information to EIFS manufacturers and building professionals to ensure efficient moisture drainage and assembly drying without compromising the thermal performance of the wall assembly. The hygrothermal model could also be upgraded to calculate the flow velocity and pressure fields and the cavity hourly air exchange rates $(\mathrm{ACH})$ could then be determined based on thermal and moisture buoyancies and wind pressures. The $(\mathrm{ACH})$ value is an essential parameter to account for to determine the effects of venting/ventilating on a wall's wetting and drying abilities and is required by many Combined Heat, Air and Moisture modelling software such as WUFI.

This research mainly focused on the negative thermal performance impacts of vented EIFS during the winter season. However, interestingly venting can also contribute to the reduction of cooling energy needs in the summer and the improvement of comfort conditions, which makes venting an important topic to study in regard to energy efficiency. It is crucial to evaluate these impacts and to be compared with the results of this research to fully understand the impacts of venting on the annual building energy demands. In addition, this research closely followed wall constructions used during the field tests, however, EIFS are typically constructed with 1 to 6 inches of EPS insulation for North American climates. It would be beneficial to evaluate the thermal performance impacts due to venting on assemblies with varying thicknesses of insulations and exposed to a range of outdoor ambient temperatures. Furthermore, the impacts of a range of solar irradiances acting on the wall can be further studied to determine the effects of venting on different façade orientations.

The calibrated models created during this research in addition to the data collected by Smegal (2017) during the field experiments, could be further adapted and utilized to evaluate the thermal performance impacts of "ventilated" EIFS assemblies and wind washing effects on the thermal 
performance for all types of EIFS assemblies. In addition, the models can be modified to include different vented/ventilated configurations including variety of cavity depths, heights, shapes and distribution. Finally, the effects of adding a low emissivity surface on the materials making up the cavity wall can be analyzed in attempts to optimize the design of the cavity with respect to thermal and moisture performances. 


\section{Appendix: Sensitivity Index Calculations}

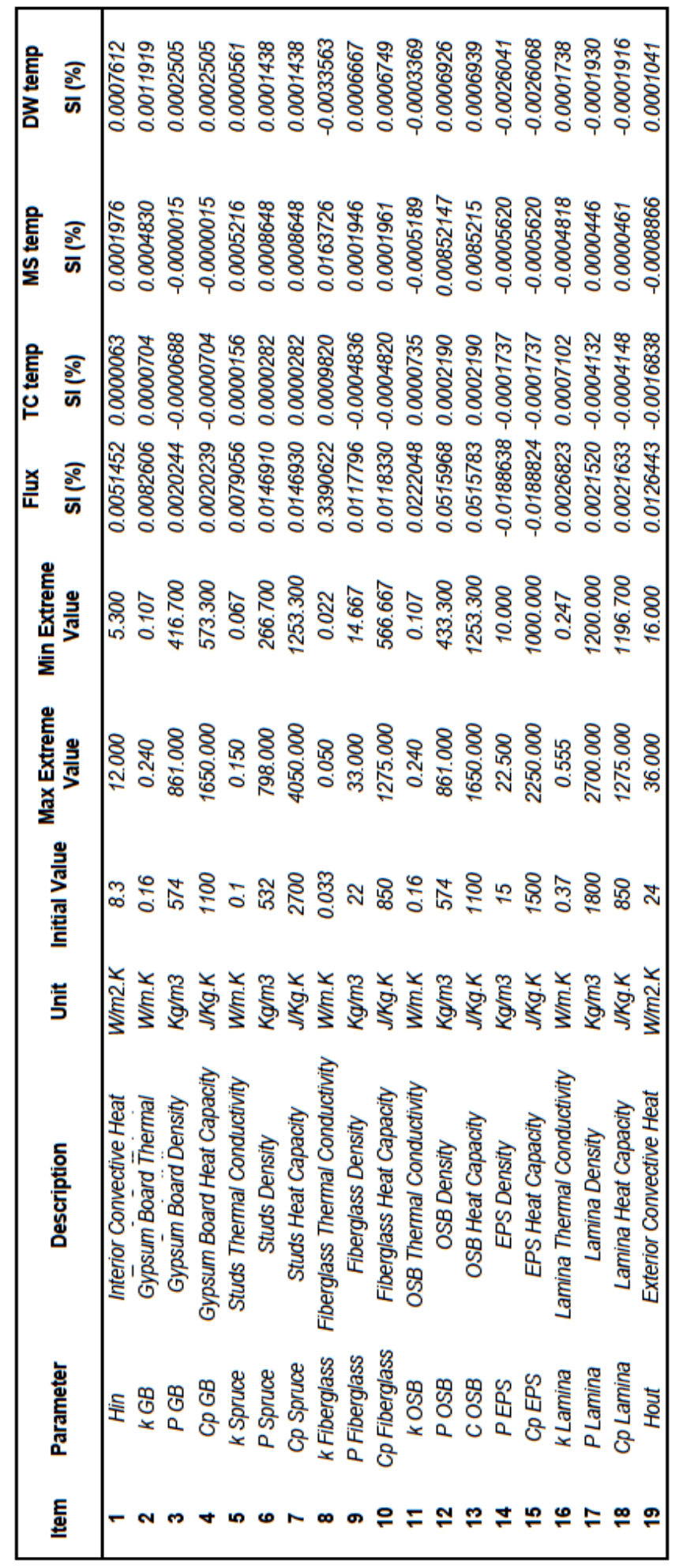




\section{References}

ASHRAE (2002). ASHRAE Guideline 14-2002: Measurement of Energy Demand and Savings; American Society of Heating, Refrigerating and Air-Conditioning Engineers: Atlanta, GA, USA.

ASHRAE (2010). ASHRAE 90.1 Energy Standard for Buildings Except Low-Rise Residential Buildings. Atlanta, GA: American Society of Heating, Refrigerating and Air-Conditioning Engineers Inc.

ASHRAE (2013). Handbook of Fundamentals (S-I Edition). Atlanta, GA: American Society of Heating, Refrigerating and Air-Conditioning Engineers, Inc.

ASTM (2013). ASTM-C1155 Standard Practice for Determining Thermal Resistance of Building Envelope Components from the In-Situ Data. America Society for Testing and Materials. West Conshohocken, Pennsylvania.

Bassett, M. \& Mcneil, S. (2007). Ventilation Measured in the Wall Cavities of High Moisture Risk Buildings. Building Research Association of New Zealand Limited (BRANZ Ltd).

COMSOL (2018). COMSOL Multiphysics 5.4. (1998-2018).

Dryvit Systems Inc. (2019). Continuous Insulation Systems. (online) Available at: http://www.dryvit.com/systems/continuous-insulation/ (Accessed 25 Feb. 2019).

EIMA (2019). EIFS Project Gallery. (online) Available at: https://www.eima.com/eifs/projectgallery

FEMP (2008). Federal Energy Management Program, M\&V Guidelines: Measurement and Verification for Federal Energy Projects Version 3.0; U.S. Department of Energy Federal Energy Management Program: Washington, DC, USA. 
Forintek (2001). Envelope Drying Rates Experiment. Forintek Canada Corp. for Canada Mortgage and Housing Corporation, Contract 99-2221.

H. Hens, (1996). 'Effects of Air and Moisture Flows on the Thermal Performance of Insulations in Ventilated Roofs and Walls.' Journal of Building Physics 19 (1996): 367-385.

Hutcheon, N. B., \& Handegord, G. O. P. (1995). Building Science for a Cold Climate. Canada: National Research Council Canada.

IEA (2012). Key World Energy Statistics. International Energy Agency.

IPMVP (2003). New Construction Subcommittee. International Performance Measurement \& Verification Protocol: Concepts and Option for Determining Energy Savings in New Construction, Volume III; Efficiency Valuation Organization (EVO): Washington, DC, USA.

Karagiozis, A. (2004). Airflow in the Ventilation Space Behind a Rainscreen Wall, Performance of Exterior Envelopes of Whole Buildings IX, ASHRAE, Atlanta.

Kersten, B. (2013). Modeling the Heat Exchange in Cavities of Building Constructions Using COMSOL. COMSOL Conference, Rotterdam, The Netherlands. Technische Universiteit Eindhoven.

Kesik, T. (2005). A Preliminary Review of Issues Facing the EIFS Industry in Canada. University of Toronto.

Kesik, T. (2014). Perspectives on the Performance of EIFS Wall Enclosure Systems. University of Toronto. 
Lstiburek, J. (2007). EIFS - Problems and Solutions. Building Science Digest 146, Building Science Corporation.

Markets and markets (2018). Exterior Insulation and Finish System (EIFS) Market by Product Type (PB, PM), Insulation material (EPS, MW), Component (Adhesive, Insulation board, Base coat, Reinforcement, Finish coat), End-use industry, and Region - Global Forecast to 2023. Report Code: BC 6519.

Mayer, E. \& Künzel, H. (1983). Investigations on the necessary back ventilation of exterior wall structures made of large-sized components. Fraunhofer Institute for Building Physics.

Morrison Hershfield (1999). Stucco-clad Wall Drying Experiment. Morrison Hershfield Ltd. Report for Canada Mortgage and Housing Corporation, Ottawa.

Morrison Hershfield Limited. (2011). ASHRAE 1365-RP Thermal Performance of Building Envelope Construction Details for Mid- and High-Rise Buildings. Atlanta, GA: American Society of Heating, Refrigerating and Air-Conditioning Engineers Inc.

Pi.on J (2004). Characterization of Ventilation Airflow in Screen-Type Wall Systems. ASHRAE 1091 - Report \#5. The Pennsylvania Housing Research/Resource Center. The Pennsylvania State University; 2004.

Pinon, J. (2004). The Airflow Characteristics of Ventilated Cavities in Screen Type Enclosure Wall Systems (RP-1091), Performance of Exterior Envelopes of Whole Buildings IX, ASHRAE, Atlanta.

Smegal, J. (2017). Dryvit Systems Canada Full Scale Wall Testing of EIFS. RDH Building Science Inc. 
Smegal, J., \& Straube. J.F. (2014). Dryvit Drainage, Airflow, and Drying Study. Building Engineering Group report for Dryvit Corp.

Straube, J. F (2012). Review of Thermal Impact of Vented EIFS System. Building Science Consulting Inc.

Straube, J. F., \& Burnett, E. F. (1997). In-Service Performance of Enclosure Walls: Summary Final Report. Building Engineering Group report for URIF corporate partners.

Straube, J. F., Burnett, E. F. (2005). Building science for building enclosures. Westford, MA: Building Science Press. 